$$
\text { UNIVERSIDADE DE SÃO PAULO }
$$

FACULDADE DE MEDICINA DE RIBEIRÃO PRETO

PROGRAMA DE PÓS-GRADUAÇÃO EM NUTRIÇÃO E METABOLISMO

NILTON AUGUSTO DA SILVA

Relação entre Estado Nutricional do Selênio e do Zinco com o Desenvolvimento Infantil

Ribeirão Preto 
NILTON AUGUSTO DA SILVA

\section{Relação entre Estado Nutricional do Selênio e do Zinco com o Desenvolvimento Infantil}

\section{Versão Corrigida}

Dissertação apresentada à Faculdade de Medicina de Ribeirão Preto da Universidade de São Paulo para obtenção de título de Mestre em Ciências.

Área de Concentração: Nutrição e Metabolismo

Orientador: Prof. Dr. Anderson Marliere Navarro

Ribeirão Preto 
Autorizo a reprodução e divulgação total ou parcial deste trabalho, por qualquer meio convencional ou eletrônico, para fins de estudo e pesquisa, desde que citada a fonte.

Catalogação na publicação

Serviço de Biblioteca e Documentação

Faculdade de Medicina de Ribeirão Preto da Universidade de São Paulo

Da Silva, Nilton Augusto

Relação entre Estado Nutricional do Selênio e do Zinco e Desenvolvimento Infantil, Ribeirão Preto, 2020.

98 p. : il. ; $30 \mathrm{~cm}$

Disserta/ção de Mestrado, apresentada à Faculdade de Medicina de Ribeirão Preto/USP. Área de concentração: Nutrição e Metabolismo.

Orientador: Navarro, Anderson Marliere.

1. Selênio. 2. Zinco. 3. Desenvolvimento Infantil. 4. Gestação. 5. Deficiencias Nutricionais. 
DA SILVA, Nilton Augusto. Relação entre Estado Nutricional do Selênio e do Zinco e Desenvolvimento Infantil. 2020. 98f. Dissertação (Mestrado em Ciências) - Faculdade de Medicina de Ribeirão Preto, Universidade de São Paulo, Ribeirão Preto, 2020.

Aprovado em: 23 de abril de 2020

\section{Banda Examinadora}

Profa Dra. Daniela Saes Sartorelli

Instituição: Universidade de São Paulo - FMRP/USP

Julgamento: Assinatura:

Prof. Dr.Ivan Savioli Ferraz

Instituição: Universidade de São Paulo - FMRP/USP

Julgamento: Assinatura:

Dra. Ane Cristina Fayão Almeida

Instituição: Universidade Anhanguera - Ribeirão Preto/SP. Julgamento: Assinatura: 


\section{Dedicatória}

Dedico ao Senhor de minha história Jesus Cristo, a minha amada e companheira esposa Thaisa e ao meu querido filho Augusto. 


\section{Agradecimentos}

Inicialmente, gostaria de louvar a Deus pela vida, pelo sustento e graça diária.

Ao meu orientador Anderson M. Navarro, não apenas pelo incentivo, competência e dedicação no processo de elaboração, execução e conclusão desta dissertação, mas por toda paciência, respeito, por compartilhar conhecimento e experiências e por acreditar em mim (mesmo quando eu achava que não era possível).

Às voluntárias que acreditaram em nosso trabalho, dispostas a participar desta pesquisa e, ainda, confiarem seus filhos a nós.

À minha amada esposa Thaisa M. Fonzar Silva pelo companheirismo, cumplicidade e pelas palavras de incentivo diárias, para que eu pudesse/possa sempre oferecer o melhor de mim.

Ao meu filho Augusto, que, mesmo tão pequeno, desperta o melhor de mim e me motiva a ser cada dia melhor.

À minha mãe Luzinete Ap. da Silva e ao meu paidrasto Mauro Ferreira Silva cujo carinho e dedicação me fizeram ser quem sou, onde cheguei e para onde irei.

Aos meus sogros Fernanda e Valter Fonzar, pois, dedicaram amor, cuidado e carinho para com a minha esposa e filho durante minhas ausências.

À Igreja Evangélica Batista Nova Aliança pelo cuidado espiritual necessário.

À Stephani Ferreira Rodrigues pela aplicação da avaliação de desenvolvimento neuropsicomotora, bem como, por todo profissionalismo, apoio e carinho.

À equipe de funcionários do Centro Médico Social Comunitário (CMSC) da Vila Lobato, pelo apoio, cuidado e dedicação com as voluntárias.

Ao Prof. Dr. Ivan S. Ferraz por disponibilizar, juntamente com a equipe, do uso do CMSC Vila Lobato para coleta de dados.

Ao Prof. Dr. Fernando Barbosa Jr. e à Técnica de laboratório Vanessa Cristina de Oliveira Souza pela parceria na dosagem dos minerais. 
À Letícia Ferreira, Daniela Takaara, Natalina Ferreira, Niara Ulhoa Faria, Mariana Pupin, Thayara B. Morgenstern e Marina I. Yodono pelo auxílio e incentivo nos dias de coleta de dados (mesmo quando todas as voluntárias faltavam).

À equipe de Nutricionistas do Hospital das Clínicas na Unidade de Emergência, pois não mediram esforços para me apoiar, incentivar e cobrirem escalas nas minhas ausências.

Ao Programa de Pós-graduação em Nutrição e Metabolismo, à Coordenação e à todos os professores, pela sabedoria e compartilhamento de seus conhecimentos.

Agradeço à Vivian Soares e Thaline Donegá pelas contribuições e apoio.

À Vanessa M. Mauler pelo auxílio e troca constante neste processo de trabalhar e estudar.

A Profa Dra. Daniela Saes Sartorelli, Prof. Dr. Ivan Savioli Ferraz e a Dra. Ane Cristina Fayão Almeida que compuseram a banca examinadora e que contribuíram com o aperfeiçoamento desta dissertação. 
O presente trabalho foi realizado com apoio da Coordenação de Aperfeiçoamento de Pessoal de Nível Superior - Brasil (CAPES) - Código de Financiamento 001 
"Pois todas as coisas vêm Dele, existem por meio Dele e são para Ele. A Jesus seja toda a glória para sempre! Amém." Bíblia Sagrada, Carta aos Romanos, Capítulo 11 versículo 36 


\section{Lista de Figuras}

Pag.

Figura 1 Recrutamento dos voluntários para o projeto de pesquisa.... 28

Figura 2 Delineamento esquematizado do estudo............................ 29 


\section{Lista de tabelas}

Pag.

Tabela 1 Recomendações de ingestão de Zinco em diferentes estágios de vida (IOM, 2000b)................................... 18

Tabela 2 Recomendações de ingestão de selênio em diferentes estágios de vida (IOM, 2000a).

Tabela 3 Pontos de corte de IMC-para-idade para crianças menores de 5 anos

Tabela 4 Caracterização das mulheres no PMI, resultados pré-natal, perinatal e lactante $(n=29)$.

Tabela 5 Diagnóstico do estado nutricional das mulheres no PMI, PMII, das crianças e dos pais

Tabela 6 Caracterização sociodemográfica e religião das famílias (n $=29)$.

Tabela 7 Dosagem de Zinco eritrocitário e plasmático das mulheres no PMI, PMII e das crianças

Tabela 8 Dosagem de Selênio eritrocitário, plasmático e urinário das mulheres no PMI, PMII e das crianças.

Tabela 9 Classificação das crianças quanto aos domínios do desenvolvimento neuropsicomotor e o diagnóstico clínico.... 40

Tabela 10 Correlação entre dosagem de Selênio plasmático da mulher no PMI e diagnóstico das crianças quanto ao desenvolvimento neuropsicomotor e aos Domínios de comunicação e motor grosso $(n=28)$. 


\section{Abreviaturas}

CEP Comitê de Ética em Pesquisa

DNPM Desenvolvimento neuropsicomotor

EN Estado nutricional

IMC Índice de Massa Corporal

PEP Prontuário eletrônico do paciente

Se Selênio

TCLE Termo de consentimento livre e esclarecido

Zn Zinco 


\section{RESUMO}

DA SILVA, Nilton Augusto. Relação entre Estado Nutricional do Selênio e do Zinco e Desenvolvimento Infantil. 2020. 98f. Dissertação (Mestrado em Ciências) Faculdade de Medicina de Ribeirão Preto, Universidade de São Paulo, Ribeirão Preto, 2020.

O selênio e o zinco vêm sendo apontados como minerais essenciais ao desenvolvimento infantil, ao mesmo tempo pesquisas recentes, com o objetivo de melhorar o entendimento dos mecanismos envolvidos tem sido o foco dos estudos. Objetivo: Verificar a relação entre o estado nutricional do selênio e do zinco durante a gestação com o desenvolvimento infantil. Métodos: O grupo amostral foi composto por 29 crianças, nascidas de mulheres que foram avaliadas durante a gestação (segundo ou terceiro trimestre), em 2015, quanto ao estado nutricional de zinco e selênio. As crianças foram submetidas a avaliação do desenvolvimento neuropsicomotor através de escala Bayley de desenvolvimento. Ocorreu dosagem de zinco e selênio plasmático, eritrocitário e urinário das crianças e mães; foi verificado o diagnóstico nutricional das crianças, mães e pais que responderam ao questionário estruturado socioeconômico. Resultados: As crianças apresentaram idade média de $3 \pm 0,3$ anos. $72,4 \%$ e $17,2 \%$ das crianças e mães, respectivamente, apresentaram deficiência de zinco eritrocitário. Quanto ao selênio eritrocitário, 62,1\% das crianças e $37,9 \%$ das mães apresentaram deficiencia. O selênio plasmático gestacional apresentou correlação significativa com o diagnóstico do desenvolvimento neuropsicomotor $(r=-0,49$ e $p=0,008)$, com os domínios de comunicação $(r=-0,46$ e $p=0,01)$ e com o motor grosso - habilidades axiais $(r=-0,55$ e $p=0,002)$. Não encontramos correlação dos níveis de Zinco gestacional plasmático e eritrocitário com desenvolvimento infantil. Conclusão: Crianças nascidas de mães que apresentaram baixos níveis de selênio durante a gestação demonstraram piores resultados quanto ao desenvolvimento neuropsicomotor; assim como, aos domínios de comunicação e motor grosso, o que não foi observado para o Zinco e sua correlação com o desenvolvimento das crianças.

Palavras-chave: Selênio; Zinco; Desenvolvimento Infantil; Gestação; Deficiências Nutricionais. 


\begin{abstract}
DA SILVA, N. A. Relationship between Selenium and Zinc Nutritional Status with Child Development. 2020. 98f. Dissertação (Mestrado) - Faculdade de Medicina de Ribeirão Preto, Universidade de São Paulo, Ribeirão Preto, 2020.

Selenium and zinc have been identified as essential minerals for child development, at the same time recent research, with the aim of improving the understanding of the mechanisms involved, has been the focus of studies. Aim: We aimed to verify the relationship between the nutritional status of selenium and zinc during pregnancy with Child Development. Methods: The sample group consisted of 29 children, born from women who were evaluated during pregnancy (second or third trimester), in 2015, regarding the nutritional status of zinc and selenium. The children were submitted to neuropsychomotor development assessment using the Bayley developmental scale. Plasma, erythrocyte and urinary selenium and plasma and erythrocyte zinc levels were analyzed in children and mothers; the nutritional diagnosis of the children, mothers and fathers who answered the structured socioeconomic questionnaire was verified. Results: The children were an average age of $3 \pm 0.3$ years. $72.4 \%$ and $17.2 \%$ of children and mothers, respectively, had erythrocyte zinc deficiency. As for erythrocyte selenium, $62.1 \%$ of children and $37.9 \%$ of mothers were lacking the mineral. The gestational plasma selenium showed a significant correlation with the diagnosis of neuropsychomotor development $(r=-0.49$ and $p=0.008)$, with the communication domains $(r=-0.46$ and $p=0.01)$ and with the gross motor - skills axial $(r=-0.55$ and $p=0.002)$. We did not find a correlation between the levels of plasmatic and erythrocyte gestational zinc with child development. Conclusion: Children born from mothers who had low levels of selenium during pregnancy showed worse results in terms of neuropsychomotor development; as well as to the domains of communication and gross motor, which was not observed for Zinc and its correlation with the development of children.
\end{abstract}

Keywords: Selenium; Zinc; Child Development; Pregnant; Deficiency Diseases . 


\section{Sumário}

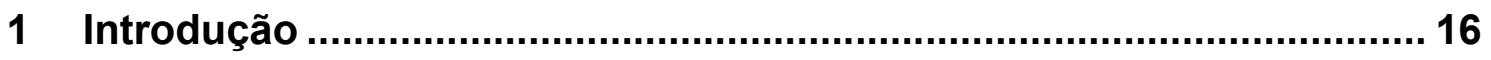

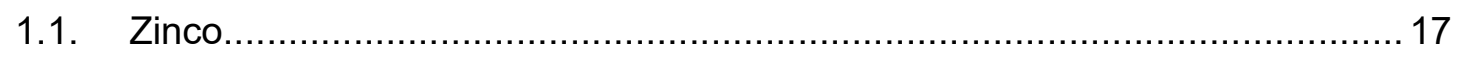

1.2. Zinco e Desenvolvimento Neuropsicomotor …………………................. 19

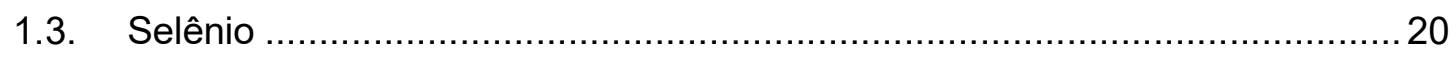

1.4. Selênio e Desenvolvimento Neuropsicomotor...........................................22

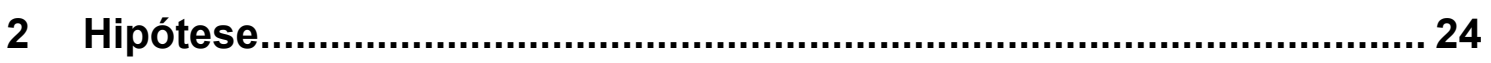

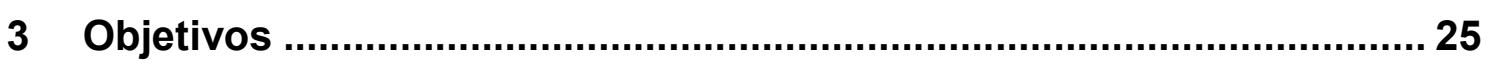

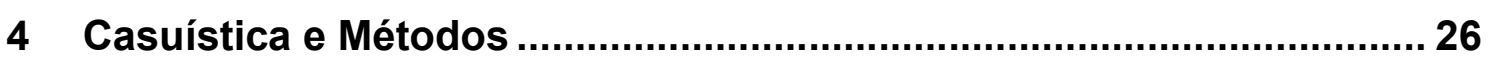

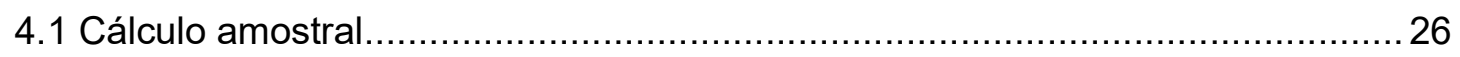

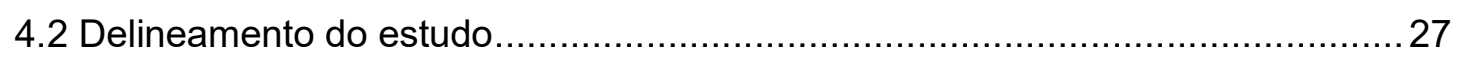

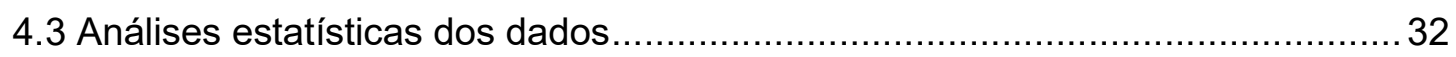

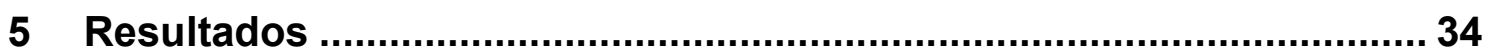

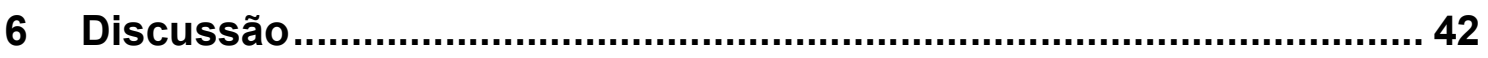

6.1 Dosagens de Zinco e suas relações com Peso ao Nascer e Desenvolvimento Infantil

6.2 Dosagens de Selênio e suas relações com Peso ao Nascer e Desenvolvimento Infantil 46

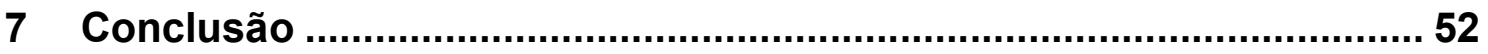

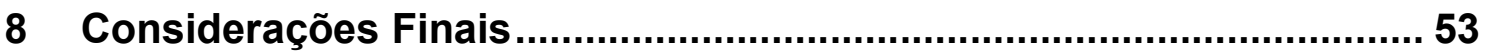

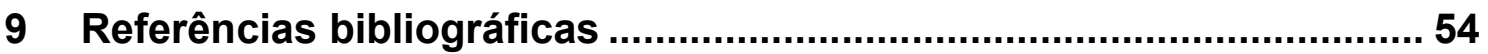

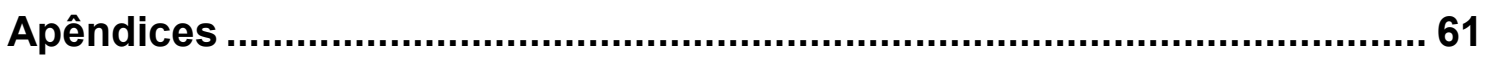

Apêndice 1: Termo de Consentimento Livre e Esclarecido.......................................61

Apêndice 2: Questionário Estruturado .................................................................63

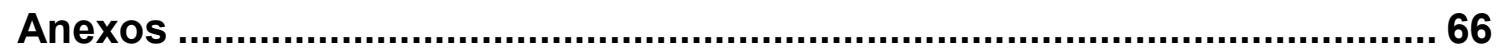

Anexo 1: Parecer de aprovação do Comitê de ética em pesquisa..............................66

Anexo 2: Tabela com percentis para avaliação do crescimento da WHO (2006).....67

Anexo 3: Certificado de Capacitação para uso do instrumento de Avaliação

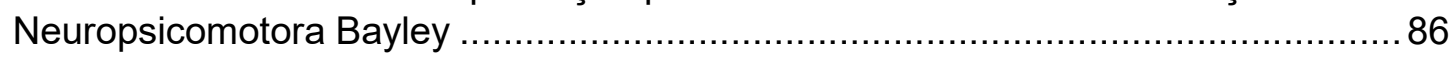

Anexo 4: Avaliação de Desenvolvimento Neuromotor Infantil.................................. 87 


\section{Introdução}

Os primeiros mil dias, que iniciam na concepção até o final do primeiro ano de vida, têm sido identificados como uma janela crucial de oportunidade para garantir adequado desenvolvimento infantil, ou, até mesmo, para identificar intervenções necessárias que melhorem a saúde da criança (DA CUNHA; LEITE; DE ALMEIDA, 2015; DARLING et al., 2020).

De acordo com Figueiras et al. (2005), desenvolvimento infantil é definido como o "processo que vai desde a concepção, envolvendo vários aspectos, indo desde o crescimento físico, passando pela maturação neurológica, comportamental, cognitiva, social e afetiva da criança".

Entretanto, nosso foco será abordar o desenvolvimento infantil nos seus aspectos relacionados ao desenvolvimento neuropsicomotor (DNPM), o qual se inicia na gestação. O período gestacional é uma fase vital do ciclo feminino em que várias mudanças físicas, fisiológicas e metabólicas acontecem, visando preparar o organismo e garantir um ambiente favorável para gerar uma nova vida (TAVARES, NUNES, SANTOS, 2010).

Essas mudanças acarretam aumento na demanda por macro e micronutrientes para atender as necessidades maternas e fetais, garantindo que não haja uma competição biológica entre ambos, que poderia afetar o crescimento e o desenvolvimento do feto, assim como a evolução do período gestacional. Após o nascimento, o neonato deve receber aleitamento materno exclusivo nos primeiros seis meses. A alimentação complementar deve ocorrer de forma adequada e balanceada, bem como, estar associada a amamentação até os dois anos de idade (DA CUNHA; LEITE; DE ALMEIDA, 2015; DARNTON-HILL; MKPARU, 2015; DARLING et al., 2020).

Contudo, mulheres que vivem em países de baixa renda, muitas vezes, não conseguem atingir as demandas de micronutrientes na gravidez devido a uma ingestão nutricional deficiente (DA CUNHA; LEITE; DE ALMEIDA, 2015). Assim, o estado nutricional (EN) materno pode influenciar o desenvolvimento cerebral do feto e, consequentemente, a maturação das funções cognitivas, habilidades, psicomotricidade, inteligência e comportamento da criança (PRADO; DEWEY, 2014; GERNAND et al., 2016). 
Desta forma, dentre os nutrientes essenciais, destacaremos o Zinco (Zn) e o Selênio (Se).

\subsection{Zinco}

O Zn é um elemento traço essencial, que desempenha funções importantes em muitas funções biológicas, incluindo atividade na barreira mucosa, imunidade inata e adaptativa, respostas de estresse oxidativo, associado a neurocognição, homeostase de glicose, cicatrização de feridas, e como cofator para diversas enzimas. No cérebro, está envolvido no controle da apoptose e também atua como um neuromodulador importante. O Zn intracelular é utilizado no fígado para a síntese de proteínas de fase aguda e no pâncreas para o metabolismo da insulina (KAWADE, 2012; IGLESIAS et al., 2014; KUMAR, SINGHI, 2014).

A absorção do Zn alimentar ocorre no intestino delgado, principalmente no duodeno e nas primeiras porções do jejuno, mediada por carreadores (ativo) e difusão simples (passivo). Quando há concentrações elevadas de Zn no lúmen, o transporte ativo é saturável, ocorrendo maior absorção por difusão simples, e, em casos de ingestão reduzida por longos períodos, sua eficiência aumenta. Por isso, a absorção por transporte passivo é proporcional à quantidade do mineral no lúmen e não se altera quando a ingestão é reduzida. Entretanto, substancias como taninos, polifenóis, oxalatos e fitatos reduzem a absorção de $\mathrm{Zn}$, prejudicando a biodisponibilidade (COMINETTI; COZZOLINO, 2009b; CRUZ; SOARES, 2011).

No sangue, o Zn circula ligado principalmente à albumina. Outros ligantes plasmáticos incluem a-macroglobulina, transferrina, cisteína e histidina. Depois de captado pelos hepatócitos, o mineral é finalmente distribuído aos outros tecidos-alvo. A deficiência de $\mathrm{Zn}$ afeta várias células imunológicas e mediadores de imunidade, levando a susceptibilidade a infecções. Infecções e inflamações são conhecidos por estarem associados a níveis plasmáticos reduzidos de Zn (POWELL, 2000; YUYAMA et al., 2007; COMINETTI; COZZOLINO, 2009b; IGLESIAS et al., 2014; KUMAR, SINGHI, 2014).

A concentração plasmática/sérica de Zn não é um parâmetro adequado para avaliar o EN relativo a este mineral, pois a redução da concentração de $Z n$ pode refletir uma redistribuição do mineral pelo organismo e não uma inibição de absorção ou deficiência. A quantidade de Zn no eritrócito reflete alterações de médio a longo prazo 
dos estoques desse mineral no organismo, devido à meia-vida destas células serem de 120 dias (COMINETTI; COZZOLINO, 2009b; IGLESIAS et al., 2014)

$\mathrm{Na}$ tabela 1 podemos verificar os valores de recomendação de $\mathrm{Zn}$ nas diversas faixas etárias, de acordo com IOM (2000b).

Tabela 1 - Recomendações de ingestão de Zinco em diferentes estágios de vida (IOM, 2000b).

\begin{tabular}{|c|c|c|c|}
\hline Estágio da vida & $\begin{array}{c}\mathrm{Al}^{*} / \mathrm{EAR} \\
\mu \mathrm{g} / \mathrm{dia}\end{array}$ & $\begin{array}{c}\text { RDA } \\
\mu \mathrm{g} / \mathrm{dia}\end{array}$ & $\begin{array}{c}\mathrm{UL} \\
\mu \mathrm{g} / \mathrm{dia}\end{array}$ \\
\hline \multicolumn{4}{|c|}{ Recém-nascidos e crianças } \\
\hline 0-6 meses & ${ }^{*} 2,0$ & - & 4,0 \\
\hline 7-12 meses & 2,2 & 3,0 & 5,0 \\
\hline $1-3$ anos & 2,0 & 3,0 & 7,0 \\
\hline 4-8 anos & 4,0 & 5,0 & 12,0 \\
\hline $9-13$ anos & 7,0 & 8,0 & 23,0 \\
\hline \multicolumn{4}{|l|}{ Adolescentes } \\
\hline $14-18$ anos $(\mathrm{M})$ & 8,5 & 11,0 & 34,0 \\
\hline 14-18 anos $(F)$ & 7,3 & 9,0 & 34,0 \\
\hline \multicolumn{4}{|l|}{ Adultos } \\
\hline $19 \geq 70$ anos $(M)$ & 9,4 & 11,0 & 34,0 \\
\hline $19 \geq 70$ anos $(F)$ & 6,8 & 8,0 & 34,0 \\
\hline \multicolumn{4}{|l|}{ Gestantes } \\
\hline$\leq 18$ anos & 10,5 & 13,0 & 34,0 \\
\hline $19-50$ anos & 9,5 & 11,0 & 40,0 \\
\hline \multicolumn{4}{|l|}{ Lactantes } \\
\hline$\leq 18$ anos & 11,6 & 14,0 & 34,0 \\
\hline $19-50$ anos & 10,4 & 12,0 & 40,0 \\
\hline
\end{tabular}

De acordo com Gogia e Sachdev (2012), a prevalência global estimada de deficiência de $\mathrm{Zn}$ é de $31 \%$ e varia de $4 \%$ a $73 \%$. A falta de consenso sobre os indicadores de deficiência dificulta os esforços para documentar a prevalência de deficiência de $\mathrm{Zn}$. A ampla gama de estimativas de deficiência citada na literatura sugere que os padrões de diagnóstico ou faixas de referência ou fatores ambientais são bastante variados. A prevalência de deficiência de Zn é alta em todo o sul e centro da África (37\% a 62\%), norte da África e região oriental do Mediterrâneo (25\% a 52\%), bem como sul e sudeste da Ásia ( $34 \%$ a $73 \%$ ). 
Cominetti e Cozzolino (2008) descrevem que o Brasil enquadra-se em um nível de risco médio, sendo que uma parcela de $20,3 \%$ da população apresenta risco de ingestões inadequadas do mineral.

As principais fontes alimentares de $\mathrm{Zn}$ incluem ostras; carne bovina, principalmente as vísceras, como fígado e rins; frutos do mar; oleaginosas; cereais integrais; leguminosas e leite. Frutas e verduras não apresentam quantidades importantes de Zinco. Entretanto, a ingestão alimentar não é garantia de utilização celular deste micronutriente, visto que pode ocorrer interação química com outras substâncias, como oxalato, fitatos, fibras e alguns minerais, prejudicando a absorção. Os produtos animais geralmente são as melhores fontes de Zinco, com relação ao conteúdo proteico e biodisponibilidade. As fontes de origem vegetal contêm fitatos, fibras e oxalatos, interferindo de forma negativa no aproveitamento deste mineral pelo organismo (COMINETTI; COZZOLINO, 2009b; CRUZ; SOARES, 2011).

No que diz respeito à gestação, mecanismos potenciais para o ajuste do metabolismo do Zn incluem redução da excreção endógena de Zn gastrointestinal, conservação renal e liberação de Zn no tecido materno (KING, 2000).

\subsection{Zinco e Desenvolvimento Neuropsicomotor}

A deficiência de zinco pode afetar o desenvolvimento cognitivo por alterações na atenção, atividade, comportamento neuropsicológico e desenvolvimento motor. Os mecanismos exatos não são claros, mas o Zn é essencial para a neurogênese, a migração neuronal, a sinaptogênese e sua deficiência pode interferir na neurotransmissão e no comportamento neuropsicológico subsequente. A deficiência de $\mathrm{Zn}$ materno e infantil em animais causa déficits de atenção, aprendizado e memória. Não há evidência sobre efeitos positivos da suplementação durante a gravidez ou na infância, afetando o desenvolvimento cognitivo da criança (BHATNAGAR; TANEJA, 2001; PRADO; DEWEY, 2014; POLANSKA et al., 2017).

Bhatnagar, Taneja (2001) descrevem que a deficiência de Zinco durante o período juvenil e adolescente afeta o desenvolvimento cognitivo, diminuindo a atividade, aumentando o comportamento emocional, prejudicando a memória e a capacidade de aprender. Entretanto, as evidências de estudos em humanos são limitadas. 


\subsection{Selênio}

O Se é um micronutriente essencial associado a diversas vias metabólicas, como a via imunológica, endócrina e antioxidante, importantes para a manutenção da integridade da membrana celular, desenvolvimento físico e intelectual. Este elemento químico é parte integrante da enzima glutationa peroxidase, das enzimas tireoidianas, da formação do esperma,da imunidade celular (leucócitos e células NK) e do funcionamento da próstata (SOUZA, 2003; CARCILLO et al., 2009; TURCATO, TANAKA, 2007; RAYMAN, 2012).

A dieta é a principal fonte de Se e aproximadamente $80 \%$ do Se são absorvidos no intestino (dependendo do tipo de alimento consumido), na forma livre ou associado a aminoácidos. Os fatores que facilitam a absorção de Se são: presença de proteínas (metionina e cisteína), vitaminas A, C e E. A biodisponibilidade do Se varia de acordo com a fonte e o EN do sujeito, sendo significativamente maior para as formas orgânicas. Por outro lado, altas doses de enxofre, metais pesados (mercúrio, arsênio e cádmio) e deficiência nutricional das vitaminas $B_{1}, B_{6}$ e $E$ reduzem a absorção (HEIDEMANN et al., 2014).

O Se circula ligado a globulinas, lipoproteínas, selenoproteína $\mathrm{P}$ ou livre e sua eliminação renal controla a homeostase do mineral. Os suplementos podem ser benéficos para indivíduos que vivem em regiões com níveis ambientais muito baixos (NAVARRO-ALARCON; CABRERA-VIQUE, 2008).

Com relação a avaliação do $\mathrm{EN}$ relativo ao $\mathrm{Se}$, a determinação de suas concentrações nas unhas e cabelos são considerados biomarcadores de longo prazo; e os níveis plasmáticos, eritrocitários e urinários, de curto e médio prazo (VITOUX; ARNAUD; CHAPPUIS, 1999). Ashton et al. (2009), realizam uma metanálise que demonstrou que os níveis de soro e plasma são os marcadores mais utilizados e razoavelmente precisos em relação ao EN do Se e os eritrócitos são indicadores de longo prazo do EN devido a meia-vida de 120 dias destas células.

Millan Adame et al. (2012), com objetivo de determinar o EN do Se na população adulta saudável na Espanha, avaliaram os níveis plasmáticos e eritrocitários de 84 adultos saudáveis (31 homens e 53 mulheres) da província de Granada, identificando $50 \%$ dos homens e $53 \%$ das mulheres com deficiências. No Brasil, de acordo com Cominetti e Cozzolino (2009a), o consumo de Se varia de baixa a adequada (entre 20 e $114 \mu \mathrm{g} / \mathrm{dia}$ ), dependendo da região estudada e também do 
nível socioeconômico da população, não havendo estudo populacional para identificar prevalência de deficiência.

Durante a gestação, as concentrações de Se diminuem de forma significativa, provavelmente devido ao aumento da demanda de oxigênio no corpo da mãe e do desenvolvimento fetal, na diminuição da peroxidação lipídica, na manutenção de proteção antioxidante suficiente ao feto e da forte demanda de eritrócitos no feto (PIECZYNSKA, GRAJETA, 2015). Além disso, Golubkina e Alfthan (2002), descrevem que há correlação entre o nível sérico de Se durante a gravidez com a redução da excreção urinária e aumento dos níveis na membrana amniótica.

A população pediátrica, especialmente os lactentes prematuros, apresentam risco de apresentarem baixas concentrações de Se devido a alterações nutricionais, possíveis complicações clínicas e baixo armazenamento hepático (FREITAS et al., 2014).

Os requisitos médios estimados (EAR) e os subsídios dietéticos recomendados (RDA) para o selênio foram estipulados em níveis que asseguram a concentração ideal da enzima glutationa peroxidase no soro sanguíneo, no entanto, devido às razões acima mencionadas durante a gravidez, o RDA para esse elemento é aumentado e varia de $55 \mu \mathrm{g} /$ dia a $60 \mu \mathrm{g} /$ dia para adultos e gestantes (PIECZYNSKA, GRAJETA, 2015). Na tabela 2 podemos verificar os valores de recomendação de Se nas diversas faixas etárias.

As melhores fontes de Se são a castanha-do-brasil e o rim bovino. Carne bovina, frango, peixe e ovos, bem como, leite e derivados, além de serem ótimas fontes de proteínas, também apresentam quantidades importantes de Se. A concentração proteica deste alimentos é um fator importante quanto a fonte de Se, pois estes incorporam melhor o mineral, principalmente uma maior concentração dos aminoácidos que contém enxofre (metionina e cisteína).Frutas e verduras em geral são pobres em selênio, exceto os vegetais denominados "acumuladores" de Se, como alho, mostarda-indiana, brócolis, couve-de-bruxelas, couve-rábano, couve-flor, repolho, cebola e alguns cogumelos, os quais podem fornecer quantidades importantes do mineral quando consumidos adequadamente. O levedo de cerveja também pode ser classificado como fonte de Selênio. Em regiões com solos que apresentam quantidade suficiente de Selênio, o trigo é uma boa fonte do mineral, e, 
por consequência, o consumo de pães e cereais pode contribuir com a ingestão do micronutriente (COMINETTI; COZZOLINO, 2009a; RAYMAN, 2012).

Tabela 2 - Recomendações de ingestão de selênio em diferentes estágios de vida (IOM, 2000a).

\begin{tabular}{|c|c|c|c|}
\hline Estágio da vida & $\begin{array}{c}\mathrm{Al}^{*} / \mathrm{EAR} \\
\mu \mathrm{g} / \mathrm{dia}\end{array}$ & $\begin{array}{c}\text { RDA } \\
\mu \mathrm{g} / \mathrm{dia}\end{array}$ & $\begin{array}{c}\mathrm{UL} \\
\mu \mathrm{g} / \mathrm{dia}\end{array}$ \\
\hline \multicolumn{4}{|c|}{ Recém-nascidos e crianças } \\
\hline $0-6$ meses & *15 & - & 45 \\
\hline 7-12 meses & *20 & - & 60 \\
\hline $1-3$ anos & 17 & 20 & 90 \\
\hline 4-8 anos & 23 & 30 & 150 \\
\hline 9-13 anos & 35 & 40 & 280 \\
\hline \multicolumn{4}{|l|}{ Adolescentes } \\
\hline 14-18 anos (M) & 45 & 55 & 400 \\
\hline $14-18$ anos $(F)$ & 45 & 55 & 400 \\
\hline \multicolumn{4}{|l|}{ Adultos } \\
\hline $19 \geq 70$ anos $(M)$ & 45 & 55 & 400 \\
\hline $19 \geq 70$ anos $(F)$ & 45 & 55 & 400 \\
\hline \multicolumn{4}{|l|}{ Gestantes } \\
\hline $14-50$ anos & 49 & 60 & 400 \\
\hline \multicolumn{4}{|l|}{ Lactantes } \\
\hline $14-50$ anos & 59 & 70 & 400 \\
\hline
\end{tabular}

$\mathrm{Al}=$ ingestão adequada; $\mathrm{EAR}=$ necessidade média estimada; $\mathrm{RDA}=$ ingestão dietética recomendada; $\mathrm{UL}=$ limite máximo tolerado de ingestão diária.

\subsection{Selênio e Desenvolvimento Neuropsicomotor}

No que diz respeito aos marcadores biológicos de Se durante a gestação e desenvolvimento infantil, Polanska et al. (2016) conduziram estudo com 410 mães com os respectivos filhos poloneses, dosando níveis de Se plasmático em cada trimestre da gravidez, no parto e no sangue do cordão umbilical. As crianças foram avaliadas quanto ao desenvolvento com um e dois anos de idade, sendo que $66 \%$ das mães e $43 \%$ dos pais haviam concluído o nível superior. Houve associação positiva estatisticamente entre os níveis de Se no primeiro trimestre de gravidez e desenvolvimento motor no primeiro ano de vida, e domínio da comunicação aos dois anos de idade. Os autores concluíram que os níveis pré-natal de selênio foram associados a habilidades psicomotoras da criança nos primeiros anos de vida.

Skröder et al. (2015), avaliaram 750 mulheres no terceiro trimestre de gestação para verificarem o impacto dos níveis eritrocitários de Se no desenvolvimento infantil 
aos 1,5 anos de idade, em Bangladesh. Os autores concluíram que os baixos níveis de Se pré-natal demonstram ter impacto negativo no desenvolvimento psicomotor e no domímio de comunicação das crianças.

Locateli et al. (2018), avaliaram as fontes dietéticas de antioxidantes consumidas pela população brasileira e verificaram baixo consumo de alimentos fontes de Se, sendo que, valores mais significativos foram encontrados apenas em carnes, tanto bovina quanto de peixes.

Considerando os resultados de Locateli et al. (2018), podemos presumir que a população brasileira é suscetível à deficiência de Se, e que este fato se agrava entre indivíduos de menor renda, por terem acesso diminuído aos alimentos de origem animal.

A Selenoproteína $\mathrm{P}$ exerce papel importante como neuroprotetor, melhorando a sobrevivência dos neurônios e prevenindo a morte celular por apoptose em resposta a danos oxidativos (CARDOSO; COMINETTI; COZZOLINO, 2013).

A redução acentuada do conteúdo de Se no cérebro após a inativação genética da selenoproteína $P$ produz distúrbios do movimento e convulsões espontâneas em camundongos (CHEN; BERRY, 2003; SCHWEIZER et al., 2004). Embora os mecanismos pelos quais o Se influencia o desenvolvimento neurológico ainda devam ser elucidados, estudos em animais relataram um papel protetor do Se contra danos neuronais induzidos por isquemia cerebral (ANSARI et al., 2004; YOUSUF et al., 2007).

Desta forma, o presente trabalho se justifica por verificar se os marcadores biológicos de Zn e Se durante a gestação tem correlação direta com o DNPM da criança, ampliando o conhecimento que, atualmente, é deficiente nesta linha de pesquisa, não havendo, até o presente momento, pesquisa com mães e filhos brasileiros, permitindo fundamentar adequadamente as condutas nutricionais durante a gestação. 


\section{Hipótese}

A hipótese deste trabalho é que crianças, nascidas de mães que apresentaram baixos níveis de Zn e Se durante a gestação, apresentam atraso do desenvolvimento neuropsicomotor. 


\section{Objetivos}

\subsection{Objetivo geral}

Verificar a relação entre o estado nutricional do Selênio e do Zinco durante a gestação com o desenvolvimento neuropsicomotor infantil.

\subsection{Objetivos específicos}

- Avaliar o EN das mães, filhos e os pais.

- Avaliar o desenvolvimento neuropsicomotor das crianças.

- Verificar correlação entre o desenvolvimento neuropsicomotor com o diagnóstico nutricional da criança.

- Associar o grau de instrução dos pais com o desenvolvimento da criança.

- Verificar correlação entre o estado nutricional dos pais com o da criança.

- Associar peso ao nascer do neonato ao diagnóstico nutricional das gestantes.

- Relacionar peso ao nascer com diagnóstico nutricional da criança. 


\section{Casuística e Métodos}

A Ms. Claudia Michielin Della Colleta Vianna iniciu estudo transversal intitulado "Perfil de selênio e zinco em gestantes", com o objetivo de avaliar o perfil de Se e Zn em gestantes. Em 2015, a amostra foi composta por mulheres entre o segundo e terceiro trimestre de gestação, nos quais foram dosados Se e Zn plasmático e eritrocitário.

O referido estudo foi aprovado pelo comitê de ética, $n^{\circ} 15228 / 2014$.

Desta forma, demos continuidade ao estudo da Ms. Claudia Michielin Della Colleta Vianna, iniciando um novo trabalho, havendo submissão e aprovação pelo CEP/CSE-FMRP cujo $\mathrm{n}^{\circ}$ é 89150118.1.00005414/2018 (anexo 1).

Neste novo estudo, para melhor visualização dos dois momentos distintos das mães, denominamos "Período Materno I" (PMI) para descrever os dados relacionados ao período gestacional e "Período Materno II" (PMII) relacionados aos dados delas após aproximadamente três anos. Além das mães, os filhos nascidos da gestação anteriormente avaliada foram incluídos, sendo denominadas "crianças", bem como, o uso dos dados relatados dos pais, denominado "Pai" no item resultados.

\subsection{Cálculo amostral}

Para a pesquisa anteriamente desenvolvida pela Ms. Claudia Michielin Della Colleta Vianna, foi realizado o cálculo do tamanho amostral, adotando um nível de significância de 0,05 e 0,80 de poder do teste, utilizando-se a equação de Singer (2001). Portanto, foi considerado uma perda de 10\%, sob amostra mínima de 114 voluntários, totalizando 126 voluntárias para a pesquisa conduzida em 2015. Assim, considerando o cálculo amostral prévio, demos continuidade a pesquisa anteriormente descrita considerando a amostra de 126 mães e os respectivos filhos e pais.

\subsubsection{Critérios de inclusão}

Mulheres que foram avaliadas quanto ao EN do Zn e Se durante o pré-natal em 2015, nas quais participaram da pesquisa referida, e seus respectivos filhos da gestação avaliada. 


\subsubsection{Critérios de exclusão}

Foram excluídos os indivíduos que não aceitaram participar voluntariamente ou que desistiram no decorrer do estudo.

\subsection{Delineamento do estudo}

A partir do número de registro que cada voluntária possuía no sistema interno do Hospital das Clínicas da Faculdade de Medicina de Ribeirão Preto (HCFMRP/USP), cadastrado no estudo anterior, foi possível acessar o sistema operacional do hospital e verificar a ficha cadastral de cada voluntária. Assim, foi verificado tanto no sistema do HC-FMRP/USP quanto no sistema de gestão de saúde utilizado nas unidades de saúde da Secretaria Municipal da Saúde de Ribeirão Preto, através no número Hygia do paciente, obter informações pessoais da voluntária para contato.

A partir das informações contidas na ficha cadastral das pacientes, foi realizado contato telefônico com as participantes, com o objetivo de agendar as avaliações e a coleta de informações, a qual ocorreu no Centro Médico Social Comunitário Vila Lobato, localizado à rua João Alves Pereira, número 175 , no bairro Jardim Antártica em Ribeirão Preto/SP.

Na figura 1 está descrito esquematicamente como foi o recrutamento dos voluntários, sendo que, todas as voluntárias que participaram da pesquisa em 2015 foram convidadas a participarem da pesquisa (quando foi possível realizar o contato), totalizando 29 mães com seus respectivos filhos (as). Destacamos que as fichas cadastrais de $41,3 \%$ dos indivíduos que participaram da pesquisa anterior estavam totalmente desatualizadas, tanto no sistema do Hospital das Clínicas da FMRP, quanto no sistema da secretaria da saúde da Prefeitura de Ribeirão Preto/SP, impossibilitando o contato com praticamente $50 \%$ de possíveis voluntários.

No dia e horário agendado, as voluntárias com os respectivos filhos, compareceram no Centro Médico Social Comunitário Vila Lobato, receberam o Termo de Consentimento Livre e Esclarecido (TCLE) para leitura e foram informadas sobre os objetivos, possíveis desconfortos e riscos envolvidos em cada um dos procedimentos propostos e, em seguida, assinaram o TCLE, concedendo a participação dela (mãe) bem como a do filho (Apêndice 1). 
Figura 1 - Recrutamento dos voluntários para o projeto de pesquisa.

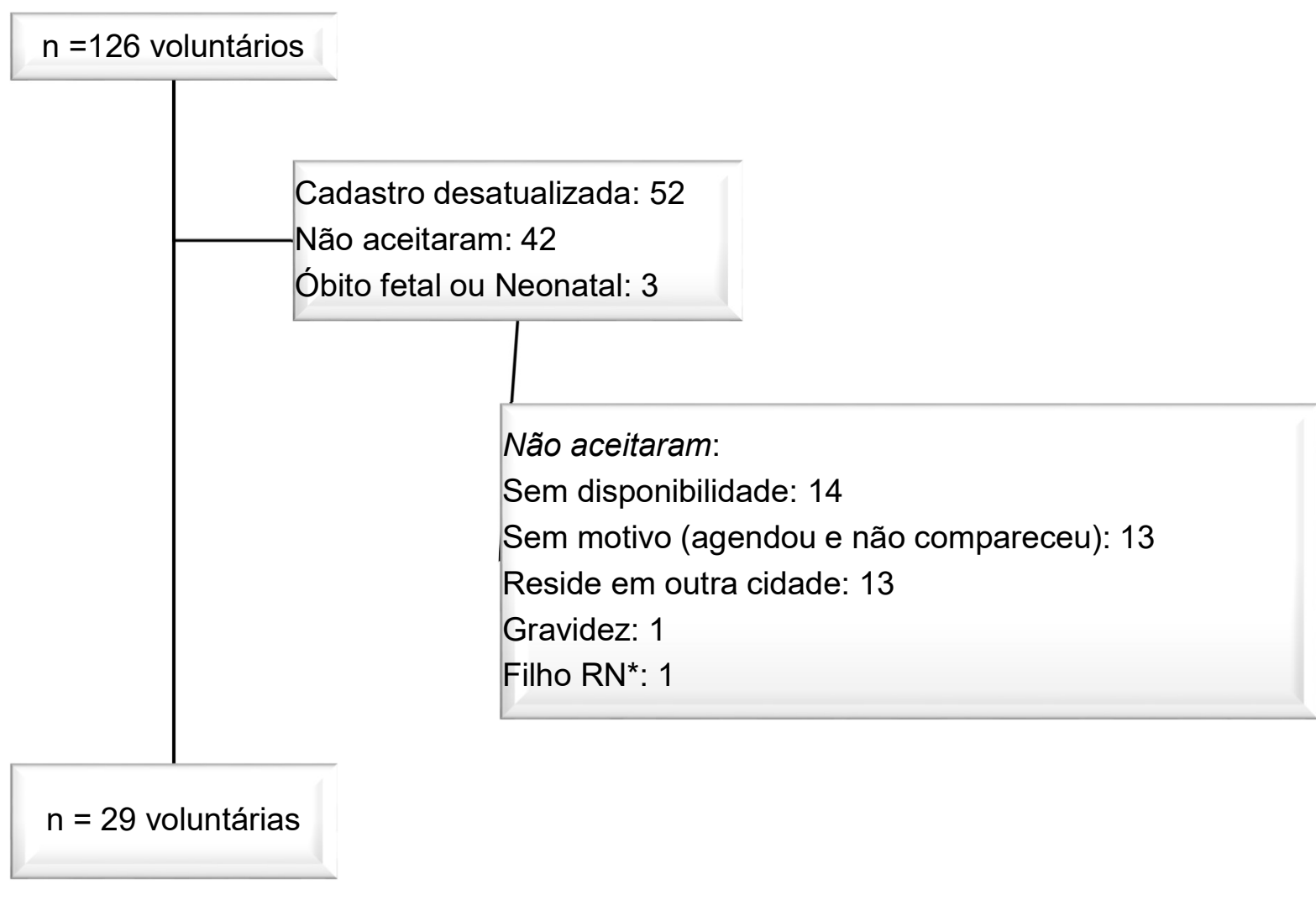

*RN: Recém-nascido

As crianças foram avaliadas quanto ao desenvolvimento neuropsicomotor (DNPM). Na sequência, a mulher e a criança foram direcionadas para a etapa de coleta de amostra sanguínea e urina, foram pesadas e medidas para realizarmos o diagnóstico nutricional e responderam ao questionário estruturado e socioeconômico (Apêndice 2).

O Delineamento do estudo pode ser visualizado esquematicamente na Figura 2. 
Figura 2 - Delineamento esquematizado do estudo.
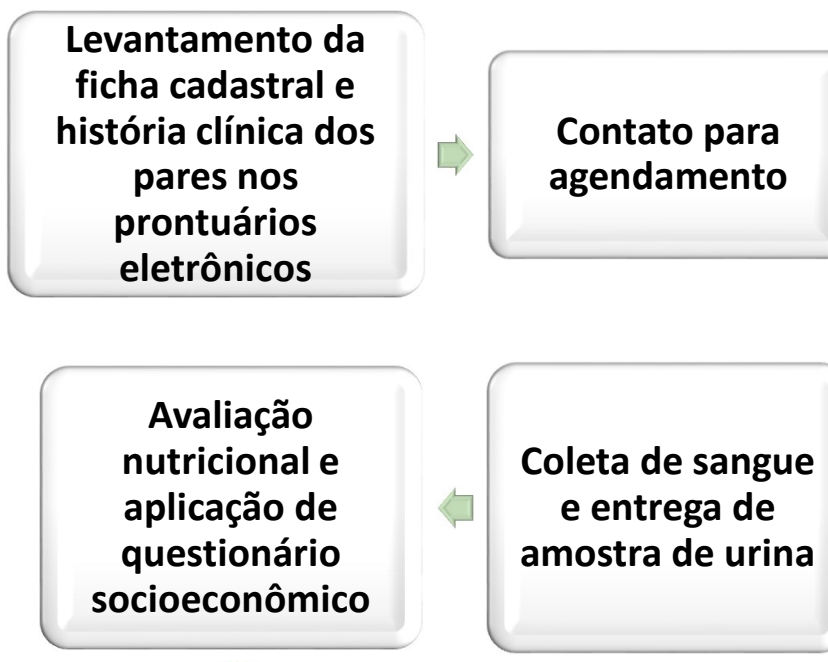

Contato para agendamento
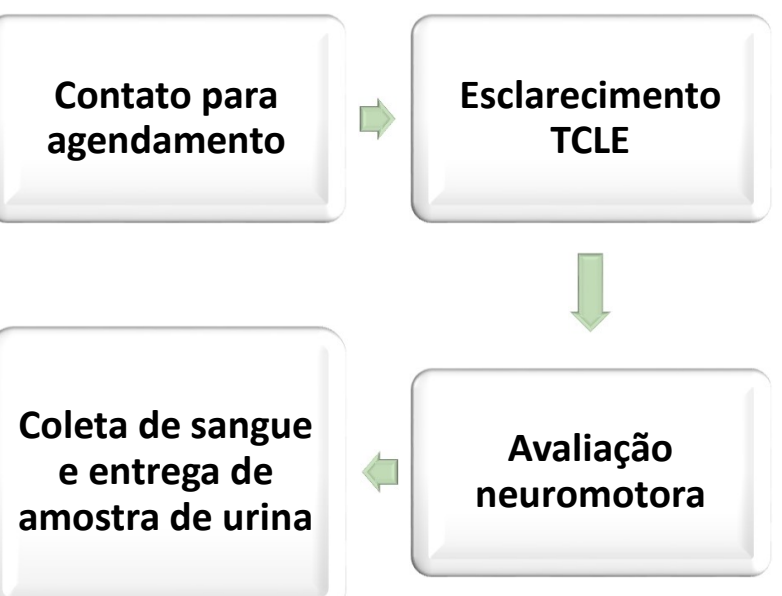

\section{Dosagem de Se e Zn (eritrocitário, plasmático e urinário)}

\subsubsection{Avaliação antropométrica}

As mulheres e crianças foram pesadas $(P)$ e foi verificado a estatura $(E)$ de acordo com Lohman, Roche, Martorell (1988). Além disto, utilizando P e E, foi calculado o Índice de Massa Corporal (IMC), através da divisão do valor do P pela $\mathrm{E}$ ao quadrado.

As crianças foram classificadas, quanto ao seu EN, utilizando a tabela de percentis das curvas de crescimento da WHO (2006), que relacionam P/ldade (I), P/E, E/I e IMC/I (Anexo 2). Os pontos de corte utilizados para são apresentados na tabela 3 , sendo que, foram agrupadas as crianças com diagnóstico de "Eutrofia" e "Risco de sobrepeso" para que houvesse uma maior linearidade quando comparados com os diagnósticos nutricionais das mães e pais. 
Tabela 3 - Pontos de corte de IMC-para-idade para crianças menores de 5 anos.

\begin{tabular}{lc}
\hline \multicolumn{1}{c}{ Valores Críticos } & Diagnóstico Nutricional \\
\hline$<$ Percentil 0,1 & Magreza Acentuada \\
$\geq$ Percentl 0,1 e $<$ Percentil 3 & Magreza \\
$\geq$ Percentil 3 e $\leq$ Percentil 85 & Eutrofia \\
$>$ Percentil 85 e $\leq$ Percentil 97 & Risco de Sobrepeso \\
$>$ Percentil 97 e $\leq$ Percentil 99 & Sobrepeso \\
$>$ Percentil 99,9 & Obesidade \\
\hline
\end{tabular}

(BRASIL, 2011)

Os adultos foram diagnosticados nutricionalmente através do IMC, de acordo com WHO (2000):

- Baixo peso: $<18,5$

- Eutrófico: $\geq 18,5$ e $<25$

- Sobrepeso: $\geq 25$ e $<29,9$

- Obesidade: $\geq 30$

Os diagnósticos de obesidade I, II e III foram agrupados para alinhar com o diagnóstico nutricional das crianças que não são diagnosticadas por graus de excesso de peso. Na ausência do pai, foi considerado $P$ e $E$ referidos pela mãe.

\subsubsection{Avaliação neuropsicomotora}

A avaliação do DNPM foi realizada por profissional devidamente treinada e certificada (Anexo 3) para aplicação do Bayley Scales of Infant Development, $3^{a}$ edição (Bayley-III), sendo considerada como padrão-ouro, principalmente por abordar uma avaliação completa e detalhada do DNPM, composta 326 itens, divididos em cinco domínios: cognição, linguagem (comunicação receptiva e expressiva), desenvolvimento motor fino e grosso (MADASCHI; PAULA, 2011).

A Avaliação motora grossa da Bayley-III verifica as habilidades motoras axiais, como sentar, levantar e andar, bem como as habilidades de controle motor fino, onde participam especialmente, as extremidades dos membros superiores - mãos e dedos, sendo a verificação das habilidades das crianças em realizar o acompanhamento visual, alcance, tentativas de pegar, manipular e agarrar objetos, ou seja, toda destreza manual para a idade avaliada. A escala de cognição avalia o desempenho da criança em diversas áreas, como visualização, memória e atenção; enquanto a 
escala de linguagem avalia dois aspectos principais da linguagem, as domínios de comunicação receptiva e expressiva, incluindo a capacidade da criança de reconhecer sons e vocabulário receptivo; o teste de comunicação avalia a comunicação préverbal, o uso de vocabulário e o desenvolvimento morfossintático (BAYLEY, 2006; MADASCHI, 2016).

A avaliação foram realizados individualmente, na presença das mães, através da observação direta da criança em situações propostas pelas atividades propostas no formulário de aplicação da Bayley-III (Anexo 4). Ao final das avaliaçãoes, as crianças foram diagnosticadas como "Risco", quando há comprometimento real no desenvolvimento, em "Emergente", quando a criança está abaixo do esperado ou vulnerável para atraso do desenvolvimento, ou "Competente", quando há desenvolvimento típico para a idade (BAYLEY, 2006).

\subsubsection{Questionário estruturado}

Foi aplicado questionário estruturado (Apêndice 2) contendo questões sobre convívio social, histórico de internações, atividade escolar e permanência da criança em instituição de ensino. Além disto, foi verificado aspectos sociais, grau de instrução das mães e dos pais, aspectos gerais sobre a gestação e estimativa de renda média domiciliar/Classe Social, de acordo com ABEP (2016).

\subsubsection{Coleta de sangue, urina e análise dos minerais}

Para as análises bioquímicas foram realizadas coletas de sangue venoso periférico em tubos SST $®$ II Advance $®$ da marca BD vacutainer $®$ de $5 \mathrm{ml}$.

Além disto, foi fornecido um pote de polietileno, próprio para coleta de amostra de urina, com capacidade de $80 \mathrm{ml}$, devidamente etiquetados com o nome da mulher e da criança. Os voluntários foram orientados para realizar micção no pote de coleta (MACHADO; MORALES JR; FRIGATTO, 2016).

Após a coleta, as amostras de sangue foram centrifugadas utilizando 0 aparelho de centrífuga Universal $320 \mathrm{R}$ Hettich $®$ por 15 minutos, à $25^{\circ} \mathrm{C}$ e a 3500 rotações/minutos (rpm) do Laboratório de Nutrição e Metabolismo da Faculdade de Medicina de Ribeirão Preto da Universidade de São Paulo (FMRP-USP). Após este processo, o plasma foi separado e o resíduo, contendo os eritrócitos, foi lavado com $5 \mathrm{ml}$ de solução fisiológica a $0,9 \%$, homogeneizado lentamente por inversão e 
centrifugado a $25^{\circ} \mathrm{C}$ com 3500 rotações/minutos (rpm) por dez minutos, sendo que, este processo de lavagem dos eritrócitos foi repetido por três vezes, descartando o sobrenadante e adicionando novamente solução fisiológica a 0,9\%.

O plasma e o eritrócito foram armazenados em freezer a $-80^{\circ} \mathrm{C}$ até o momento das análises.

A avaliação bioquímica do Se e Zn, no eritrocitário, plasmático e urinário, foi realizada no Laboratório de Toxicologia e Essencialidade de Metais da Faculdade de Ciências Farmacêuticas de Ribeirão Preto-USP utilizando-se um espectrômetro de massa equipado com plasma indutivamente acoplado (DRC-ICP-MS ELAN DRCII, Perkin Elmer, Sciex, Norwalk, CT, EUA), operando com argônio de alta pureza $(99,999 \%$, Praxaair, Brasil). As amostras foram colocadas em tubos Falcon® de polipropileno de $15 \mathrm{ml}$ (Becton Dickinson), para um volume final de $10 \mathrm{ml}$ (diluição de 20 vezes) com uma solução contendo HNO3 0,5\% (v/v), $10 \mu \mathrm{g} / \mathrm{L}$ Rh e Triton X-100 $0,01 \%(v / v)$. Padrões de calibração analíticos foram preparados numa concentração variando entre 0 e $20 \mathrm{mg} / \mathrm{L}$, no mesmo diluente. A curva foi feita por ajuste de matriz, a qual continha os padrões de calibração, plasma ovino diluído 20 vezes (plasma base) e diluente. Após a preparação da amostra, a mesma foi injetada diretamente no equipamento. $\mathrm{O}$ controle de qualidade para as análises foi assegurado por meio da análise de materiais de referência do Instituto Nacional de Saúde Pública de Quebec, Canadá (BATISTA, et al., 2009).

As seguintes referências foram adotas como faixa de normalidade, para as dosagens de Zn e Se:

- Zn Plasmático ( $\mu \mathrm{g} / \mathrm{ml}): 75$ a 110 (GUTHRIE, PICCIANO, 1994);

- Zn Eritrocitário ( $\mu \mathrm{g} / \mathrm{dl})$ : 10 a 14 (BRODY, 1994);

- Se Plasmático ( $\mu \mathrm{g} / \mathrm{L}): 60$ a 120 (VAN DAEL; DEELSTRA, 1993);

- Se Eritrocitário ( $\mu \mathrm{g} / \mathrm{L})$ : 90 a 190 (ORTUÑO et al., 1997);

- Se Urinário ( $\mu \mathrm{g} / \mathrm{L})$ : 14 a 38 (YANG et al., 1983);

\subsection{Análises estatísticas dos dados}

Foi realizada uma análise exploratória dos dados para uma visão global das características das variáveis obtidas. 
Nas estatísticas descritivas para as variáveis numéricas, calculamos média, desvio padrão, mediana, mínimo e máximo. Para as variáveis categóricas fornecemos a frequência e o percentual.

Na verificação da relação entre as variáveis numéricas, utilizamos o coeficiente de correlação não paramétrico de Spearman, pois estas rejeitaram a hipótese de normalidade.

$\mathrm{Na}$ associação das variáveis categóricas, utilizamos o teste Qui-quadrado ou o teste exato de Qui-quadrado quando a tabela apresentou valor esperado $\leq 5 \mathrm{em}$ mais de $20 \%$ das caselas.

$\mathrm{Na}$ comparação entre as variáveis categóricas e as variáveis numéricas, aplicamos o teste $t$ para duas amostras independentes, quando estas variáveis apresentaram distribuição normal, ou o teste Mann-Whitney, quando elas não apresentaram distribuição normal.

Adotamos $p \leq 0,05$ como nível de significância em todas as análises. 


\section{Resultados}

Os resultados descrevem as informações das 29 mulheres no PMII, com as respectivas 29 crianças e dados dos 29 pais (progenitores). A idade média das mulheres em PMII, crianças e pais foi de $36 \pm 6,3 \pm 0,3$ e $38 \pm 6$ anos de vida, respectivamente.

Na Tabela 4 podemos verificar que durante o PMI, 89,7\% não apresentaram consumo de bebida alcoólica e $13,8 \%$ realizaram o consumo de cigarros. De acorco com a classificação de Amaral et al. (2017), 86,2\% dos indivíduos nasceram com idade gestacional adequada. Além disso, $79,3 \%$ das crianças nasceram com o peso adequado e, destacamos ainda que, $41,4 \%$ dos bebês foram amamentados exclusivamente entre o primeiro e terceiro mês de vida.

Quando questionadas sobre qual foi o primeiro alimento ofertado ao bebê, além do leite materno ou formula infantil, $17(58,6 \%)$ responderam que ofertaram fruta ou suco de frutas natural, $8(27,6 \%)$ informaram papa de legumes, $1(3,45 \%)$ chá, 1 $(3,45 \%)$ iogurte, $1(3,45 \%)$ papa de cereais e $1(3,45 \%)$ ofertou preparado industrializado para bebês.

Para alinhar os diagnósticos do estado nutricional das mulheres do PMl e das crianças com os diagnósticos das mulheres do PMII e dos pais, as classificações dos graus I, II e III de obesidade para adultos foram agrupadas, os quais podem ser visualizados na Tabela 5. Aproximadamente, 35\% das mulheres do PMII e dos pais apresentaram diagnóstico de sobrepeso, sendo que, a prevalência de sobrepeso nas crianças avaliadas foi de $24,1 \%$. Ocorreram 28 diagnósticos do estado nutricional dos pais, uma vez que uma das mulheres não sabia relatar as informações, pois não mantinha contato com o progenitor da criança.

Destacamos que das 12 mulheres do PMI que foram diagnosticadas, quanto ao EN com eutrofia, apenas nove se mantiveram neste mesmo EN no PMII, havendo aumento da prevalência de obesidade no grupo amostral. 
Tabela 4 - Caracterização das mulheres no PMI, resultados pré-natal, perinatal e lactante $(n=29)$.

\begin{tabular}{lcc}
\hline \multicolumn{1}{c}{ Variável } & $\mathrm{n}$ & $\%$ \\
\hline Pré-natal & & \\
Bebida alcoólica & 26 & 89,7 \\
Não & 2 & 6,9 \\
Raramente & 0 & 0 \\
Quinzenalmente & 1 & 3,4 \\
Semanalmente & 0 & 0 \\
Diariamente & & \\
Fumo & & \\
Sim & 4 & 13,8 \\
Não & 25 & 86,2
\end{tabular}

Consumo de Suplemento

Nenhum

Ac Fólico

3,4

Ac. Fólico e Ferro

$\begin{array}{ll}1 & 3,4 \\ 9 & 31\end{array}$

Polivitaminas/Minerais

14

48,3

$5 \quad 17,2$

Idade Gestacional

Prematuro ( $\leq 36$ semanas)

4

13,8

Termo (entre 37 e 42 semanas)

25

86,2

Pós-termos ( $\geq 42$ semanas)

0

Perinatal

Tipo de Parto

Normal/Vaginal

Cesariana

\section{Sexo do RN}

Masculino

Feminino

Peso ao nascer do $\mathrm{RN}^{* * *}$

Baixo peso $(\leq 2,49 \mathrm{~kg})$

$3 \quad 10,3$

Adequado (Entre 2,5 e 3,99 Kg)

$23 \quad 79,3$

Macrossômico $(\geq 4,0 \mathrm{~kg})$

$3 \quad 10,3$

\section{Lactante}

Aleitamento materno exclusivo

Não ofertou Leite Materno

4

1-3 meses

4-5 meses

8

6 ou mais meses

$5 \quad 17,2$

\section{Introdução alimentar}

1-3 meses

4-5 meses

6 ou mais meses

$\mathrm{n}$ = número de participantes da pesquisa;

PMI: mulher em período gestacional;

***: Classificação de acordo com Puffer; Serrano (1987). 
Tabela 5 - Diagnóstico do estado nutricional das mulheres no PMI, PMII, das crianças e dos pais.

\begin{tabular}{lcccccccc}
\hline \multirow{2}{*}{ Estado Nutricional } & \multicolumn{2}{c}{ PMI } & \multicolumn{2}{c}{ PMII } & \multicolumn{2}{c}{ Pai } & \multicolumn{2}{c}{ Criança } \\
& $\mathrm{n}$ & $\%$ & $\mathrm{n}$ & $\%$ & $\mathrm{n}$ & $\%$ & $\mathrm{n}$ & $\%$ \\
\hline Eutrófico & 12 & 41,4 & 9 & 31,0 & 9 & 32,1 & 23 & 79,3 \\
Sobrepeso $_{\text {Obesidade }^{* *}}^{10}$ & 34,5 & 10 & 34,5 & 9 & 32,1 & 4 & 13,8 \\
Total & 7 & 24,1 & 10 & 34,5 & 10 & 35,8 & 2 & 6,9 \\
\hline
\end{tabular}

$\mathrm{n}=$ número de participantes da pesquisa.

**As classificações de Graus I, II e III foram agrupadas para os pais e mães.

Não houve nenhum indivíduo classificado com baixo peso.

Houve correlação positiva e significativa $(r=0,78$ e $p<0,001)$ quando observado o estado nutricional da mulher no PMI e no PMII, ou seja, conforme uma variável aumenta a outra também se eleva, havendo linearidade entre as duas variáreis. Não foram encontradas mais nenhuma correlação, com significância estatística, quanto ao estado nutricional da mulher no PMI, PMII, do pai com o da criança.

Com base no questionário apresentado pela ABEP (2016), foi possível estimar a renda média domiciliar dos voluntários, apresentados na Tabela 6 , bem como, a respectiva classe social familiar. Além disto, podemos verificar o grau de escolaridade das mulheres no PMII e dos pais, sendo que, $44,8 \%$ e $31 \%$ apresentaram ensino médio completo, respectivamente, e 55,2\% relataram professar a religião evangélica.

As mulheres foram questionadas quantas vezes os filhos (as) permaneceram internadas em hospital, devido alguma condição clínica, sendo que, 17 (58,6\%) disseram que nenhuma vez e $12(41,3 \%)$ informaram que foi entre uma ou duas vezes, porém, este dado não apresentou correlação com nenhuma outra variável.

$\mathrm{Na}$ tabela 7 são apresentados os valores médios referentes a dosagem de $\mathrm{Zn}$ eritrocitário e plasmático das mulheres no PMI, PMIl e da criança, sendo que, destacamos que $82,8 \%$ das mulheres no PMII apresentaram-se adequadas quanto aos níveis de Zn eritrocitário, porém, $72,4 \%$ das crianças estavam deficientes. 
Tabela 6 - Caracterização sociodemográfica e religião das famílias $(n=29)$.

\begin{tabular}{|c|c|c|}
\hline Variável & $\mathrm{n}$ & $\%$ \\
\hline \multicolumn{3}{|c|}{ Renda familiar média e classe social } \\
\hline$A(R \$ 20.888,00)$ & 1 & 3,4 \\
\hline B1 (R\$ 9.254,00) & 2 & 6,9 \\
\hline $\mathrm{B} 2(\mathrm{R} \$ 4.852,00)$ & 11 & 37,9 \\
\hline $\mathrm{C} 1(\mathrm{R} \$ 2.705,00)$ & 5 & 17,2 \\
\hline $\mathrm{C} 2(\mathrm{R} \$ 1.625,00)$ & 9 & 31 \\
\hline $\mathrm{D} / \mathrm{E}(\mathrm{R} \$ 768,00)$ & 1 & 3,4 \\
\hline \multicolumn{3}{|c|}{ Escolaridade da mulher PMII } \\
\hline Ens. Fund. Incompleto & 5 & 17,2 \\
\hline Ens. Fund. Completo & 1 & 3,4 \\
\hline Ens. Méd. Incompleto & 3 & 10,3 \\
\hline Ens. Méd. Completo & 13 & 44,8 \\
\hline Ens. Sup. Incompleto & 1 & 3,4 \\
\hline Ens. Sup. Completo & 6 & 20,7 \\
\hline \multicolumn{3}{|l|}{ Escolaridade do pai } \\
\hline Ens. Fund. Incompleto & 5 & 17,2 \\
\hline Ens. Fund. Completo & 3 & 10,3 \\
\hline Ens. Méd. Incompleto & 5 & 17,2 \\
\hline Ens. Méd. Completo & 9 & 31 \\
\hline Ens. Sup. Incompleto & 2 & 6,9 \\
\hline Ens. Sup. Completo & 5 & 17,2 \\
\hline \multicolumn{3}{|l|}{ Religião } \\
\hline Sem religião & 1 & 3,4 \\
\hline Católica & 11 & 37,9 \\
\hline Evangélica & 16 & 55,2 \\
\hline Espírita & 0 & 0 \\
\hline Outras & 1 & 3,4 \\
\hline
\end{tabular}

$\mathrm{n}=$ número de participantes da pesquisa.

PMI: mulher em período gestacional 
Tabela 7 - Dosagem de Zinco eritrocitário e plasmático das mulheres no PMI, PMII e das crianças.

\begin{tabular}{|c|c|c|c|c|c|c|c|c|c|}
\hline \multirow{2}{*}{ Zinco } & \multicolumn{2}{|l|}{ Total } & \multicolumn{3}{|c|}{ Deficiente } & \multicolumn{3}{|c|}{ Adequado } & \multirow[t]{2}{*}{ Referência } \\
\hline & Média $\pm D P$ & $\mathrm{n}$ & Média $\pm D P$ & $\mathrm{n}$ & $\%$ & Média土DP & $\mathrm{n}$ & $\%$ & \\
\hline \multicolumn{10}{|c|}{ Plasma $(\mu \mathrm{g} / \mathrm{ml})$} \\
\hline Mulher PMI & $56,8 \pm 8,9$ & 28 & $55,9 \pm 7,8$ & 27 & 96,4 & 79,8 & 1 & 3,6 & \multirow{3}{*}{$\begin{array}{c}75 \text { a } 110 \\
\text { (a) }\end{array}$} \\
\hline Mulher PMII & $110,7 \pm 24,8$ & 29 & 71,8 & 1 & 3,4 & $112,1 \pm 24,0$ & 28 & 96,6 & \\
\hline Criança & $110,6 \pm 38,2$ & 29 & $30,5 \pm 40,3$ & 2 & 6,9 & $116,6 \pm 31,2$ & 27 & 93,1 & \\
\hline \multicolumn{10}{|c|}{ Eritrócito $(\mu \mathrm{g} / \mathrm{dl})$} \\
\hline Mulher PMI & $10,3 \pm 1,8$ & 28 & $8,7 \pm 0,9$ & 13 & 46,4 & $11,7 \pm 1,2$ & 15 & 53,6 & \multirow{3}{*}{$\begin{array}{c}10 \text { a } 14 \\
\text { (b) }\end{array}$} \\
\hline Mulher PMII & $12,3 \pm 2,7$ & 29 & $8,3 \pm 1,5$ & 5 & 17,2 & $13,2 \pm 2,1$ & 24 & 82,8 & \\
\hline Criança & $9,0 \pm 2,1$ & 29 & $8,0 \pm 1,36$ & 21 & 72,4 & $11,5 \pm 1,47$ & 8 & 27,6 & \\
\hline
\end{tabular}

(a): Guthrie, Picciano, 1994; (b): Brody, 1994.

PMI: mulher em período gestacional; PMII: mulher após 3 anos de gestação;

Diversas inferências foram testadas utilizando as dosagens de $\mathrm{Zn}$, nos diferentes indivíduos e níveis, com o objetivo de verificar correlações ou frequências relevantes, porém, não houve diferença estatística em relação a nenhuma variável.

Os valores médios referentes a dosagem de Se eritrocitário, plasmático e urinário em mulheres no PMI, PMIl e filhos são apresentados na Tabela 8 , sendo que, podemos observar que $62,1 \%$ das crianças apresentavam deficiência de Se em nível eritrocitário, sendo este o parâmetro mais adequado para dosagem do mineral (ASHTON et al., 2009). 
Tabela 8 - Dosagem de Selênio eritrocitário, plasmático e urinário das mulheres no PMI, PMIl e das crianças.

\begin{tabular}{lccccccccc}
\hline \multicolumn{1}{c}{$\begin{array}{c}\text { Selênio } \\
(\mu \mathrm{g} / \mathrm{L})\end{array}$} & Média $\pm \mathrm{DP}$ & $\mathrm{n}$ & Média $\pm \mathrm{DP}$ & $\mathrm{n}$ & $\%$ & Média $\pm \mathrm{DP}$ & $\mathrm{n}$ & $\%$ & \\
\hline Plasma & & & & & & & & & \\
PMI & $46,4 \pm 8,0$ & 28 & $46,4 \pm 8,0$ & 28 & 100,0 & 0 & 0 & 0,0 & 60 a 120 \\
PMII & $101,3 \pm 32,1$ & 29 & $53,1 \pm 4,4,1$ & 3 & 10,3 & $106,9 \pm 29,0$ & 26 & 89,7 & (a) \\
Criança & $92,2 \pm 29,5$ & 29 & $30,3 \pm 40,2$ & 2 & 6,9 & $96,8 \pm 23,7$ & 27 & 93,1 & \\
\hline Eritrocitário & & & & & & & & & \\
PMI & $57,57 \pm 17,2$ & 28 & $55,6 \pm 14,1$ & 27 & 96,4 & 110,0 & 1 & 3,6 & 90 a 190 \\
PMII & $97,1 \pm 20,5$ & 29 & $78,0 \pm 9,5$ & 11 & 37,9 & $108,7 \pm 16,2$ & 18 & 62,1 & (b) \\
Criança & $87,7 \pm 13,2$ & 29 & $79,1 \pm 7,4$ & 18 & 62,1 & $101,8 \pm 6,5$ & 11 & 37,9 & \\
\hline Urinário & & & & & & & & & \\
PMII & $28,3 \pm 13,8$ & 28 & $10,6 \pm 2,6$ & 4 & 14,3 & $31,2 \pm 12,7$ & 24 & 85,7 & 14 a 38 \\
Criança & $33,8 \pm 15,6$ & 29 & $11,1 \pm 2,1$ & 2 & 6,9 & $35,5 \pm 14,9$ & 27 & 93,1 & (c) \\
\hline
\end{tabular}

(a): Van Dael; Deelstra, 1993; (b): Ortuño et al., 1997; (c): Yang et al., 1983;

PMI: mulher em período gestacional; PMIl: mulher após 3 anos de gestação;

Verificamos correlação significativa entre o Se plasmático com o urinário da criança $(r=0,41$ e $p=0,03)$ e Se plasmático com o urinário da mulher no PMII $(r=$ $0,37$ e $p=0,05)$, ou seja, quando os valores de uma variável aumentam os da outra também tendem a aumentar.

Ao correlacionarmos as dosagens de Se com a renda familiar média (ou classe social estimada), verificamos que houve correlação inversa entre os níveis de Se plasmático da criança e a renda familiar média $(r=-0,46$ e $p=0,01)$.

Aproximadamente, $90 \%$ das crianças apresentaram diagnóstico do DNPM competente, ou seja, desenvolvimento típico para a idade, o qual pode ser verificado na tabela 9, bem como, os demais diagnósticos dos domínios. 
Tabela 9 - Classificação das crianças quanto aos domínios do desenvolvimento neuropsicomotor e o diagnóstico clínico.

\begin{tabular}{|c|c|c|c|c|c|c|c|c|c|c|}
\hline \multirow[t]{2}{*}{ Classificação } & \multicolumn{2}{|c|}{ Cognitivo } & \multicolumn{2}{|c|}{$\begin{array}{c}\text { Comunicação } \\
\text { receptiva e } \\
\text { expressiva }\end{array}$} & \multicolumn{2}{|c|}{$\begin{array}{l}\text { Motor } \\
\text { fino }\end{array}$} & \multicolumn{2}{|c|}{$\begin{array}{c}\text { Motor } \\
\text { grosso }\end{array}$} & \multicolumn{2}{|c|}{$\begin{array}{c}\text { Diagnósticc } \\
\text { DNPM }\end{array}$} \\
\hline & $\mathrm{N}$ & $\%$ & $\mathrm{n}$ & $\%$ & $\mathrm{n}$ & $\%$ & $\mathrm{~N}$ & $\%$ & $\mathrm{n}$ & $\%$ \\
\hline Competente & 27 & 93,1 & 23 & 79,3 & 23 & 79,3 & 25 & 86,2 & 26 & 89,7 \\
\hline Emergente & 1 & 3,4 & 5 & 17,2 & 5 & 17,2 & 2 & 6,9 & 2 & 6,9 \\
\hline Risco & 1 & 3,4 & 1 & 3,4 & 1 & 3,4 & 2 & 6,9 & 1 & 3,4 \\
\hline Total & 29 & 100 & 29 & 100 & 29 & 100 & 29 & 100 & 29 & 100 \\
\hline
\end{tabular}

$\mathrm{n}=$ número de participares da pesquisa.

DNPM = Desenvolvimento neuropsicomotor.

Os resultados da avaliação do DNPM das crianças foram relacionados com o grau de instrução dos progenitores, sendo verificada a correlação inversa entre o grau de instrução das mulheres no PMII e os critérios de diagnóstico do domínio de comunicação ( $r=-0,47$ e $p=0,01)$, ou seja, quando aumenta o grau de instrução da mãe (melhora a educação) tende a diminuir o risco para atraso na comunicação (emergente e risco).

Houve correlação significativa do diagnóstico do DNPM e os domínios comunicação e motor grosso com os níveis de Se plasmático da mulher no PMI, nos quais, são apresentados na Tabela 10. As demais dosagens de Zn e Se plasmáticos, eritrocitário e urinário não apresentaram correlação significativa.

Tabela 10 - Correlação entre dosagem de Selênio plasmático da mulher no PMI e diagnóstico das crianças quanto ao desenvolvimento neuropsicomotor e aos Domínios de comunicação e motor grosso $(n=28)$.

\begin{tabular}{clccccc}
\hline Variáveis & \multicolumn{7}{c}{ Selênio plasmático da mulher no PMI $(\mu \mathrm{g} / \mathrm{L})^{* *}$} & \multirow{2}{*}{$\mathrm{r}$} & \multirow{2}{*}{$\mathrm{p}$} \\
& & Média $\pm \mathrm{DP}$ & $\mathrm{n}$ & $\%$ & & \\
\hline \multirow{2}{*}{$\begin{array}{c}\text { Desenvolvimento } \\
\text { neuropsicomotor }\end{array}$} & Competente & $47,7 \pm 7,5$ & 25 & 89,3 & & \\
& Emergente & $35,4 \pm 0,6$ & 2 & 7,1 & $-0,49$ & 0,008 \\
& Risco & $35,7(\mathrm{a})$ & 1 & 3,6 & & \\
\hline Comunicação & Competente & $48,1 \pm 7,6$ & 22 & 78,6 & & \\
(Receptiva e & Emergente & $40,7 \pm 6,6$ & 5 & 17,8 & $-0,46$ & 0,01 \\
Expressiva) & Risco & $35,8(\mathrm{a})$ & 1 & 3,6 & & \\
\hline \multirow{3}{*}{ Motor Grosso } & Competente & $48,13 \pm 7,3$ & 24 & 85,8 & & \\
& Emergente & $35,9 \pm 1,3$ & 2 & 7,1 & $-0,55$ & 0,002 \\
& Risco & $35,8 \pm 0,1$ & 2 & 7,1 & & \\
\hline
\end{tabular}

(a): Valor referente a dosagem de apenas um indivíduo; ${ }^{* *}$ Referência: 60 a $120 \mu \mathrm{g} / \mathrm{L}$ $r$ = coeficiente de correlação de Spearman. PMl: mulher em período gestacional; 
Conforme descrito na Tabela 10, verificamos que quando os níveis plasmáticos de Se aumentam na mulher no PMI tende haver diminuição no atraso do DNPM, bem como, na comunicação e desenvolvimento do motor grosso (emergente e risco). 


\section{Discussão}

De acordo com WHO (2015), a taxa ideal de cesárea para os paídes seria entre $10 \%$ e $15 \%$, sendo que, acima desta porcentagem pode ocorrer aumento do risco de complicações para a mãe e para o recém-nascido.

Zaiden et al. (2019), ao realizarem um levantamento de dados da pesquisa Nascer no Brasil, realizada entre fevereiro de 2011 e outubro de 2012, incluindo amostra da Região Sudeste, compreendendo 10.155 mulheres, identificaram prevalência de cesariana eletiva de 45,7\%.

Identificamos $55,2 \%$ de partos cesarianos dentre as mulheres no PMI avaliadas, semelhantes aos resultados de Zaiden et al. (2019) e muito próximo a taxa de 57\% apresentada por WHO (2017), no qual, descreve que o Brasil ocupa o segundo lugar no mundo em percentual deste tipo de parto.

Ao realizarem 52.395 entrevistas na Vigitel (Vigilância de Fatores de Risco e proteção para Doenças Crônicas por inquérito telefônico), Brasil (2019), identificaram excesso de peso em 55,7\% de adultos em todo o Brasil, sendo ligeiramente maior entre homens $(57,8 \%)$ do que entre mulheres $(53,9 \%)$. Quanto a obesidade, a frequência de adultos obesos foi de 19,8\%, sendo ligeiramente maior entre as mulheres $(20,7 \%)$ do que entre os homens $(18,7 \%)$.

Somando os índices de sobrepeso e obesidade dos pais e das mulheres no PMII, identificamos índice de $68,42 \%$ de excesso de peso, sendo $38,1 \%$ de obesidade, valores acima dos descritos por Brasil (2019).

Ramon-Arbues, Abadia, Gomez (2017) conduziram estudo descritivo longitudinal com 301 mulheres durante a gravidez e o puerpério (6 meses após o parto), na Espanha, identificando que a retenção de peso pós-parto estava diretamente relacionada ao ganho de peso gestacional.

Haugen et al. (2014), conduziram estudo com 56.101 mulheres grávidas e após a gravidez (18 meses), na Noruega, e verificaram que o ganho excessivo de peso gestacional aumentou o risco de uma retenção de peso pós-parto materna aos 18 meses.

Como verificado nos resultados, encontramos correlação significativa ( $r=0,78$ e $p=<0,001$ ) quando observado o estado nutricional da mulher no PMI e com o PMII, 
corroborando com os resultados de Ramon-Arbues, Abadia, Gomez (2017) e Haugen et al. (2014). O ganho de peso após a gestação pode ser explicado devido ao alto nível de desgaste psicológico e a várias demandas existentes na nova rotina da mulher, colaborando para que haja baixo comprometimento com alimentação equilibrada e prática de atividade física (MCKINLEY et al., 2018).

Chaves Junior (2020) avaliou 160 crianças entre 3 e 5 anos, no município de Piracicaba/SP, de ambos os sexos, havendo prevalência de $71 \%$ de crianças eutróficas, $11 \%$ com sobrepeso e $10 \%$ com obesidade.

Lins et al. (2018) realizaram diagnóstico nutricional em 42 pré-escolares (4 a 6 anos) em Frei Paulo/SE. Desta forma, verificaram que uma criança estava abaixo do peso $(2,38 \%)$, $3(7,14 \%)$ eram obesos e $4(9,52 \%)$ apresentavam sobrepeso.

Ao compararmos as prevalências de Chaves Junior (2020) e Lins et al. (2018) com os nossos resultados, verificamos que obtivemos taxas muito semelhantes aos dados dos autores, sendo observado $13,8 \%$ e $6,9 \%$ de sobrepeso e obesidade, respectivamente, em nosso grupo amostral.

\subsection{Dosagens de Zinco e suas relações com Peso ao Nascer e Desenvolvimento Infantil}

Podemos verificar nos resultados discrepância entre os achados plasmáticos e eritrocitários de Zn, porém, embora a concentração plasmática seja comumente usada como um indicador, a interpretação da medição das concentrações pode oscilar conforme prática de exercícios vigorosos e ingestão de alimentos, bem como, ocorrer diminuição dos níveis em caso de infecção, além das concentrações em jejum serem maiores pela manhã e as concentrações diminuírem após as refeições, sendo o indicador menos sensível para diagnosticar deficiência de Zn. Em contrapartida, o Zn encontrado nos eritrócitos não reflete mudanças recentes nos níveis de um indivíduo, e é um parâmetro de estado nutricional relativo ao Zn de médio prazo (KING, 2000; MAFRA; COZZOLINO, 2004; SANDSTEAD; AU, 2007).

Por este motivo, podemos destacar que as mulheres no PMII e as crianças, possivelmente, apresentaram consumo de alimentos fontes de Zn próximo ao dia da coleta e que os $72,4 \%$ das crianças realmente apresentavam deficiência de $\mathrm{Zn}$, devido aos baixos valores eritrocitários. 
Salgueiro et al. (2002), em revisão sobre o papel do $\mathrm{Zn}$ no crescimento e desenvolvimento das crianças, descreveram que mulheres grávidas e crianças apresentam maior risco de deficiência, pois a ingestão é baixa em comparação com as recomendadas, e a dieta consumida pela maioria das mulheres tem um alto teor de fitato, o que poderia nos auxiliar a compreender a elevada prevalência de deficiência de $\mathrm{Zn}$ nos grupos avaliados.

Não houve diferença estatística quanto ao tipo de parto, classificação quanto a idade gestacional do nascimento do bebe e nem quanto ao peso ao nascer da criança com os níveis de Zn plasmáticos ou eritrocitários da gestante.

Wang et al. (2015) avaliaram 3.187 chinesas gestantes, e, após dosarem o Zn sérico, identificaram $92,2 \%$ de gestante com níveis adequados e $7,8 \%$ deficientes, sendo que, das gestantes deficientes, 7,3\% geraram recém-nascidos com baixo peso ao nascer. Por isso, os autores concluíram que a deficiência materna de zinco, durante a gravidez, aumenta os riscos de bebês com baixo peso ao nascer.

Tsuzuki et al. (2013) avaliaram 44 gestantes em Tóquio, Japão, sendo verificado as concentrações séricas de Ferro, Zn, Cobre e Se. Não houve correlação nas concentrações maternas de Ferro, Zn ou Cobre com o peso do RN.

Os dados de Wang et al. (2015) contradizem nossos resultados e temos concordância com o estudo conduzido por Tsuzuki et al. (2013). Entretanto, o peso ao nascer depende de muitos fatores além dos níveis maternos de $\mathrm{Zn}$, tais como sexo da criança, idade materna, raça, ganho de peso gestacional, tabagismo e consumo de álcool. Se for encontrada uma correlação significativa entre o peso ao nascer e algum marcador biológico de $\mathrm{Zn}$, uma análise de regressão múltipla por etapas deve ser realizada para avaliar se a associação foi devido a fatores de confusão que podem ou não influenciar o peso ao nascer (KING, 2000; SALGUEIRO et al., 2002).

Rondán Flores (2006) avaliou o estado nutricional do Zn em mulheres de 19 a 31 anos na cidade de São Paulo/SP, sendo que, a concentração plasmática foi de $81,17 \pm 14,7 \mu \mathrm{g} / \mathrm{dL}$ e a eritrocitária de 41,4 $\pm 8,5 \mu \mathrm{gZn} / \mathrm{gHb}$. Assim, aproximadamente $32 \%$ apresentaram deficiência quanto aos níveis plasmáticos (valores abaixo de 75 $\mu \mathrm{g} / \mathrm{dL}$ ), e $52,6 \%$ quanto as dosagens em nível eritrocitário (abaixo de $40 \mu \mathrm{gZn} / \mathrm{gHb}$ ).

Nossos resultados diferem dos achados de Rondán Flores (2006) inicialmente no nível plasmático, uma vez que a prevalência, do presente estudo, foi de $96,6 \%$ de 
níveis adequados e apenas 3,4\% de deficiência. Com relação ao nível eritrocitário, nossos resultados são de $82,8 \%$ de mulheres com padrão de normalidade e $17,2 \%$ deficientes. Divergimos também na referência adotada para o nível eritrocitário. $A$ diferença na prevalência pode ser explicada pelo baixo consumo de alimentos fontes pelas voluntárias, informação que Rondán Flores (2006) descreve.

De modo geral, a deficiência de Zn é distribuída mundialmente, entretanto, acredita-se que a prevalência seja maior em regiões onde as proteínas alimentares são principalmente de origem vegetal ou em países de baixa renda (COMINETTI; COZZOLINO, 2009b).

Costa et al. (2008) avaliaram os níveis de $\mathrm{Zn}$ eritrocitário, bem como, o crescimento linear através das curvas da National Center for Health Statistics (NCHS) de 239 crianças, com idades entre três e seis anos, selecionadas em creches na cidade de Teresina/PI (Nordeste do Brasil). Encontraram prevalência de deficiência de $74,3 \%$, e o grau de deficiência de $Z n$ não influenciou os perfis de crescimento, ou seja, não apresentou significância estatística.

Pedraza et al. (2011) avaliaram o EN relativo ao Zn sérico de 235 crianças préescolares assistidas em creches do estado da Paraíba. As prevalências de deficiência de zinco no soro e déficit de estatura foram de $16,2 \%$ e 7,7\%, respectivamente, porém sem nenhuma correlação.

Destacamos a proximidade dos valores de prevalência de deficiência de $\mathrm{Zn}$ eritrocitário dos resultados de Costa et al. (2008), sendo que obtivemos $72,4 \%$ e eles 74,3\%. E assim como Costa et al. (2008) e Pedraza et al. (2011), não verificamos correlação dos níveis plasmáticos e eritrocitários de Zn (PMI, PMII ou da própria criança) com o EN da criança, não sendo encontrado, no grupo analisado, crianças com baixo peso ou desnutridas.

Lai et al (2019), verificaram as concentrações plasmáticas de zinco e magnésio de 715 gestantes (entre 26 e 28 semanas) e correlacionaram com o teste Lollipop de DNPM nos filhos (das referidas mães) aos quatro anos de idade. O grupo era composto por $35,4 \%$ de mães com ensino superior completo; $19 \%$ das mães eram deficientes em Zn, porém, nenhuma associação significativa foi encontrada para os testes, sugerindo poucas influências a longo prazo de Zn e Magnésio maternos no desenvolvimento das crianças. 
Petry et al. (2016) realizaram uma revisão sistemática e uma meta-análise de ensaios randomizados de fortificação, biofortificação e suplementação em mulheres (grávidas e lactantes) e crianças (6-23 meses) que administravam Ferro ou Zn. Observaram que o fornecimento de $\mathrm{Zn}$ durante a gestação não teve efeitos nos resultados do nascimento. Havia dados limitados ou inexistentes sobre os efeitos do Zn com relação ao crescimento, morbidade e DNPM.

Nossos resultados corroboram com os achados de Lai et al. (2019) e com Petry et al. (2016), uma vez que também não houve significância estatística para a relação de Zn (plasmático e eritrocitário) com o DNPM infantil.

Além disto, não foram encontrados artigos científicos que apresentassem pesquisas que correlacionassem os níveis de Zn com o DNPM infantil. Porém, Black (2003) destaca que as evidências que vinculam a deficiência de $\mathrm{Zn}$ ao desenvolvimento cognitivo e motor das crianças sugerem uma relação entre as crianças mais vulneráveis, mas falta um consenso claro, destacando a necessidade de pesquisas adicionais sobre o momento da deficiência de zinco e a ocorrência com outras deficiências de micronutrientes.

\subsection{Dosagens de Selênio e suas relações com Peso ao Nascer e Desenvolvimento Infantil}

Destacamos que as discrepâncias apresentadas no diagnóstico de deficiência de Se nos níveis plasmáticos e eritrocitários pode ser explicada pelo nível plasmático apresentar maior alteração, em curto prazo, do que os eritrócitos, uma vez que os níveis de soro e plasma são os marcadores de curto prazo em relação ao EN do Se e os eritrócitos são indicadores de longo prazo devido a meia-vida de 120 dias destas células. Além disto, o Se plasmático é afetado pela resposta inflamatória, enquanto a concentração de Se nos eritrócitos não, e a selenometionina se incorpora aleatoriamente em proteínas no lugar da metionina (ASHTON et al., 2009; COMINETTI; COZZOLINO, 2009a; STEFANOWICZ et al., 2013).

De acordo com Cominetti e Cozzolino (2009a), a urina é considerada um bom índice para se avaliar a excreção do mineral, uma vez que os valores excretados se correlacionam com os níveis plasmáticos como foi verificado em nossos achados, o qual houve correlação significativa entre o Se plasmático com o urinário da criança ( $r$ $=0,41$ e $p=0,03)$ e Se plasmático com o urinário da mulher no PMII $(r=0,37$ e $p=$ $0,05)$. 
Como verificado nos resultados, houve correlação inversa entre os níveis de Se plasmático da criança e a renda familiar média $(r=-0,46$ e $p=0,01)$, ou seja, quando aumenta a pobreza há diminuição dos níveis de Se plasmático da criança. Os alimentos com maior concentração proteica é um fator importante quanto a fonte de Se, pois estes incorporam melhor o mineral, por este motivo, podemos que estes alimentos possuem maior custo financeiro as família, sendo de difícil acesso para as famílias de baixa renda (COMINETTI; COZZOLINO, 2009a; RAYMAN, 2012).

Tsuzuki et al. (2013) avaliaram 44 gestantes em Tóquio, Japão, sendo analisadas as concentrações séricas de Ferro, Zn, Cobre e Se. A análise de regressão linear multivariada mostrou que apenas o Se sérico materno foi significativamente associado ao peso ao nascer $(p=0,015)$. Desta forma, os autores concluíram que a concentração sérica materna de Se pode influenciar o peso ao nascer neonatal.

Freitas et al. (2014) revisaram trabalhos que analisaram as concentrações sanguíneas de Se associadas à idade gestacional, à alimentação, à suplementação e ao quadro clínico de prematuros. Verificaram que os prematuros, principalmente com baixo peso ao nascer, apresentam os menores níveis de Se. Entretanto, apesar de ter havido em nossos achados $100 \%$ das mulheres em PMI deficientes em Se no nível plasmático e 96,4\% em nível eritrocitário, não houve associação com o peso ao nascer do RN, havendo ocorrência de apenas $10,3 \%$ de baixo peso dos RN, assim, nossos achados divergem dos resultados de Tsuzuki et al. (2013) e da revisão de Freitas et al. (2014).

Millan Adame et al. (2012), avaliaram os níveis plasmáticos e eritrocitários do Se em 84 adultos saudáveis na Espanha (31 homens e 53 mulheres), sendo que a concentração média no plasma foi de 76,6 $\mu \mathrm{g} / \mathrm{L}(67,3 \pm 10,7 \mu \mathrm{g} / \mathrm{L}$ no sexo feminino), enquanto a concentração média nos eritrócitos foi de 104,6 $\mu \mathrm{g} / \mathrm{L}(101,7 \pm 21,7 \mu \mathrm{g} / \mathrm{L}$ nas mulheres). Os autores consideraram $90 \mu \mathrm{g} / \mathrm{L}$ a concentração plasmática e eritrocitária mínima. Desta forma, 53\% das mulheres foram classificadas como deficientes quando levaram em consideração os níveis plasmáticos e $37,7 \%$ quanto aos valores eritrocitários.

Silva (2018) avaliou 55 mulheres com excesso de peso, entre 18 e 55 anos, na cidade de São Paulo/SP, não sendo verificado deficiência de selênio na amostra analisada, tanto nos valores plasmáticos quanto nos eritrocitários. O autor adotou as 
mesmas referências de normalidade para avaliar o EN de Se que nós utilizamos no presente estudo.

Os achados de Millan Adame et al. (2012) divergem no parâmetro para normalidade uma vez que consideraram $90 \mu \mathrm{g} / \mathrm{L}$ a concentração plasmática mínima, porém, estabelecemos o mínimo de $60 \mu \mathrm{g} / \mathrm{L}$, havendo classificação de apenas 10,3\% das mulheres (PMII) como deficientes. Por este motivo, acreditamos que os nossos resultados de deficiência de Se plasmático se apresentaram menores. Entretanto, classificamos $37,9 \%$ das mulheres (PMII) como deficientes em Se, semelhante a prevalência apresentada por estes autores, no nível eritrocitário.

Apesar de utilizarmos as mesmas referências para classificarmos Se plasmático e eritrocitário que Silva (2018), nossas prevalências são próximas quanto aos níveis plasmáticos, mas, divergem quanto aos níveis eritrocitários, provavelmente pela população que compôs o estudo Silva (2018) apresentar consumo de alimentos fontes de Se.

Silva (2006) realizou dosagem de Se na unha de 26 crianças, entre dois e três anos de idade, de ambos os gêneros, sendo que todos se apresentaram dentro da faixa de normalidade para o parâmetro.

Rocha (2009) avaliou o EN relativo ao Se de 42 crianças ribeirinhas de três a nove anos de idade residentes nas localidades de Demarcação, no Rio Machado e Gleba do Rio Preto, no Rio Preto. Em relação aos níveis plasmáticos, $84 \%$ das crianças apresentaram concentrações abaixo do valor de referência e 16\% foram classificadas como normais. Nos eritrócitos, 45\% das crianças apresentaram concentrações baixas e as demais níveis adequados.

Destacamos a dificuldade de se encontrar artigos referentes ao estado nutricional de Se em crianças sadias (principalmente na faixa de idade pré-escolar). $\mathrm{Na}$ revisão bibliográfica, diversos autores abordam o estado nutricional do Se em situações patológicas. Nossos achados apresentam-se discrepantes aos resultados de Silva (2006), podendo ser devido a estes terem dosado Se na unha, bem como, diferente dos achados de Rocha (2009).

Conforme apresentamos nos resultados, houveram correlação da dosagem de Se plasmático das mulheres em PMI com os critérios de diagnóstico do DNPM ( $r=-$ 
0,49 e p = 0,008), bem como, com os domínios da avaliação de DNPM de comunicação $(r=-0,46$ e $p=0,01)$ e motor grosso $(r=-0,55$ e $p=0,002)$.

Polanska et al. (2016) conduziram estudo com 410 pares mãe/filho poloneses, dosando níveis de Se plasmático em cada trimestre da gravidez, no parto e no sangue do cordão umbilical. As crianças foram avaliadas com um e dois anos de idade usando as escalas Bayley de desenvolvimento infantil; $66 \%$ das mães e $43 \%$ dos pais haviam concluído o nível superior. Houve associação positiva estatisticamente significante entre os níveis de Se no primeiro trimestre de gravidez e desenvolvimento motor no primeiro ano de vida, e desenvolvimento da comunicação aos dois anos de idade. Os autores concluíram que os níveis pré-natal de selênio foram associados a habilidades psicomotoras da criança nos primeiros anos de vida.

Amorós et al. (2018) conduziram estudo com 490 pares mãe/filho com o objetivo de verificar associação entre as concentrações maternas, no final do primeiro trimestre de Se no soro e o desenvolvimento neuropsicológico infantil, avaliado por volta aos 5 anos de idade pelas escalas de desenvolvimento infantil de McCarthy Scales of Children's Abilities (MSCA). Os autores não encontraram associação significativa entre os níveis de Se e desenvolvimento neuropsicológico, entretanto, observaram que as crianças cujas mães tiveram concentrações de Se acima de $85 \mu \mathrm{g} / \mathrm{L}$ no primeiro trimestre de gravidez obtiveram escores mais baixos nas escalas de memória.

Skröder et al. (2015), com objetivo de avaliar o impacto dos níveis eritrocitários de Se durante a gravidez no desenvolvimento infantil aos 1,5 anos de idade, avaliaram em Bangladesh, 750 mães na $30^{a}$ semana gestacional, ou seja, no terceiro trimestre utilizaram a Bayley-III para avaliar o DNPM e uma versão do Inventário de Desenvolvimento Comunicativo de MacArthur foi usada para avaliar a compreensão e expressão da linguagem. Verificaram que o aumento do Se eritrocitário em $0,50 \mu \mathrm{g} / \mathrm{g}$ de hemoglobina foi associado a um aumento na compreensão da linguagem infantil em 3,7 pontos ( 0,5 desvios padrão; intervalo de confiança de 95\%: 0,40,7,1; $p=0,028$ ), bem como, ao um aumento no desenvolvimento motor em 12 pontos (desvio padrão de 0,9; intervalo de confiança de 95\%: 4,3, 19; $p=0,002)$. Desta forma, os autores concluíram que os baixos níveis de Selênio pré-natal demonstram ser desvantajoso para o desenvolvimento psicomotor e de linguagem das crianças. 
Nossos achados corroboram com os dados de Polanska et al. (2016) e de Skröder et al. (2015), porém, divergem de Amorós et al. (2018), provavelmente por estes últimos autores terem realizado a avaliação do DNPM aos 5 anos de idade e com instrumento de avaliação do desenvolvimento deferente de Polanska et al. (2016) e de SkrÖder et al. (2015). Além disto, nossos estudos divergem quanto a idade das crianças que foram submetidas a avalição de DNPM, sendo que o presente estudo avaliou crianças que apresentavam $3 \pm 0,3$ anos de idade, Polanska et al. (2016) avaliaram com um e dois anos, Amorós et al. (2018) e Skröder et al. (2015) com 5 anos e 1,5 anos de idade, respectivamente.

A participação do Se no desenvolvimento infantil é evidenciado nos nossos resultados, porém, este efeito positivo não é claro. Uma hipótese que poderíamos elencar é a ação indireta do Se sob a ativação dos hormônios tireoidanos, que são fundamentais para o desenvolvimento cerebral, implicando na maturação das funções cognitivas (BECKETT et al., 1989; POLANSKA et al. 2016; SKRÖDER et al., 2017).

Estudos in vitro demonstraram que o Se protege os neurônios contra danos oxidativos e processos inflamatórios, por isto, também podemos destacar que há uma ação direta do Se no cérebro ou no sistema nervoso periférico (DALLA PUPPA et al., 1999; STEINBRENNER; SIES, 2013). Por isto, outra hipótese é que o cérebro em rápido desenvolvimento no final da gestação é particularmente sensível à insuficiência de nutrientes, com destaque ao Se.

Não houve diferença estatística quanto ao tipo de parto, classificação quanto a idade gestacional do nascimento do bebê e nem quanto ao peso ao nascer da criança com os níveis de Se plasmáticos, eritrocitários ou urinários da mulher no PMI.

Podemos destacar que o tamanho do grupo amostral deste trabalho foi um fator limitante dos nossos resultados, corroborando inclusive, para que algumas análises necessárias para que pudéssemos compreender claramente o comportamento das variáveis não pudessem ser aplicadas.

A baixa adesão dos voluntários pode ser explicado pela dificuldade de locomoção até o local, bem como, dos horários disponíveis para coleta, ocorrendo em horário comercial de segunda a sexta-feira (período de funcionamento do Centro Médico Social Comunitário Vila Lobato). Além disto, não tivemos acesso a 41,3\% das 
126 voluntárias, correspondendo a 52 mães que poderiam contribuir de forma substancial para aumentar o grupo amostral.

Podemos destacar também que, durante as análises em 2015, não foram verificadas as concentrações hormonais tireoidianas nas gestantes, nos quais poderiam basear a hipótese da associação entre Se com T3 e T4.

Outra limitação foi não ter havido a inclusão sobre o consumo da criança ou da mãe de suplemento alimentar ou de produto alimentício que pudesse ser suplementado com Zn e/ou Se no questionário estruturado. 


\section{Conclusão}

Concluímos que crianças nascidas de mães com baixos níveis de Se durante a gestação apresentam piores resultados quanto ao desenvolvimento neuropsicomotor, assim como, comunicação e motor fino.

Não encontramos associação dos níveis de $\mathrm{Zn}$ gestacional com desenvolvimento das crianças.

Não houve correlação entre o desenvolvimento neuropsicomotor com o diagnóstico nutricional da criança.

Foi verificada correlação entre o estado nutricional da mulher no PMI com o PMII.

Não houver associação do Grau de Instrução dos Pais com o desenvolvimento da criança.

A associação entre o estado nutricional dos Pais com o da criança não foi verificado, bem como, correlações com o peso ao nascer do neonato.

Não houve relação entre o peso ao nascer com estado nutricional da criança; 


\section{Considerações Finais}

Com a observação da correlação entre o estado nutricional da mulher no PMI com o PMII, podemos destacar a importância das gestantes manterem-se eutróficas, realizando seguimento com obstetra e nutricionista durante o pré-natal. Além disso, faz-se necessário a implantação de políticas públicas para promover a mudança conceitual da população quanto ao consumo excessivo de alimentos durante a gestação, garantindo não somente um peso adequado após o período gestacional, mas principalmente evitando doenças crônicas não transmissíveis que estão associadas ao excesso de peso.

Pesquisas adicionais são necessárias para determinar os mecanismos biológicos exatos, os períodos críticos que demonstrem o momento necessário da intervenção, o limiar de gravidade e os efeitos a longo prazo da privação ou de menores taxas nos marcadores biológicos de selênio na gestação com o desenvolvimento da criança. 


\section{Referências bibliográficas}

ABEP - Associação Brasileira de Empresas de Pesquisa. Critério Brasil 2015 e atualização da distribuição de classes para 2016. ABEP: São Paulo, 2016. Disponivel em: <http://www.abep.org/criterio-brasil>. Acessado em: 23 fev 2018.

AMARAL, E. M. et al. Manual de Consulta Rápida para os Profissionais de Saúde. Secretaria da Saúde do Estado de São Paulo, São Paulo, Mar, 2017.

AMORÓS, R. et al. Maternal selenium status and neuropsychological development in Spanish preschool children. Environ Res., New York, v. 166, p. 215-222, Out., 2018.

ANSARI, M. A. et al. Selenium protects cerebral ischemia in rat brain mitochondria. Biol. Trace Elem. Res., Londres, v. 101, p. 73-86, 2004.

ASHTON, K. et al. Methods of assessment of selenium status in humans: a systematic review. Am J Clin Nutr, Rockville, v. 89, p. 2025S-2039S, 2009.

BAYLEY, N. Bayley scales of infant and toddler development III. San Antonio: Harcourt Brace, 2006.

BECKETT, G. J. et al. Inhibition of type I and type II iodothyronine deiodinase activity in rat liver, kidney and brain produced by selenium deficiency. Biochem $\mathbf{J}$, Londres, v. 3, n. 259, p. 887-92, Mai, 1989.

BLACK, M. M. The evidence linking zinc deficiency with children's cognitive and motor functioning. J Nutr., Rockville, v. 133, Mai, 2003.

BHATNAGAR, S; TANEJA, S. Zinc and cognitive development. $\mathbf{B r} \mathbf{J}$ Nutr., Cambridge, v. 85, May, 2001. Supplement 2.

BRASIL. Ministério da Saúde. Secretaria de Vigilância em Saúde. Departamento de Análise em Saúde e Vigilância de Doenças não Transmissíveis. Vigitel Brasil 2018: vigilância de fatores de risco e proteção para doenças crônicas por inquérito telefônico: estimativas sobre frequência e distribuição sociodemográfica de fatores de risco e proteção para doenças crônicas nas capitais dos 26 estados brasileiros e no Distrito Federal em 2018. Brasília: Ministério da Saúde, 2019.

BRASIL. Ministério da Saúde. Secretaria de Atenção à Saúde. Departamento de Atenção Básica. Orientações para a coleta e análise de dados antropométricos em serviços de saúde: Norma Técnica do Sistema de Vigilância Alimentar e Nutricional - SISVAN / Ministério da Saúde, Secretaria de Atenção à Saúde, Departamento de Atenção Básica. Brasília: Ministério da Saúde, 2011.

BRODY, T. Nutritional biochemistry. San Diego: Academic Press, 1994.

CARCILLO, J. et al. Rationale and Design of the Pediatric Critical Illness StressInduced Immune Suppression (CRISIS) Prevention Trial. JPEN, Silver Spring, v. 33, n. 4, p. 368-74, 2009. 
CARDOSO, B. R.; COMINETTI, C.; COZZOLINO, S. M. Importance and management of micronutrient deficiencies in patients with Alzheimer's disease. Clin Interv Aging., Auckland, v. 8, p. 531-42, 2013.

CHAVES JUNIOR, S. C. Avaliação do comportamento alimentar, aspectos nutricionais, condições bucais e biomarcadores salivares na primeira infância. 2020. 53f. Tese (Doutorado em Odontologia) - Faculdade de Odontologia de Piracicaba, Universidade Estadual de Campinas, Piracicaba, 2020.

CHEN, J.; BERRY, M. J. Selenium and selenoproteins in the brain and brain diseases. J. Neurochem., Manila, v. 86, Fev, 2004.

COMINETTI, C.; COZZOLINO, S. M. F. Aspectos fisiológicos e epidemiológicos da deficiência em zinco. In: RAMALHO, A. Diagnóstico, Tratamento e Prevenção da Fome Oculta. São Paulo: Atheneu, p. 53-67, 2008.

COMINETTI, C.; COZZOLINO, S. M. F. Funções Plenamente Reconhecidas de Nutrientes - Selênio. ILSI, São Paulo, v. 7, Jul, 2009a.

COMINETTI, C.; COZZOLINO, S. M. F. Funções Plenamente Reconhecidas de Nutrientes - Zinco. ILSI, São Paulo, v. 7, Jul, 2009b.

COSTA, G. A. et al. Erythrocytary Zinc and the Infant Growth Profile in Northeast Brazil. Biol Trace Elem Res, v. 126, 2008. Supplement 1.

CRUZ, J. B. F.; SOARES, H. F. Uma revisão sobre o Zinco. Uma revisão sobre o zinco. Ens Cien., Campo Grande, v. 15, n. 1, p. 207-222, 2011.

DA CUNHA, A. J. L. A.; LEITE, Á. J. M.; DE ALMEIDA, I. S. The pediatrician's role in the first thousand days of the child: the pursuit of healthy nutrition and development. $\mathbf{J}$ Pediatr., Rio de Janeiro, v. 91, 2015.

DALLA PUPPA, L. D. et al. The role of selenite on microglial migration. Ann NY Acad Sci, New York, n. 1096, p. 179-83, Jan, 2007.

DARLING, J. C. et al. The First Thousand Days: early, integrated and evidence-based approaches to improving child health: coming to a population near you?. Arch Dis Child., Londres, Feb, 2020.

DARNTON-HILL, I; MKPARU, U. C. Micronutrients in pregnancy in low-and middleincome countries. Nutrients, Basel, v. 10, n. 7, p. 1744-68, 2015.

FIGUEIRAS, A. C. et al. Manual para Vigilância do Desenvolvimento Infantil no Contexto da AIDPI (Atenção Integrada às Doenças Prevalentes na Infância). OPAS Organização Pan-Americana da Saúde, Washington, 2005.

FREITAS, R. G. B. O. N. Deficiência de selênio e os efeitos da suplementação em prematuros. Rev Paul Pediatr, São Paulo, v. 32, n. 1, p. 126-35, 2014. 
GERNAND, A. D. et al. Micronutrient deficiencies in pregnancy worldwide: health effects and prevention. Nat Rev Endocrinol., Londres, v. 12, n. 5, p. 274-289, Mai, 2016.

GOGIA, S.; SACHDEV, H. S. Zinc supplementation for mental and motor development in children. Cochrane Database Syst Rev., Vista, v. 3, Dec, 2012.

GOLUBKINA, N. A.; ALFTHAN, G. Selenium status of pregnant women and newborns in the former Soviet Union. Biol Trace Elem Res., Londres, v. 89, v. 1, p. 13-23, Out., 2002.

GUTHRIE, H. A.; PICCIANO, M. F. Human nutrition. Boston: McGraw Hill; 1994.

HAUGEN, M. et al. Associations of pre-pregnancy body mass index and gestational weight gain with pregnancy outcome and postpartum weight retention: A prospective observational cohort study. BMC Pregnancy Childbirth, Londres, v. 14, n. 01, 2014.

HEIDEMANN, S. M. et al, Baseline Serum Concentrations of Zinc, Selenium, and Prolactin in Critically III Children. Pediatr Crit Care Med, Ilinois, v. 14, n. 4, Mai, 2013.

IGLESIAS, S. B. O. et al. Low plasma selenium concentrations in critically ill children: the interaction effect between inflammation and selenium deficiency. Critical Care, Filadélfia, v. 18, 2014.

IOM - Institute of Medicine. Dietary reference intakes for vitamin C, vitamin E, selenium, and carotenoids. Washington: National Academy Press, 2000a.

IOM - Institute of Medicine. Dietary reference intakes for vitamin A, vitamin $\mathrm{K}$, arsenic, boron, chromium, copper, iodine, iron, manganese, molybdenum, nickel, silicon, vanadium and zinc. Washington: National Academy Press, 2002.

KAWADE, R. Zinc status and its association with the health of adolescents: a review of studies in India. Glob Health Action, Suécia, v.5, 2012.

KING, J. C. Determinants of maternal zinc status during pregnancy. Am J Clin Nutr., Rockville, v. 71, May, 2000. Supplement 5.

KUMAR, S.; SINGHI, S. Zinc and selenium in critically ill children: where do they stand?. IPP, India, v. 2, n. 1, p. 297-306, 2014.

LAI, J. S. et al. Associations of maternal zinc and magnesium with offspring learning abilities and cognitive development at 4 years in GUSTO. Nutr Neurosci., Londres, Jul, p. 1-10, 2019.

LINS, I. F. S. et al. Prevalência de Sobrepeso e Obesidade em Pré-Escolares do Município de Frei Paulo-SE: Um Estudo Longitudinal. Rev. bras. ciênc. saúde, João Pessoa, v. 22, n. 2, p. 165-172, 2018. 
LOCATELI, G. et al. Fontes dietéticas de antioxidantes consumidas pela população brasileira: Inquérito Nacional de Alimentação 2008-2009. BRASPEN J, São Paulo, v. 33, n. 3, p. 238-47, 2018.

LOHMAN, T. G.; ROCHE, A. F.; MARTORELL, R. Anthropometric standardization reference manual. Champaing: Human Kinetics Books, 1988.

MACHADO, A. M. O.; MORALES JR, A.; FRIGATTO, E. A. M. Manual de Coleta 2016/17 - Laboratório Central, Unifesp, São Paulo, 2016.

MCKINLEY, M. C. et al. Weight loss after pregnancy: challenges and opportunities. Nutr Res Rev., Cambridge, v. 31, n. 2, p. 225-238, Dez, 2018.

MADASCHI, V. et al. Bayley-III Scales of Infant and Toddler Development: Transcultural Adaptation and Psychometric Properties. Paidéia, Ribeirão Preto, v. 26, n. 64, p. 189-197, Aug., 2016.

MADASCHI, V.; PAULA, C. S. Medidas de avaliação do desenvolvimento infantil: uma reisão da literatura nos últimos cinco anos. Cad, Pós-grad. Distúrb. Desenvol., São Paulo, v.11, n.1, p. 52-56, 2011.

MAFRA, D.; COZZOLINO, S. M. F. Importância do zinco na nutrição humana. Rev. Nutr., Campinas, v. 17, n. 1, p. 79-87, jan./mar., 2004.

MAIHARA, V. A. et al. Daily dietary selenium intake of selected Brazilian population groups. J Radioanal Nucl Chem, n. 259, p. 465-468, 2004.

MILLAN ADAME, E. et al. Deficient selenium status of a healthy adult Spanish population. Nutr. Hosp., Madrid, v. 27, n. 2, p. 524-528, abr., 2012.

NAVARRO-ALARCON, M.; CABRERA-VIQUE, C. Selenium in food and the human body: A review. Sci Total Environ., Amsterdam, n. 400, p. 115-41, Ago, 2008.

ORTUÑO, J. et al. Importância nutricional del selênio. Arch Lat Am Nutr, Caracas, v. 47, n. 1, p. 1-13, 1997.

PETRY, N. et al. The Effect of Low Dose Iron and Zinc Intake on Child Micronutrient Status and Development during the First 1000 Days of Life: A Systematic Review and Meta-Analysis. Nutrients, Basel, v. 30, n. 8, Nov., 2016

PIECZYNSKA, J.; GRAJETA, $H$. The role of selenium in human conception and pregnancy. J Trace Elem Med Biol, New York, v. 29, p. 31-8, 2015.

PRADO, E. L; DEWEY, K. G. Nutrition and brain development in early life. Nutr Rev, Washington, v. 72, n. 4, p. 267-284, 2014.

POLANSKA, K. et al. Micronutrients during pregnancy and child psychomotor development: Opposite effects of Zinc and Selenium. Environ Res, New York, v. 158, p. 583-589, 2017. 
POLANSKA, K. et al. Selenium status during pregnancy and child psychomotor Development - Polish Mother and Child Cohort study. Pediatr Res, Londres, v. 79, n. 6, Jun 2016.

POWELL, S. R. The antioxidant properties of zinc. J Nutr, Rockville, v. 130, p. 1447S1454S, 2000.

PUTTER, M. R. R.; SERRANO, C. V. Patterns of birthweights. Pan American Health Organization, Washington, n. 504, 1987.

RAMON-ARBUES, E.; MARTINEZ, B. A.; GOMEZ, S. M. Ganancia de peso gestacional y retención de peso posparto en una cohorte de mujeres en Aragón (España). Nutr. Hosp., Madri, v. 34, n. 5, p. 1138-1145, out., 2017.

RAYMAN, M. P. Selenium and human health. Lancet, Londres, v. 379, p. 1256-68, 2012.

ROCHA, A. V. Estado nutricional relativo ao selênio de crianças residentes em duas localidades de Rondônia, Amazônia Ocidental. 2009. 118f. Dissertação (mestrado) - Faculdade de Ciências Farmacêuticas, Universidade de São Paulo, São Paulo, 2009.

RONDÁN FLORES, L. M. Avaliação do estado nutricional relativo ao zinco de um grupo de estudantes universitárias da Universidade de São Paulo. 2006. 82f. Dissertação (mestrado) - Faculdade de Ciências Farmacêuticas, Universidade de São Paulo, São Paulo, 2006.

SALEH, E. A. et al.; Maternal-Foetal status of copper, iron, molybdenum, selenium and zinc in obese gestacional diabetic pregnancies. Acta Diabetol, Milan, v. 44, p.106113, 2007.

SALGUEIRO, M. J. et al. The Role of Zinc in the Growth and Development of Children. Nutrition, Burbank, v. 18, n. 6, p. 510-9, Jun, 2002.

SANDSTEAD, H. H.; AU, W. Zinc. In: NORDBERG, G. F. et al. Handbook on the Toxicology of Metals. Burlington: Elsevier, $3^{\mathrm{a}}$ ed, p. 925-947, 2007.

SCHWEIZER, U. et al. Selenium and brain function: a poorly recognized liaison. Brain Res., Boston, v. 45, Jul, p. 164-178, 2004.

SILVA, G. B. Efeito do consumo de castanhas-do-brasil (Bertholettia excelsa H.B.K.) sobre os biomarcadores inflamatórios e o estado nutricional relativo ao selênio de mulheres obesas. 2018. 96f. Tese (Doutorado) - Faculdade de Ciências Farmacêuticas, Universidade de São Paulo, São Paulo, 2018.

SILVA, C. R. Avaliação do estado nutricional relativo ao selênio de pré-escolares institucionalizados. 2006. 135f. Dissertação (mestrado) - Faculdade de Engenharia de Alimentos, Universidade Estadual de Campinas, Campinas, 2006. 
SINGER, J. A. Simple procedure to compute the sample size needed to compare two independent groups when the population variances are unequal. Stat Med, Chichester, v. 20, p.1089-1095, 2001.

SKRÖDER, H. et al. Early-Life Selenium Status and Cognitive Function at 5 and 10 Years of Age in Bangladeshi Children. Environ Health Perspect., Durham, v. 125, n. 11, nov, 2017.

SKRÖDER, H. M. et al. Selenium status in pregnancy influences children's cognitive function at 1.5 years of age. Clin Nutr, New York, v. 34, p. 923-930, 2015.

SOUZA, M. S. F. Elementos-traço. In: FEFERBAUM, R.; FALCÃO, M. C. Nutrição do Recém-nascido. São Paulo: Atheneu, 2003. p. 179-90.

STEFANOWICZ, F. A. et al. Erythrocyte selenium concentration as a marker of selenium status. Clin Nutr., New York, v. 32, n. 5, p. 837-42, Out, 2013.

STEINBRENNER, H.; SIES, H. Selenium homeostasis and antioxidant selenoproteins in brain: implications for disorders in the central nervous system. Arch Biochem Biophys, New York, v. 2, n. 536, p. 152-7, Aug, 2013.

TAVARES, T. B.; NUNES, S. M.; SANTOS, M. O. Obesity and quality of life: literature review. Rev Med Minas Gerais, Belo Horizonte, v.3, p.359-366, 2010.

TURCATO, M. F; TANAKA, N. Y. Y. Terapia Nutricional nos Erros Inatos do Metabolismo. In: MONTEIRO, J. M; CAMILO JR, J. S. Caminhos da Nutrição e Terapia Nutricional: da concepção à adolescência. Rio de Janeiro: Guanabara Koogan, 2007.p. 454-501.

TSUZUKI, S. et al. Associations of Maternal and Neonatal Serum Trace Element Concentrations with Neonatal Birth Weight. PLoS One, San Francisco, v. 8, Set, 2013.

VAN DAEL, P.; DEELSTRA, H. Selenium. Int J Vitam Nutr Res, Boston, v. 63, p. 312316, 1993.

VARSI, K. et al. Impact of Maternal Selenium Status on Infant Outcome during the First 6 Months of Life. Nutrients, Basel, v. 9, n. 5, Mai, 2017.

VITOUX, D.; ARNAUD, J.; CHAPPUIS, P. Are Copper, Zinc and Selenium in Erythrocytes Valuable Biological Indexes of Nutrition and Pathology?. J Trace Elements Med Biol, Paris, v. 13, p. 113-28, 1999.

WANG, $\mathrm{H}$. et al. Maternal zinc deficiency during pregnancy elevates the risks of fetal growth restriction: a population-based birth cohort study. Sci Rep., Londres, v. 5, 2015.

WHO. Obesity: preventing and managing the global epidemic. WHO Technical Report Series 894. World Health Organization, Geneva, 2000.

WHO. The WHO Child Growth Standards. World Health Organization, Genova, 2006. 
WHO. Declaração da OMS sobre Taxas de Cesáreas. WHO, April, 2015. Disponível em:

<https://www.who.int/reproductivehealth/publications/maternal_perinatal_health/csstatement/en/>. Acessado em: 25 fev 2020.

WHO. UNICEF alerta para elevado número de cesarianas no Brasil. WHO, 20 abr. 2017. Disponível em: <https://nacoesunidas.org/unicef-alerta-para-elevado-numerode-cesarianas-no-brasil/>. Acessado em 25 fev 2020.

YANG, G. Q. et al. Endemic selenium intoxication of humans in China. Am J Clin Nutr, Rockville, v. 37, p. 872-881, 1983.

YOUSUF, S. et al. Selenium plays a modulatory role against cerebral ischemiainduced neuronal damage in rat hippocampus. Brain Res, Londres, v. 25, p. 218-25, Mai, 2007.

YUYAMA, L.K.O. et al. Zinco. In: COZZOLINO, S.M.F. Biodisponibilidade de Nutrientes. Barueri: Manole, 3 ed, 2007. p. 513-38.

ZAIDEN, L. et al. Influência das características hospitalares na realização de cesárea eletiva na Região Sudeste do Brasil. Cad. Saúde Pública, Rio de Janeiro, v. 36, Supl. $1,2019$. 


\section{Apêndices}

Apêndice 1: Termo de Consentimento Livre e Esclarecido

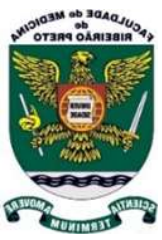

\section{UNIVERSIDADE DE SÃO PAULO FACULDADE DE MEDICINA DE RIBEIRÃO PRETO DEPARTAMENTO DE NUTRIÇÃO E METABOLISMO}

Av. Bandeirantes, 3900. Cep 14049-900 - Ribeirão Preto/SP

A Sra que participou do projeto intitulado "Selênio e Zinco Eritrocitário em Gestantes Obesas", no ano de 2015, está sendo convidada para participar da continuidade da pesquisa, porém, nesta nova etapa, conjuntamente com seu(a) filho(a)

gerado na gestação do ano citado, como voluntários.

Projeto: "Relação entre Estado Nutricional do Selênio e do Zinco e Desenvolvimento Infantil"

Pesquisadores envolvidos: Nilton Augusto da Silva - Nutricionista e Mestrando do Programa de Pós-Graduação em Nutrição e Metabolismo da FMRP/USP, telefone: (16) 99204-0976; Prof. Dr. Anderson Marliere Navarro - Coordenador e Docente do Programa de Pós-Graduação em Nutrição e Metabolismo da FMRP/USP, telefone: (16) 33150745.

O selênio é um nutriente essencial importante em diversas ações no corpo, tais como de "defesa" e envolvido na produção de hormônios, na manutenção da integridade das células do corpo, desenvolvimento físico e mental. O zinco é nutriente essencial, que também participa da "defesa", desenvolvimento físico e mental, controle do "açúcar" do sangue e cicatrização de feridas.

O objetivo do trabalho é verificar a relação entre o Estado Nutricional do Selênio e do Zinco durante o pré-natal com o Desenvolvimento Infantil. Nosso projeto se justificativa por verificar se existe associação entre os níveis de Zinco e Selênio, durante o pré-natal com o desenvolvimento da criança.

A Sra, juntamente com seu (a) filho (a), passarão pelas etapas de coleta de sangue, na qual serão coletados $5 \mathrm{ml}$ de amostra (1 colher de sobremesa cheia), receberão um pote de $80 \mathrm{ml}$ para coletar urina, terão o peso e altura verificados e irão responder a um questionário. Em seguida, o (a) seu (sua) filho (a) será avaliado (a) quanto ao desenvolvimento neuromotor. O tempo previsto para toda a coleta de dados é de 2 a 3 horas.

A coleta de sangue será feita por enfermeiros e/ou auxiliares de enfermagem, que possuem experiência em coleta por mais de 10 anos. Em alguns casos poderá ocorrer pequena luxação e/ou dor no local da coleta de sangue, sendo indicado o uso de compressas frias, ou, no caso de haver qualquer outra complicação, como a coleta será realizado pelos profissionais do Centro de Saúde, a sra e/ou a criança, será encaminhada para atendimento médico, se necessário.

Para minimizar qualquer constrangimento, a pesagem, aferição de altura, aplicação de questionário e avaliação do desenvolvimento da criança, será utilizado sala fechada e reservada.

Tanto você, quanto seu filho, serão beneficiados com a pesquisa, pois iremos informar se a relação de peso e altura estão adequados para a idade, bem como se as dosagens de Zinco e Selênio no sangue estão normais. Além disto, seu (sua) filho (a) ao ser avaliado (a) quanto ao desenvolvimento Neuromotor, você terá conhecimento se ele (a) está tendo um desenvolvimento adequado. 
Caso você e/ou seu (sua) filho (o), seja identificado com alguma alteração de saúde, será elaborado um relatório, descrevendo os dados pessoais e diagnóstico, para que possam procurar por seguimento junto a Secretaria de Saúde do seu município de origem.

Após o período de coleta, será verificado no seu Prontuário Eletrônico do Hospital das Clinicas de Ribeirão Preto/FMRP/USP, bem como, no sistema de dados da Secretaria Municipal da Saúde de Ribeirão Preto/SP, através no número Hygia, bem como do(a) seu (sua) filho(a), informações sobre a história clínica de ambos, limitada apenas no tempo relativo ao pré-natal e após o nascimento.

Sua participação nesta pesquisa é voluntária e a senhora tem liberdade de deixar de participar a qualquer momento, é só avisar algum dos pesquisadores.

Será mantido sigilo absoluto dos dados obtidos individualmente neste estudo, para assegurar a privacidade dos participantes. Fica também garantida a indenização em casos de danos, comprovadamente decorrentes da participação na pesquisa, conforme as leis vigentes no Brasil.

Os pesquisadores estarão disponíveis para qualquer dúvida a qualquer momento durante o estudo e a Sra tem a garantia de acesso aos resultados da pesquisa.

Este projeto foi aprovado pelo Comitê de Ética em Pesquisa do Centro de Saúde Escola, $\mathrm{n}^{\circ}$ 89150118.1.0000.5414/2018, da Faculdade de Medicina de Ribeirão Preto (FMRP/USP), cuja função é defender os interesses das pessoas, em sua integridade e dignidade, contribuindo no desenvolvimento da pesquisa dentro dos padrões éticos. Assim, caso tenha dúvidas sobre aspectos éticos desta pesquisa a senhora também poderá entrar em contato através do telefone (16) 3315-0009, ou dirigir-se ao endereço Rua Terezina, $n^{\circ}$ 690 , bairro Sumarezinho na cidade de Ribeirão Preto/SP. O horário de funcionamento é $8 \mathrm{~h}$ às $17 \mathrm{~h}$.

Você será ressarcida do valor referente ao transporte (ida e volta) até o local da coleta. Ao aceitar participar da pesquisa, uma via deste Termo de Consentimento Livre e Esclarecido, assinado e rubricado em todas as páginas pelo participante e pesquisador. Você poderá deixar de participar a qualquer momento sem nenhum tipo de prejuízo para o seu tratamento no hospital. Garantimos que seus dados pessoais são confidenciais e apenas os resultados serão utilizados sem identificação dos pacientes.

Após ser esclarecida sobre as informações, no caso de aceitar fazer parte deste estudo, assine ao final deste documento.

\section{Nome do Participante e Responsável Legal da Criança:}

\section{Assinatura}

Data____ $/ 201$

Assinatura do Pesquisador:

Data_L_ $/ 201$

\begin{tabular}{|l|l}
\hline Rubrica do pesquisador & Rubrica do participante/responsável
\end{tabular}


Apêndice 2: Questionário Estruturado

DADOS PESSOAIS / AVALIAÇÃO NUTRICIONAL

Nome da Mãe:

Registro HC: Hygia:

Telefones de contato:

Idade: Estatura: Peso: IMC: $\mathrm{kg} / \mathrm{m}^{2}$

Nome

da

Criança:

Registro HC: Hygia:

Idade : anos meses (Data de nascimento:

Peso: Comprimento:

Curvas de Crescimento: P/l:

P/E: $\mathrm{IMC/I}:$ E/l:

Diagnóstico Nutricional Atual:

( ) Muito Baixo Peso ( ) Baixo Peso ( ) Eutrófico ( ) Sobrepeso ( ) Excesso de peso

Nome

do

Pai:

Idade:

Estatura:

Peso:

IMC:

$\mathrm{kg} / \mathrm{m}^{2}$

\section{MÃE E FILHO}

Peso ao Nascer: ( ) Baixo Peso ( ) Adequado ( ) Macrossomico

IG do nascimento: ( ) Prematuro ( )Prem. Tardio ( ) Termo ( )Pós-termo Houveram complicações pós-nascimento? ( ) Não ( ) Se sim, quais:

Você desenvolveu alguma patologia durante a gestação da(o) $?$

Se sim, qual(is):

\section{Durante a gestação:}

\section{Você consumiu bebidas alcoólicas?}

( ) Não ( ) Raramente ( ) Quinzenalmente ( ) Semanalmente ( ) Diariamente Se sim, qual a quantidade média? 
Fumou durante a gestação?

( ) $\operatorname{Sim}($ ) Não

Se sim, qual o consumo médio de cigarros?

Consumiu algum suplemento Nutricional? ( ) Não ( ) Se Sim, qual (is):

Até qual idade a criança foi alimentada exclusivamente (apenas) com leite materno?
( ) 1-3 meses
( ) 3-5 meses ( ) 6 meses ou mais

Com quantos meses a criança recebeu o primeiro alimento, além do leite materno?

( ) 1-3 meses

( ) 3-5 meses ( ) 6 meses ou mais

Qual

(is)

alimento

(s)

foi

(ram):

Após o nascimento, quantas vezes a criança permaneceu internada?
( ) nenhuma ( ) 1-2x
( ) $3-4 x$
( ) 5x ou mais
$\mathrm{Se}$
$\operatorname{sim}$,
por
qual(is)
motivo(s):

MÃE

Grau de Instrução: ( ) Ens. Fund Incomp ( ) Ens. Fund Compl ( ) Ens. Médio Incomp ( ) Ens. Médio Compl ( ) Ens. Superior Incomp （ ） Ensino Superior Compl

Estado Civil: ( ) Casada ( ) Solteira ( ) Amasiada ( ) Divorciada

Você segue alguma religião? Qual?

( ) Não/Sem religião ( ) Católica ( ) Evangélica ( ) Espirita ( ) Outra:

Qual sua atividade profissional atualmente? Qual

Se trabalha fora do lar, qual local a criança permanece durante o período que você exerce atividade profissional?

( ) Cuidadora Contratada

( ) Instituição de Ensino Público
( ) Cuidadora Familiar (Avos ou outro parente de 1 grau)

( ) Instituição de Ensino Privado

Quantas horas a criança permanece neste local?

( ) 4-6h ( ) 7-8h ( )9-10h ( )10h ou mais

\section{PAl}

Grau de Instrução: ( ) Ens. Fund Incomp ( ) Ens. Fund Compl ( ) Ens. Médio Incomp ( ) Ens. Médio Compl ( ) Ens. Superior Incomp （ ） Ensino Superior Compl

Exerce atividade Remunerada? ( ) Sim （ ) Não

Qual a atividade profissional dele atualmente? Qual

Quantas pessoas residem na mesma casa? adultos crianças (0-14 anos). 


\section{AVALIAÇÃO SOCIOECONÔMICA}

\begin{tabular}{|c|c|c|c|c|c|}
\hline & \multicolumn{5}{|c|}{ Quantidade que Possui } \\
\hline Itens de Conforto & $\mathbf{0}$ & 1 & 2 & 3 & 4 ou + \\
\hline $\begin{array}{l}\text { Quantidade de automóveis de passeio exclusivamente para uso } \\
\text { particular }\end{array}$ & & & & & \\
\hline $\begin{array}{l}\text { Quantidade de empregados mensalistas, considerando apenas os que } \\
\text { trabalham pelo menos cinco dias por semana }\end{array}$ & & & & & \\
\hline Quantidade de máquinas de lavar roupa, excluindo tanquinho & & & & & \\
\hline Quantidade de banheiros & & & & & \\
\hline $\begin{array}{l}\text { DVD, incluindo qualquer dispositivo que leia DVD e desconsiderando } \\
\text { DVD de automóvel }\end{array}$ & & & & & \\
\hline Quantidade de geladeiras & & & & & \\
\hline Quantidade de freezers independentes ou parte da geladeira duplex & & & & & \\
\hline $\begin{array}{l}\text { Quantidade de microcomputadores, considerando computadores de } \\
\text { mesa, laptops, notebooks e netbooks e desconsiderando tablets, palms } \\
\text { ou smartphones }\end{array}$ & & & & & \\
\hline Quantidade de lavadora de louças & & & & & \\
\hline Quantidade de fornos de micro-ondas & & & & & \\
\hline $\begin{array}{l}\text { Quantidade de motocicletas, desconsiderando as usadas exclusivamente } \\
\text { para uso profissional }\end{array}$ & & & & & \\
\hline Quantidade de máquinas secadoras de roupas, considerando lava e seca & & & & & \\
\hline
\end{tabular}

\begin{tabular}{|l|l|}
\hline \multicolumn{2}{|l|}{ A água utilizada neste domicílio é proveniente de? } \\
\hline 1 & Rede geral de distribuição \\
\hline 2 & Poço ou nascente \\
\hline 3 & Outro meio \\
\hline
\end{tabular}

\begin{tabular}{|l|l|}
\hline \multicolumn{2}{|c|}{ Considerando o trecho da rua do seu domicílio, você diria que a rua é: } \\
\hline 1 & Asfaltada/Pavimentada \\
\hline 2 & Terra/Cascalho \\
\hline
\end{tabular}

\begin{tabular}{|l|l|l|}
\hline \multicolumn{2}{|l|}{$\begin{array}{l}\text { Qual é o grau de instrução do chefe da família? Considere como chefe da família a } \\
\text { pessoa que contribui com a maior parte da renda do domicílio. }\end{array}$} \\
\hline & Nomenclatura Atual & Nomenclatura Anterior \\
\hline 1 & Analfabeto / Fundamental I incompleto & Analfabeto/Primário Incompleto \\
\hline 2 & $\begin{array}{l}\text { Fundamental I completo / Fundamental } \\
\text { II incompleto }\end{array}$ & Primário Completo / Ginásio Incompleto \\
\hline 3 & $\begin{array}{l}\text { Fundamental } \\
\text { Incompleto }\end{array}$ & Ginásio Completo / Colegial incompleto \\
\hline 4 & Médio completo/Superior incompleto & Colegial Completo /Superior Incompleto \\
\hline 5 & Superior completo & Superior Completo \\
\hline
\end{tabular}




\section{Anexos}

Anexo 1: Parecer de aprovação do Comitê de ética em pesquisa

\section{FACULDADE DE MEDICINA DE RIBEIRÃO PRETO} UNIVERSIDADE DE SÃO PAULO

COMITÊ DE ÉTICA EM PESQUISA

Prezado Senhor,

Comunicamos que o projeto de pesquisa abaixo especificado foi analisado e Aprovado do Comitê de Ética em pesquisa do Centro de Saúde Escola da Faculdade de Medicina de Ribeirão Preto da Universidade de São Paulo, na data de 03 de Julho de 2018.

\section{CAAE: 89150118.1.0000.5414}

Projeto de pesquisa: "Relação entre Estado Nutricional do Selênio e do Zinco e Desenvolvimento Infantil “

Pesquisador: Nilton Augusto da Silva

Em atendimento à Resolução 466/12, deverá ser encaminhado a este CEP o relatório final da pesquisa e a publicação de seus resultados, para acompanhamento, bem como comunicada qualquer intercorrência ou a sua interrupção.

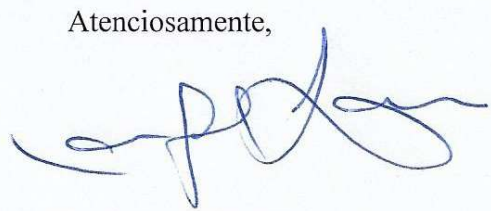

Prof. Dr. Laércio Joel Franco

Coordenador do CEP/CSE-FMRP-USP.

Ilmo. Prof. Dr. Anderson Marliere Navarro

Docente do Departamento de Nutrição e Metabolismo da Faculdade de Medicina de Ribeirão Preto/USP

Rua Terezina, 690 -Sumarezinho - Ribeirão Preto, SP - 14055-380 - E-mail: cep.cse@fmrp.usp.br Fnno: 55 16 2215_nnno 
Anexo 2: Tabela com percentis para avaliação do crescimento da WHO (2006)

1 - Peso (kg) para idade (meses) segundo curvas da OMS (2006) (1: sexo masculino; 2: sexo feminino)

\begin{tabular}{|c|c|c|c|c|c|c|c|c|c|c|}
\hline & & \multicolumn{9}{|c|}{ PERCENTIL } \\
\hline sexo & idade (meses) & P 0,1 & \begin{tabular}{|l|} 
P 3 \\
\end{tabular} & P5 & \begin{tabular}{|l|} 
P10 \\
\end{tabular} & P 15 & P 50 & P85 & \begin{tabular}{|l|} 
P 97 \\
\end{tabular} & P 99,9 \\
\hline 1 & 0 & 2,0 & 2,5 & 2,6 & 2,8 & 2,9 & 3,3 & 3,9 & 4,3 & 5,1 \\
\hline 1 & 1 & 2,9 & 3,4 & 3,6 & 3,8 & 3,9 & 4,5 & 5,1 & 5,7 & 6,6 \\
\hline 1 & 2 & 3,7 & 4,4 & 4,5 & 4,7 & 4,9 & 5,6 & 6,3 & 7,0 & 8,1 \\
\hline 1 & 3 & 4,4 & 5,1 & $\overline{5,2}$ & 5,5 & 5,6 & 6,4 & 7,2 & 7,9 & $\overline{9,1}$ \\
\hline 1 & 4 & 4,9 & 5,6 & 5,8 & 6,0 & 6,2 & 7,0 & 7,9 & 8,6 & 9,8 \\
\hline 1 & 5 & 5,3 & 6,1 & 6,2 & 6,5 & 6,7 & 7,5 & 8,4 & 9,2 & 10,5 \\
\hline 1 & 6 & 5,6 & 6,4 & 6,6 & 6,9 & 7,1 & $\overline{7,9}$ & 8,9 & 9,7 & 11,1 \\
\hline 1 & 7 & 5,9 & 6,7 & 6,9 & 7,2 & 7,4 & 8,3 & 9,3 & 10,2 & 11,5 \\
\hline 1 & 8 & 6,1 & 7,0 & 7,2 & 7,5 & 7,7 & 8,6 & 9,6 & $\mid 10,5$ & 12,0 \\
\hline 1 & 9 & 6,3 & 7,2 & $\overline{7,4}$ & 7,7 & 7,9 & $\overline{8,9}$ & 10,0 & $\mid 10,9$ & 12,4 \\
\hline 1 & 10 & 6,5 & 7,5 & 7,7 & 8,0 & 8,2 & $\overline{9,2}$ & 10,3 & 11,2 & 12,8 \\
\hline 1 & 11 & 6,7 & 7,7 & 7,9 & 8,2 & 8,4 & $\overline{9,4}$ & 10,5 & $\mid 11,5$ & 13,1 \\
\hline 1 & 12 & 6,9 & 7,8 & 8,1 & 8,4 & 8,6 & 9,6 & 10,8 & $\mid 11,8$ & 13,5 \\
\hline 1 & 13 & 7,0 & 8,0 & $\overline{8,2}$ & 8,6 & 8,8 & $\overline{9,9}$ & 11,1 & \begin{tabular}{|l|}
12,1 \\
\end{tabular} & 13,8 \\
\hline 1 & 14 & 7,2 & 8,2 & 8,4 & 8,8 & 9,0 & 10,1 & 11,3 & 12,4 & 14,1 \\
\hline 1 & 15 & 7,3 & 8,4 & 8,6 & 9,0 & 9,2 & 10,3 & 11,6 & 12,7 & 14,5 \\
\hline 1 & 16 & 7,5 & 8,5 & 8,8 & 9,1 & 9,4 & 10,5 & 11,8 & $\mid 12,9$ & 14,8 \\
\hline 1 & 17 & $7 \overline{7,6}$ & 8,7 & 8,9 & 9,3 & 9,6 & 10,7 & 12,0 & 13,2 & 15,1 \\
\hline 1 & 18 & 7,7 & 8,9 & 9,1 & 9,5 & 9,7 & 10,9 & 12,3 & $\mid 13,5$ & 15,4 \\
\hline 1 & 19 & 7,9 & 9,0 & 9,3 & 9,7 & 9,9 & 11,1 & 12,5 & \begin{tabular}{|l|}
13,7 \\
\end{tabular} & 15,7 \\
\hline 1 & 20 & 8,0 & 9,2 & 9,4 & 9,8 & 10,1 & 11,3 & 12,7 & 14,0 & 16,0 \\
\hline 1 & 21 & 8,2 & 9,3 & 9,6 & 10,0 & 10,3 & 11,5 & 13,0 & 14,3 & 16,4 \\
\hline 1 & 22 & 8,3 & 9,5 & 9,8 & 10,2 & 10,5 & 11,8 & 13,2 & 14,5 & 16,7 \\
\hline 1 & 23 & 8,4 & 9,7 & $\overline{9,9}$ & 10,3 & 10,6 & 12,0 & 13,4 & 14,8 & 17,0 \\
\hline 1 & 24 & 8,5 & 9,8 & 10,1 & 10,5 & 10,8 & 12,2 & 13,7 & 15,1 & 17,3 \\
\hline 1 & 25 & 8,7 & 10,0 & 10,2 & \begin{tabular}{|l|l}
10,7 \\
\end{tabular} & 11,0 & 12,4 & 13,9 & 15,3 & 17,6 \\
\hline 1 & 26 & 8,8 & \begin{tabular}{|l|}
10,1 \\
\end{tabular} & 10,4 & 10,8 & 11,1 & 12,5 & 14,1 & 15,6 & 18,0 \\
\hline 1 & 27 & 8,9 & \begin{tabular}{|l|}
10,2 \\
\end{tabular} & 10,5 & 11,0 & 11,3 & \begin{tabular}{|l|}
12,7 \\
\end{tabular} & 14,4 & 15,9 & 18,3 \\
\hline 1 & 28 & 9,0 & \begin{tabular}{|l|}
10,4 \\
\end{tabular} & 10,7 & \begin{tabular}{|l|}
11,1 \\
\end{tabular} & 11,5 & 12,9 & 14,6 & 16,1 & 18,6 \\
\hline 1 & 29 & 9,2 & \begin{tabular}{|l|}
10,5 \\
\end{tabular} & 10,8 & 11,3 & 11,6 & 13,1 & 14,8 & \begin{tabular}{|l|}
16,4 \\
\end{tabular} & 18,9 \\
\hline 1 & 30 & $\overline{9,3}$ & \begin{tabular}{|l|}
10,7 \\
\end{tabular} & 11,0 & 11,4 & 11,8 & 13,3 & 15,0 & 16,6 & 19,2 \\
\hline 1 & 31 & 9,4 & 10,8 & 11,1 & 11,6 & 11,9 & 13,5 & 15,2 & 16,9 & 19,5 \\
\hline 1 & 32 & 9,5 & \begin{tabular}{|l|}
10,9 \\
\end{tabular} & 11,2 & 11,7 & 12,1 & 13,7 & 15,5 & 17,1 & 19,8 \\
\hline 1 & 33 & 9,6 & \begin{tabular}{|l|}
11,1 \\
\end{tabular} & 11,4 & 11,9 & 12,2 & 13,8 & 15,7 & 17,3 & 20,1 \\
\hline 1 & 34 & 9,7 & 11,2 & 11,5 & 12,0 & 12,4 & 14,0 & 15,9 & 17,6 & 20,4 \\
\hline 1 & 35 & 9,8 & \begin{tabular}{|l|}
11,3 \\
\end{tabular} & 11,6 & 12,2 & 12,5 & 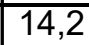 & 16,1 & \begin{tabular}{|l|}
17,8 \\
\end{tabular} & 20,7 \\
\hline 1 & 36 & 9,9 & \begin{tabular}{|l|}
11,4 \\
\end{tabular} & 11,8 & 12,3 & 12,7 & 14,3 & 16,3 & \begin{tabular}{|l|}
18,0 \\
\end{tabular} & 21,0 \\
\hline 1 & 37 & 10,0 & 11,6 & 11,9 & \begin{tabular}{|l|l|}
12,4 \\
\end{tabular} & 12,8 & 14,5 & 16,5 & 18,3 & 21,2 \\
\hline 1 & 38 & 10,1 & \begin{tabular}{|l|}
11,7 \\
\end{tabular} & 12,0 & 12,6 & 12,9 & \begin{tabular}{|l|l}
14,7 \\
\end{tabular} & 16,7 & $\mid 18,5$ & 21,5 \\
\hline 1 & 39 & 10,2 & 11,8 & 12,2 & \begin{tabular}{|l|}
12,7 \\
\end{tabular} & 13,1 & 14,8 & 16,9 & \begin{tabular}{|l|}
18,7 \\
\end{tabular} & 21,8 \\
\hline 1 & 40 & 10,3 & \begin{tabular}{|l|}
11,9 \\
\end{tabular} & 12,3 & 12,8 & 13,2 & 15,0 & 17,1 & 19,0 & 22,1 \\
\hline
\end{tabular}




\begin{tabular}{|c|c|c|c|c|c|c|c|c|c|c|}
\hline 1 & 41 & 10,4 & 12,1 & 12,4 & 13,0 & 13,4 & 15,2 & 17,3 & 19,2 & 22,4 \\
\hline 1 & 42 & 10,5 & 12,2 & 12,5 & 13,1 & 13,5 & 15,3 & 17,5 & 19,4 & 22,7 \\
\hline 1 & 43 & 10,6 & 12,3 & 12,7 & 13,2 & 13,6 & 15,5 & 17,7 & 19,7 & 23,0 \\
\hline 1 & 44 & 10,7 & 12,4 & 12,8 & 13,4 & 13,8 & 15,7 & 17,9 & 19,9 & 23,3 \\
\hline 1 & 45 & 10,8 & 12,5 & 12,9 & 13,5 & 13,9 & 15,8 & 18,1 & 20,1 & 23,6 \\
\hline 1 & 46 & 10,9 & 12,7 & 13,0 & 13,6 & 14,1 & 16,0 & 18,3 & 20,4 & 23,9 \\
\hline 1 & 47 & 11,0 & 12,8 & 13,2 & 13,8 & 14,2 & 16,2 & 18,5 & 20,6 & 24,2 \\
\hline 1 & 48 & 11,1 & 12,9 & 13,3 & 13,9 & 14,3 & 16,3 & 18,7 & 20,9 & 24,5 \\
\hline 1 & 49 & 11,2 & 13,0 & 13,4 & 14,0 & 14,5 & 16,5 & 18,9 & 21,1 & 24,8 \\
\hline 1 & 50 & 11,3 & 13,1 & 13,5 & 14,2 & 14,6 & 16,7 & 19,1 & 21,3 & 25,1 \\
\hline 1 & 51 & 11,4 & 13,3 & 13,7 & 14,3 & 14,7 & 16,8 & 19,3 & 21,6 & 25,4 \\
\hline$\overline{1}$ & 52 & 11,5 & 13,4 & 13,8 & 14,4 & 14,9 & \begin{tabular}{|c|}
17,0 \\
\end{tabular} & 19,5 & 21,8 & 25,7 \\
\hline 1 & 53 & 11,6 & 13,5 & 13,9 & 14,6 & 15,0 & 17,2 & 19,7 & 22,1 & 26,0 \\
\hline 1 & 54 & 11,7 & 13,6 & 14,0 & 14,7 & 15,2 & 17,3 & 19,9 & 22,3 & 26,3 \\
\hline 1 & 55 & 11,8 & 13,7 & 14,1 & 14,8 & 15,3 & 17,5 & 20,1 & 22,5 & 26,6 \\
\hline 1 & 56 & 11,9 & 13,8 & 14,3 & 14,9 & 15,4 & 17,7 & 20,3 & 22,8 & 27,0 \\
\hline 1 & 57 & 12,0 & 13,9 & 14,4 & 15,1 & 15,6 & 17,8 & 20,5 & 23,0 & 27,3 \\
\hline 1 & 58 & 12,0 & 14,1 & 14,5 & 15,2 & 15,7 & 18,0 & 20,7 & 23,3 & 27,6 \\
\hline 1 & 59 & 12,1 & 14,2 & 14,6 & 15,3 & 15,8 & 18,2 & 20,9 & 23,5 & 27,9 \\
\hline 1 & 60 & 12,2 & 14,3 & 14,7 & 15,5 & 16,0 & 18,3 & 21,1 & 23,8 & 28,2 \\
\hline 2 & 0 & 2,0 & 2,4 & 2,5 & 2,7 & 2,8 & 3,2 & 3,7 & 4,2 & 4,8 \\
\hline 2 & 1 & 2,7 & 3,2 & 3,3 & 3,5 & 3,6 & 4,2 & 4,8 & 5,4 & 6,3 \\
\hline 2 & 2 & 3,4 & 4,0 & 4,1 & 4,3 & 4,5 & 5,1 & 5,9 & 6,5 & 7,6 \\
\hline 2 & 3 & 3,9 & 4,6 & \begin{tabular}{|c|}
4,7 \\
\end{tabular} & 5,0 & 5,1 & 5,8 & \begin{tabular}{|c|}
6,7 \\
\end{tabular} & 7,4 & 8,6 \\
\hline 2 & 4 & 4,4 & 5,1 & 5,2 & 5,5 & 5,6 & 6,4 & 7,3 & 8,1 & 9,4 \\
\hline 2 & 5 & 4,7 & 5,5 & 5,6 & 5,9 & 6,1 & 6,9 & 7,8 & 8,7 & 10,1 \\
\hline 2 & 6 & 5,0 & 5,8 & 6,0 & 6,2 & 6,4 & 7,3 & 8,3 & 9,2 & 10,7 \\
\hline 2 & $\overline{7}$ & 5,3 & 6,1 & 6,3 & 6,5 & 6,7 & 7,6 & 8,7 & 9,6 & 11,2 \\
\hline 2 & 8 & 5,5 & 6,3 & 6,5 & 6,8 & 7,0 & 7,9 & 9,0 & 10,0 & 11,7 \\
\hline 2 & 9 & 5,7 & 6,6 & 6,8 & 7,0 & \begin{tabular}{|l|}
7,3 \\
\end{tabular} & 8,2 & 9,3 & 10,4 & 12,1 \\
\hline 2 & 10 & 5,9 & \begin{tabular}{ll|}
6,8 \\
\end{tabular} & 7,0 & 7,3 & 7,5 & 8,5 & 9,6 & 10,7 & 12,5 \\
\hline 2 & 11 & 6,0 & 7,0 & 7,2 & 7,5 & 7,7 & 8,7 & 9,9 & 11,0 & 12,9 \\
\hline 2 & 12 & 6,2 & 7,1 & \begin{tabular}{|l|}
7,3 \\
\end{tabular} & 7,7 & 7,9 & 8,9 & 10,2 & 11,3 & 13,3 \\
\hline 2 & 13 & 6,4 & 7,3 & 7,5 & 7,9 & 8,1 & 9,2 & 10,4 & 11,6 & 13,6 \\
\hline 2 & 14 & 6,5 & 7,5 & 7,7 & 8,0 & 8,3 & 9,4 & 10,7 & 11,9 & 14,0 \\
\hline 2 & 15 & 6,7 & $\begin{array}{l}7,7 \\
\end{array}$ & 7,9 & 8,2 & 8,5 & 9,6 & 10,9 & 12,2 & 14,3 \\
\hline 2 & 16 & 6,8 & \begin{tabular}{ll|}
7,8 \\
\end{tabular} & 8,1 & 8,4 & 8,7 & 9,8 & 11,2 & 12,5 & 14,6 \\
\hline 2 & 17 & 7,0 & 8,0 & 8,2 & 8,6 & 8,8 & 10,0 & 11,4 & 12,7 & 15,0 \\
\hline 2 & 18 & 7,1 & 8,2 & 8,4 & 8,8 & 9,0 & 10,2 & 11,6 & 13,0 & 15,3 \\
\hline 2 & 19 & 7,3 & \begin{tabular}{|l|}
8,3 \\
\end{tabular} & 8,6 & 8,9 & 9,2 & 10,4 & 11,9 & 13,3 & 15,6 \\
\hline 2 & 20 & 7,4 & 8,5 & 8,7 & 9,1 & 9,4 & 10,6 & 12,1 & 13,5 & 15,9 \\
\hline 2 & 21 & 7,6 & 8,7 & 8,9 & 9,3 & 9,6 & 10,9 & 12,4 & 13,8 & 16,2 \\
\hline 2 & 22 & 7,7 & 8,8 & 9,1 & 9,5 & 9,8 & 11,1 & 12,6 & 14,1 & 16,6 \\
\hline 2 & 23 & 7,8 & 9,0 & 9,2 & 9,7 & 9,9 & 11,3 & 12,8 & 14,3 & 16,9 \\
\hline 2 & 24 & 8,0 & 9,2 & 9,4 & 9,8 & 10,1 & 11,5 & 13,1 & 14,6 & 17,2 \\
\hline
\end{tabular}




\begin{tabular}{|c|c|c|c|c|c|c|c|c|c|c|}
\hline 2 & 25 & 8,1 & 9,3 & 9,6 & \begin{tabular}{|l|}
10,0 \\
\end{tabular} & \begin{tabular}{|l|l}
10,3 \\
\end{tabular} & 11,7 & 13,3 & \begin{tabular}{|l|}
14,9 \\
\end{tabular} & 17,6 \\
\hline 2 & 26 & 8,3 & 9,5 & 9,8 & \begin{tabular}{|l|}
10,2 \\
\end{tabular} & \begin{tabular}{|l}
10,5 \\
\end{tabular} & 11,9 & 13,6 & 15,2 & 17,9 \\
\hline 2 & 27 & 8,4 & 9,6 & 9,9 & 10,4 & \begin{tabular}{|l|}
10,7 \\
\end{tabular} & 12,1 & 13,8 & 15,4 & 18,2 \\
\hline 2 & 28 & 8,5 & 9,8 & 10,1 & 10,5 & \begin{tabular}{|c|}
10,8 \\
\end{tabular} & 12,3 & 14,0 & 15,7 & 18,6 \\
\hline 2 & 29 & 8,7 & 10,0 & 10,2 & \begin{tabular}{|l|}
10,7 \\
\end{tabular} & $\begin{array}{ll}11,0 \\
\end{array}$ & 12,5 & 14,3 & \begin{tabular}{|l|}
16,0 \\
\end{tabular} & 18,9 \\
\hline 2 & 30 & 8,8 & 10,1 & 10,4 & \begin{tabular}{|c|}
10,9 \\
\end{tabular} & \begin{tabular}{|l}
11,2 \\
\end{tabular} & 12,7 & 14,5 & \begin{tabular}{|l|}
16,2 \\
\end{tabular} & 19,2 \\
\hline 2 & 31 & 8,9 & 10,3 & 10,5 & \begin{tabular}{|l|}
11,0 \\
\end{tabular} & \begin{tabular}{|l}
11,3 \\
\end{tabular} & 12,9 & 14,7 & \begin{tabular}{|l|l}
16,5 \\
\end{tabular} & 19,6 \\
\hline 2 & 32 & 9,0 & 10,4 & 10,7 & \begin{tabular}{|l|}
11,2 \\
\end{tabular} & \begin{tabular}{|l}
11,5 \\
\end{tabular} & 13,1 & 15,0 & \begin{tabular}{|l|}
16,8 \\
\end{tabular} & 19,9 \\
\hline 2 & 33 & 9,2 & 10,5 & 10,8 & 11,3 & 11,7 & 13,3 & 15,2 & 17,0 & 20,2 \\
\hline 2 & 34 & 9,3 & 10,7 & 11,0 & 11,5 & 11,8 & 13,5 & 15,4 & 17,3 & 20,6 \\
\hline 2 & 35 & 9,4 & 10,8 & 11,1 & 11,6 & 12,0 & 13,7 & 15,7 & 17,6 & 20,9 \\
\hline 2 & 36 & 9,5 & 11,0 & 11,3 & \begin{tabular}{|l|}
11,8 \\
\end{tabular} & \begin{tabular}{|l|}
12,1 \\
\end{tabular} & 13,9 & 15,9 & \begin{tabular}{|l|}
17,8 \\
\end{tabular} & 21,2 \\
\hline 2 & 37 & 9,6 & 11,1 & 11,4 & \begin{tabular}{|l|}
11,9 \\
\end{tabular} & 12,3 & 14,0 & 16,1 & \begin{tabular}{|l|}
18,1 \\
\end{tabular} & 21,6 \\
\hline 2 & 38 & 9,7 & 11,2 & 11,6 & \begin{tabular}{|l|}
12,1 \\
\end{tabular} & \begin{tabular}{|l|}
12,5 \\
\end{tabular} & 14,2 & 16,3 & 18,4 & 21,9 \\
\hline 2 & 39 & 9,8 & 11,4 & 11,7 & \begin{tabular}{|l|}
12,2 \\
\end{tabular} & 12,6 & 14,4 & 16,6 & \begin{tabular}{|l|}
18,6 \\
\end{tabular} & 22,3 \\
\hline 2 & 40 & 10,0 & 11,5 & 11,8 & \begin{tabular}{|l|}
12,4 \\
\end{tabular} & 12,8 & 14,6 & 16,8 & 18,9 & 22,6 \\
\hline 2 & 41 & 10,1 & 11,6 & 12,0 & 12,5 & 12,9 & 14,8 & 17,0 & 19,2 & 23,0 \\
\hline 2 & 42 & 10,2 & 11,8 & 12,1 & 12,7 & \begin{tabular}{|l|}
13,1 \\
\end{tabular} & 15,0 & 17,3 & 19,5 & 23,3 \\
\hline 2 & 43 & 10,3 & 11,9 & 12,2 & 12,8 & 13,2 & 15,2 & 17,5 & \begin{tabular}{|l|}
19,7 \\
\end{tabular} & 23,7 \\
\hline 2 & 44 & 10,4 & 12,0 & 12,4 & \begin{tabular}{|l|}
13,0 \\
\end{tabular} & \begin{tabular}{|l|}
13,4 \\
\end{tabular} & 15,3 & 17,7 & 20,0 & 24,1 \\
\hline 2 & 45 & 10,5 & 12,1 & 12,5 & \begin{tabular}{|l|}
13,1 \\
\end{tabular} & \begin{tabular}{|l}
13,5 \\
\end{tabular} & 15,5 & 17,9 & 20,3 & 24,4 \\
\hline 2 & 46 & 10,6 & 12,3 & 12,6 & \begin{tabular}{|l|}
13,2 \\
\end{tabular} & \begin{tabular}{|l|}
13,7 \\
\end{tabular} & 15,7 & 18,2 & 20,6 & 24,8 \\
\hline 2 & 47 & 10,7 & 12,4 & 12,8 & 13,4 & 13,8 & 15,9 & 18,4 & 20,8 & 25,2 \\
\hline 2 & 48 & 10,8 & 12,5 & 12,9 & 13,5 & 14,0 & 16,1 & 18,6 & \begin{tabular}{|l|}
21,1 \\
\end{tabular} & 25,5 \\
\hline 2 & 49 & 10,9 & 12,6 & 13,0 & \begin{tabular}{|l|}
13,7 \\
\end{tabular} & \begin{tabular}{|l|}
14,1 \\
\end{tabular} & 16,3 & 18,9 & 21,4 & 25,9 \\
\hline 2 & 50 & 11,0 & 12,8 & 13,2 & \begin{tabular}{|l|}
13,8 \\
\end{tabular} & \begin{tabular}{|l|}
14,3 \\
\end{tabular} & 16,4 & 19,1 & \begin{tabular}{|l|}
21,7 \\
\end{tabular} & 26,3 \\
\hline 2 & 51 & 11,1 & 12,9 & 13,3 & \begin{tabular}{|l|}
13,9 \\
\end{tabular} & \begin{tabular}{|l|}
14,4 \\
\end{tabular} & 16,6 & 19,3 & 22,0 & 26,7 \\
\hline 2 & 52 & 11,2 & 13,0 & 13,4 & \begin{tabular}{|l|}
14,1 \\
\end{tabular} & \begin{tabular}{|l|}
14,5 \\
\end{tabular} & 16,8 & 19,5 & 22,2 & 27,0 \\
\hline 2 & 53 & 11,3 & 13,1 & 13,5 & \begin{tabular}{|l|}
14,2 \\
\end{tabular} & \begin{tabular}{|l}
14,7 \\
\end{tabular} & 17,0 & 19,8 & 22,5 & 27,4 \\
\hline 2 & 54 & 11,3 & 13,2 & 13,7 & \begin{tabular}{|l|}
14,3 \\
\end{tabular} & 14,8 & 17,2 & 20,0 & 22,8 & 27,8 \\
\hline 2 & 55 & 11,4 & 13,4 & 13,8 & \begin{tabular}{|l|}
14,5 \\
\end{tabular} & 15,0 & 17,3 & 20,2 & 23,1 & 28,2 \\
\hline 2 & 56 & 11,5 & 13,5 & 13,9 & \begin{tabular}{|l|}
14,6 \\
\end{tabular} & 15,1 & 17,5 & 20,4 & 23,3 & 28,5 \\
\hline 2 & 57 & 11,6 & 13,6 & 14,0 & 14,8 & 15,3 & 17,7 & 20,7 & 23,6 & 28,9 \\
\hline 2 & 58 & 11,7 & 13,7 & 14,2 & \begin{tabular}{|l|}
14,9 \\
\end{tabular} & \begin{tabular}{|l|}
15,4 \\
\end{tabular} & 17,9 & 20,9 & 23,9 & 29,3 \\
\hline 2 & 59 & 11,8 & 13,8 & 14,3 & 15,0 & \begin{tabular}{|l|}
15,5 \\
\end{tabular} & 18,0 & 21,1 & 24,2 & 29,6 \\
\hline 2 & 60 & 11,9 & 14,0 & 14,4 & \begin{tabular}{|l|}
15,2 \\
\end{tabular} & \begin{tabular}{|l|}
15,7 \\
\end{tabular} & 18,2 & 21,3 & 24,4 & 30,0 \\
\hline
\end{tabular}


2 - Peso (kg) para comprimento (cm) segundo curvas da OMS (2006) (1: sexo masculino; 2: sexo feminino)

\begin{tabular}{|c|c|c|c|c|c|c|c|c|c|c|}
\hline & & \multicolumn{9}{|c|}{ PERCENTIL } \\
\hline sexo & comprimento & $\overline{P 0,1}$ & $\overline{P 3}$ & P5 & P10 & P 15 & P 50 & P 85 & P 97 & P 99,9 \\
\hline 1 & 45 & 1,9 & 2,1 & 2,1 & 2,2 & 2,2 & 2,4 & 2,7 & 2,9 & 3,3 \\
\hline 1 & 45,5 & 1,9 & 2,1 & 2,2 & 2,3 & 2,3 & 2,5 & 2,8 & 3,0 & 3,4 \\
\hline 1 & 46 & 2,0 & 2,2 & 2,3 & 2,3 & 2,4 & 2,6 & 2,9 & 3,1 & 3,5 \\
\hline 1 & 46,5 & 2,1 & 2,3 & 2,3 & 2,4 & 2,5 & 2,7 & 3,0 & 3,2 & 3,6 \\
\hline 1 & 47 & 2,1 & 2,4 & 2,4 & 2,5 & 2,5 & 2,8 & 3,1 & 3,3 & 3,7 \\
\hline 1 & 47,5 & 2,2 & 2,4 & 2,5 & 2,6 & 2,6 & 2,9 & 3,1 & 3,4 & 3,8 \\
\hline 1 & 48 & 2,3 & 2,5 & 2,6 & 2,6 & 2,7 & 2,9 & 3,2 & 3,5 & 4,0 \\
\hline 1 & 48,5 & 2,3 & 2,6 & 2,6 & 2,7 & 2,8 & 3,0 & 3,3 & 3,6 & 4,1 \\
\hline 1 & 49 & 2,4 & 2,7 & 2,7 & 2,8 & 2,9 & 3,1 & 3,4 & 3,7 & 4,2 \\
\hline 1 & 49,5 & 2,5 & 2,7 & 2,8 & 2,9 & 2,9 & 3,2 & 3,5 & 3,8 & $\overline{4,3}$ \\
\hline 1 & 50 & 2,6 & 2,8 & 2,9 & 3,0 & 3,0 & 3,3 & 3,7 & 4,0 & $\overline{4,4}$ \\
\hline 1 & 50,5 & 2,6 & 2,9 & 3,0 & 3,1 & 3,1 & $\overline{3,4}$ & 3,8 & 4,1 & 4,6 \\
\hline 1 & 51 & 2,7 & 3,0 & 3,1 & 3,2 & 3,2 & 3,5 & 3,9 & 4,2 & 4,7 \\
\hline 1 & 51,5 & 2,8 & 3,1 & 3,2 & 3,3 & 3,3 & 3,6 & 4,0 & 4,3 & 4,9 \\
\hline 1 & 52 & 2,9 & 3,2 & 3,3 & 3,4 & 3,4 & 3,8 & 4,1 & 4,5 & 5,0 \\
\hline 1 & 52,5 & 3,0 & 3,3 & 3,4 & 3,5 & 3,6 & 3,9 & 4,3 & 4,6 & 5,2 \\
\hline 1 & 53 & 3,1 & 3,4 & 3,5 & 3,6 & 3,7 & 4,0 & 4,4 & 4,7 & 5,3 \\
\hline 1 & 53,5 & 3,2 & 3,5 & 3,6 & 3,7 & 3,8 & 4,1 & 4,5 & 4,9 & 5,5 \\
\hline 1 & 54 & 3,3 & 3,6 & 3,7 & 3,8 & 3,9 & 4,3 & 4,7 & 5,0 & 5,7 \\
\hline 1 & 54,5 & 3,4 & 3,8 & 3,8 & 4,0 & 4,0 & 4,4 & 4,8 & 5,2 & 5,8 \\
\hline 1 & 55 & 3,5 & 3,9 & 4,0 & 4,1 & 4,2 & 4,5 & 5,0 & 5,4 & 6,0 \\
\hline 1 & 55,5 & 3,6 & 4,0 & 4,1 & 4,2 & 4,3 & 4,7 & 5,1 & 5,5 & 6,2 \\
\hline 1 & 56 & 3,8 & 4,1 & 4,2 & 4,3 & 4,4 & 4,8 & 5,3 & 5,7 & 6,4 \\
\hline 1 & 56,5 & 3,9 & 4,3 & 4,3 & 4,5 & 4,6 & 5,0 & 5,4 & 5,9 & 6,6 \\
\hline 1 & 57 & 4,0 & 4,4 & 4,5 & 4,6 & 4,7 & 5,1 & 5,6 & 6,0 & 6,7 \\
\hline 1 & 57,5 & 4,1 & 4,5 & 4,6 & 4,7 & 4,8 & 5,3 & 5,8 & 6,2 & 6,9 \\
\hline 1 & 58 & 4,2 & 4,6 & 4,7 & 4,9 & 5,0 & 5,4 & 5,9 & 6,4 & 7,1 \\
\hline 1 & 58,5 & 4,3 & 4,8 & 4,9 & 5,0 & 5,1 & 5,6 & 6,1 & 6,5 & 7,3 \\
\hline 1 & 59 & 4,5 & 4,9 & 5,0 & 5,1 & 5,2 & 5,7 & 6,2 & 6,7 & 7,5 \\
\hline 1 & 59,5 & 4,6 & 5,0 & 5,1 & 5,3 & 5,4 & 5,9 & 6,4 & 6,9 & 7,7 \\
\hline 1 & 60 & 4,7 & 5,1 & 5,2 & 5,4 & 5,5 & 6,0 & 6,5 & 7,0 & 7,8 \\
\hline 1 & 60,5 & 4,8 & 5,3 & 5,4 & 5,5 & 5,6 & 6,1 & 6,7 & 7,2 & 8,0 \\
\hline 1 & 61 & 4,9 & 5,4 & 5,5 & 5,6 & 5,8 & 6,3 & 6,8 & 7,4 & 8,2 \\
\hline 1 & 61,5 & 5,0 & 5,5 & 5,6 & 5,8 & 5,9 & 6,4 & 7,0 & 7,5 & 8,4 \\
\hline 1 & 62 & 5,1 & 5,6 & 5,7 & 5,9 & 6,0 & 6,5 & 7,1 & 7,7 & 8,5 \\
\hline 1 & 62,5 & 5,2 & 5,7 & 5,8 & 6,0 & 6,1 & 6,7 & 7,3 & 7,8 & 8,7 \\
\hline 1 & 63 & 5,3 & 5,8 & 5,9 & 6,1 & 6,2 & 6,8 & 7,4 & 8,0 & 8,9 \\
\hline 1 & 63,5 & 5,4 & 5,9 & 6,0 & 6,2 & 6,3 & 6,9 & 7,5 & 8,1 & $\overline{9,0}$ \\
\hline 1 & 64 & 5,5 & 6,0 & 6,2 & 6,3 & 6,5 & 7,0 & 7,7 & 8,2 & 9,2 \\
\hline 1 & 64,5 & 5,6 & 6,1 & 6,3 & 6,4 & 6,6 & 7,1 & 7,8 & 8,4 & 9,3 \\
\hline 1 & 65 & 5,7 & 6,3 & 6,4 & 6,6 & 6,7 & 7,3 & 7,9 & 8,5 & 9,5 \\
\hline
\end{tabular}




\begin{tabular}{|c|c|c|c|c|c|c|c|c|c|c|}
\hline 1 & 65,5 & 5,8 & 6,4 & 6,5 & 6,7 & 6,8 & 7,4 & 8,1 & 8,7 & 9,6 \\
\hline 1 & 66 & 5,9 & 6,5 & 6,6 & 6,8 & 6,9 & 7,5 & 8,2 & 8,8 & 9,8 \\
\hline 1 & 66,5 & 6,0 & 6,6 & 6,7 & 6,9 & 7,0 & 7,6 & 8,3 & 8,9 & 9,9 \\
\hline 1 & 67 & 6,1 & 6,7 & 6,8 & 7,0 & 7,1 & 7,7 & 8,4 & 9,1 & 10,1 \\
\hline 1 & 67,5 & 6,2 & 6,8 & 6,9 & 7,1 & 7,2 & 7,9 & \begin{tabular}{|c|}
8,6 \\
\end{tabular} & 9,2 & 10,2 \\
\hline 1 & 68 & 6,2 & 6,9 & 7,0 & 7,2 & 7,3 & 8,0 & 8,7 & 9,3 & 10,4 \\
\hline 1 & 68,5 & 6,3 & 7,0 & 7,1 & 7,3 & 7,4 & 8,1 & 8,8 & 9,5 & 10,5 \\
\hline 1 & 69 & 6,4 & 7,1 & 7,2 & 7,4 & 7,5 & 8,2 & 8,9 & 9,6 & 10,7 \\
\hline 1 & 69,5 & 6,5 & 7,1 & 7,3 & 7,5 & \begin{tabular}{|l|}
7,6 \\
\end{tabular} & 8,3 & 9,1 & \begin{tabular}{|c|}
9,7 \\
\end{tabular} & 10,8 \\
\hline 1 & 70 & 6,6 & 7,2 & 7,4 & 7,6 & \begin{tabular}{|l|}
7,7 \\
\end{tabular} & 8,4 & 9,2 & 9,9 & 11,0 \\
\hline 1 & 70,5 & 6,7 & 7,3 & 7,5 & 7,7 & 7,8 & 8,5 & 9,3 & 10,0 & 11,1 \\
\hline 1 & 71 & 6,8 & 7,4 & 7,6 & 7,8 & 8,0 & 8,6 & 9,4 & 10,1 & 11,3 \\
\hline 1 & 71,5 & 6,9 & 7,5 & 7,7 & 7,9 & 8,1 & 8,8 & 9,6 & 10,3 & 11,4 \\
\hline 1 & 72 & 6,9 & 7,6 & 7,8 & 8,0 & 8,2 & 8,9 & 9,7 & 10,4 & 11,6 \\
\hline 1 & 72,5 & 7,0 & 7,7 & 7,9 & 8,1 & 8,3 & 9,0 & 9,8 & 10,5 & 11,7 \\
\hline 1 & 73 & 7,1 & 7,8 & 8,0 & 8,2 & 8,4 & 9,1 & 9,9 & 10,7 & 11,9 \\
\hline 1 & 73,5 & 7,2 & 7,9 & 8,0 & 8,3 & 8,4 & 9,2 & 10,0 & 10,8 & 12,0 \\
\hline 1 & 74 & 7,3 & 8,0 & 8,1 & 8,4 & 8,5 & 9,3 & 10,1 & 10,9 & 12,2 \\
\hline 1 & 74,5 & 7,4 & 8,1 & 8,2 & 8,5 & 8,6 & 9,4 & 10,3 & 11,0 & 12,3 \\
\hline 1 & 75 & 7,4 & 8,2 & 8,3 & 8,6 & 8,7 & 9,5 & 10,4 & 11,2 & 12,4 \\
\hline 1 & 75,5 & 7,5 & 8,2 & 8,4 & 8,7 & 8,8 & 9,6 & 10,5 & 11,3 & 12,6 \\
\hline 1 & 76 & 7,6 & 8,3 & 8,5 & 8,7 & 8,9 & 9,7 & 10,6 & 11,4 & 12,7 \\
\hline 1 & 76,5 & 7,7 & 8,4 & 8,6 & 8,8 & 9,0 & $\begin{array}{l}9,8 \\
\end{array}$ & 10,7 & 11,5 & 12,8 \\
\hline 1 & 77 & 7,7 & 8,5 & 8,7 & 8,9 & 9,1 & 9,9 & 10,8 & 11,6 & 13,0 \\
\hline 1 & 77,5 & 7,8 & 8,6 & 8,7 & 9,0 & 9,2 & 10,0 & 10,9 & 11,7 & 13,1 \\
\hline 1 & 78 & 7,9 & 8,7 & 8,8 & 9,1 & 9,3 & 10,1 & 11,0 & 11,8 & 13,2 \\
\hline 1 & 78,5 & 8,0 & 8,7 & 8,9 & 9,2 & 9,3 & 10,2 & 11,1 & 12,0 & 13,3 \\
\hline 1 & $\overline{79}$ & 8,0 & 8,8 & 9,0 & 9,2 & 9,4 & 10,3 & 11,2 & 12,1 & 13,4 \\
\hline 1 & 79,5 & 8,1 & 8,9 & 9,1 & 9,3 & \begin{tabular}{|c|}
9,5 \\
\end{tabular} & 10,4 & 11,3 & 12,2 & 13,6 \\
\hline 1 & 80 & 8,2 & 9,0 & 9,1 & 9,4 & \begin{tabular}{|c|}
9,6 \\
\end{tabular} & 10,4 & 11,4 & 12,3 & 13,7 \\
\hline 1 & 80,5 & 8,2 & 9,1 & 9,2 & 9,5 & 9,7 & 10,5 & 11,5 & 12,4 & 13,8 \\
\hline 1 & 81 & 8,3 & 9,1 & 9,3 & 9,6 & 9,8 & 10,6 & 11,6 & 12,5 & 13,9 \\
\hline 1 & 81,5 & 8,4 & 9,2 & 9,4 & 9,7 & 9,9 & 10,7 & 11,7 & 12,6 & 14,0 \\
\hline 1 & 82 & 8,5 & 9,3 & 9,5 & 9,8 & 10,0 & 10,8 & 11,8 & 12,7 & 14,2 \\
\hline 1 & 82,5 & 8,6 & 9,4 & 9,6 & 9,9 & 10,1 & 10,9 & 11,9 & 12,8 & 14,3 \\
\hline 1 & 83 & 8,7 & 9,5 & 9,7 & 10,0 & 10,1 & 11,0 & 12,0 & 13,0 & 14,4 \\
\hline 1 & 83,5 & 8,7 & 9,6 & 9,8 & 10,1 & 10,3 & 11,2 & 12,2 & 13,1 & 14,6 \\
\hline 1 & 84 & 8,8 & 9,7 & 9,9 & 10,2 & 10,4 & 11,3 & 12,3 & 13,2 & 14,7 \\
\hline 1 & 84,5 & 8,9 & 9,8 & 10,0 & 10,3 & 10,5 & 11,4 & 12,4 & 13,3 & 14,8 \\
\hline 1 & 85 & 9,0 & 9,9 & 10,1 & 10,4 & 10,6 & 11,5 & 12,5 & 13,5 & 15,0 \\
\hline 1 & 85,5 & 9,1 & 10,0 & 10,2 & 10,5 & 10,7 & 11,6 & 12,7 & 13,6 & 15,1 \\
\hline 1 & 86 & 9,2 & 10,1 & 10,3 & 10,6 & 10,8 & 11,7 & 12,8 & 13,7 & 15,3 \\
\hline 1 & 86,5 & 9,3 & 10,2 & 10,4 & 10,7 & 10,9 & 11,9 & 12,9 & 13,9 & 15,4 \\
\hline 1 & 87 & 9,4 & 10,3 & 10,5 & 10,8 & 11,0 & 12,0 & 13,1 & 14,0 & 15,6 \\
\hline 1 & 87,5 & 9,5 & 10,4 & 10,6 & 10,9 & 11,2 & 12,1 & 13,2 & 14,2 & 15,7 \\
\hline
\end{tabular}




\begin{tabular}{|c|c|c|c|c|c|c|c|c|c|c|}
\hline 1 & 88 & 9,6 & 10,6 & 10,7 & 11,1 & 11,3 & 12,2 & 13,3 & 14,3 & 15,9 \\
\hline 1 & 88,5 & 9,7 & 10,7 & 10,9 & 11,2 & 11,4 & 12,4 & 13,5 & 14,4 & 16,0 \\
\hline 1 & 89 & 9,8 & 10,8 & 11,0 & 11,3 & 11,5 & 12,5 & 13,6 & \begin{tabular}{|l|}
14,6 \\
\end{tabular} & 16,2 \\
\hline 1 & 89,5 & 9,9 & 10,9 & 11,1 & 11,4 & 11,6 & 12,6 & 13,7 & \begin{tabular}{|l|l|}
14,7 \\
\end{tabular} & 16,3 \\
\hline 1 & 90 & 10,0 & 11,0 & 11,2 & 11,5 & 11,7 & 12,7 & 13,8 & $\mid 14,9$ & 16,5 \\
\hline 1 & 90,5 & 10,1 & 11,1 & 11,3 & 11,6 & 11,8 & 12,8 & 14,0 & \begin{tabular}{|c|}
15,0 \\
\end{tabular} & 16,6 \\
\hline 1 & 91 & 10,2 & 11,2 & 11,4 & 11,7 & 11,9 & 13,0 & \begin{tabular}{|l|}
14,1 \\
\end{tabular} & $\mid 15,1$ & 16,8 \\
\hline 1 & 91,5 & 10,3 & 11,3 & 11,5 & 11,8 & 12,0 & 13,1 & 14,2 & 15,3 & 16,9 \\
\hline 1 & $\overline{92}$ & 10,4 & 11,4 & 11,6 & 11,9 & 12,2 & 13,2 & \begin{tabular}{|l|}
14,4 \\
\end{tabular} & \begin{tabular}{|l|}
15,4 \\
\end{tabular} & 17,1 \\
\hline 1 & 92,5 & 10,5 & 11,5 & 11,7 & 12,0 & 12,3 & 13,3 & 14,5 & 15,5 & 17,3 \\
\hline 1 & 93 & 10,6 & 11,6 & 11,8 & 12,1 & 12,4 & 13,4 & 14,6 & 15,7 & 17,4 \\
\hline 1 & 93,5 & 10,7 & \begin{tabular}{|l|}
11,7 \\
\end{tabular} & 11,9 & 12,2 & 12,5 & 13,5 & \begin{tabular}{|l|}
14,7 \\
\end{tabular} & \begin{tabular}{|c|}
15,8 \\
\end{tabular} & 17,6 \\
\hline 1 & 94 & 10,8 & 11,8 & 12,0 & 12,3 & 12,6 & 13,7 & 14,9 & \begin{tabular}{|c|}
16,0 \\
\end{tabular} & 17,7 \\
\hline 1 & 94,5 & 10,9 & 11,9 & 12,1 & 12,4 & 12,7 & 13,8 & 15,0 & 16,1 & 17,9 \\
\hline 1 & 95 & 10,9 & 12,0 & 12,2 & 12,6 & 12,8 & 13,9 & 15,1 & 16,2 & 18,0 \\
\hline 1 & 95,5 & 11,0 & 12,1 & 12,3 & 12,7 & 12,9 & 14,0 & \begin{tabular}{|l|}
15,3 \\
\end{tabular} & \begin{tabular}{|l|}
16,4 \\
\end{tabular} & 18,2 \\
\hline 1 & 96 & 11,1 & 12,2 & 12,4 & 12,8 & 13,0 & 14,1 & \begin{tabular}{|l|}
15,4 \\
\end{tabular} & \begin{tabular}{|c|}
16,5 \\
\end{tabular} & 18,3 \\
\hline 1 & 96,5 & 11,2 & 12,3 & 12,5 & 12,9 & 13,1 & 14,3 & 15,5 & \begin{tabular}{|c|}
16,7 \\
\end{tabular} & 18,5 \\
\hline 1 & 97 & 11,3 & 12,4 & 12,6 & 13,0 & 13,2 & 14,4 & 15,7 & \begin{tabular}{|l|}
16,8 \\
\end{tabular} & 18,7 \\
\hline 1 & 97,5 & 11,4 & 12,5 & 12,7 & 13,1 & 13,4 & 14,5 & 15,8 & \begin{tabular}{|l|l|}
17,0 \\
\end{tabular} & 18,9 \\
\hline 1 & 98 & 11,5 & 12,6 & 12,8 & 13,2 & 13,5 & 14,6 & 15,9 & 17,1 & 19,0 \\
\hline 1 & 98,5 & 11,6 & 12,7 & 13,0 & 13,3 & 13,6 & 14,8 & 16,1 & 17,3 & 19,2 \\
\hline 1 & 99 & 11,7 & 12,8 & 13,1 & 13,4 & 13,7 & 14,9 & \begin{tabular}{|l|}
16,2 \\
\end{tabular} & \begin{tabular}{|c|}
17,4 \\
\end{tabular} & 19,4 \\
\hline 1 & 99,5 & 11,8 & 12,9 & 13,2 & 13,6 & 13,8 & 15,0 & 16,4 & \begin{tabular}{|c|}
17,6 \\
\end{tabular} & 19,6 \\
\hline 1 & 100 & 11,9 & 13,0 & 13,3 & 13,7 & 13,9 & 15,2 & \begin{tabular}{|l|}
16,5 \\
\end{tabular} & \begin{tabular}{|c|}
17,8 \\
\end{tabular} & 19,8 \\
\hline 1 & 100,5 & 12,0 & 13,2 & 13,4 & 13,8 & 14,1 & 15,3 & \begin{tabular}{|l|}
16,7 \\
\end{tabular} & \begin{tabular}{|l|l|}
17,9 \\
\end{tabular} & 20,0 \\
\hline 1 & 101 & 12,1 & 13,3 & 13,5 & 13,9 & 14,2 & 15,4 & \begin{tabular}{|l|}
16,8 \\
\end{tabular} & 18,1 & 20,2 \\
\hline 1 & 101,5 & 12,2 & 13,4 & 13,6 & 14,0 & 14,3 & 15,6 & 17,0 & 18,3 & 20,4 \\
\hline 1 & 102 & 12,3 & 13,5 & 13,8 & 14,2 & 14,5 & 15,7 & 17,2 & 18,5 & 20,6 \\
\hline 1 & 102,5 & 12,4 & 13,6 & 13,9 & 14,3 & 14,6 & 15,9 & 17,3 & 18,6 & 20,8 \\
\hline 1 & 103 & 12,5 & 13,8 & 14,0 & 14,4 & 14,7 & 16,0 & 17,5 & $\mid 18,8$ & 21,0 \\
\hline 1 & 103,5 & 12,6 & 13,9 & 14,1 & 14,6 & 14,8 & 16,2 & \begin{tabular}{|l|}
17,7 \\
\end{tabular} & \begin{tabular}{|c|}
19,0 \\
\end{tabular} & 21,2 \\
\hline 1 & 104 & 12,7 & 14,0 & 14,3 & 14,7 & 15,0 & 16,3 & \begin{tabular}{|l|}
17,8 \\
\end{tabular} & $\mid 19,2$ & 21,4 \\
\hline 1 & 104,5 & 12,8 & 14,1 & 14,4 & 14,8 & 15,1 & 16,5 & 18,0 & 19,4 & 21,6 \\
\hline 1 & 105 & 13,0 & 14,2 & 14,5 & 14,9 & 15,3 & 16,6 & 18,2 & 19,6 & 21,9 \\
\hline 1 & 105,5 & 13,1 & 14,4 & 14,6 & 15,1 & 15,4 & 16,8 & 18,4 & 19,8 & 22,1 \\
\hline 1 & 106 & 13,2 & 14,5 & 14,8 & 15,2 & 15,5 & 16,9 & 18,5 & 20,0 & 22,3 \\
\hline 1 & 106,5 & 13,3 & 14,6 & 14,9 & 15,4 & 15,7 & 17,1 & \begin{tabular}{|l|}
18,7 \\
\end{tabular} & 20,2 & 22,6 \\
\hline 1 & 107 & 13,4 & 14,8 & 15,0 & 15,5 & 15,8 & 17,3 & \begin{tabular}{|l|}
18,9 \\
\end{tabular} & 20,4 & 22,8 \\
\hline 1 & 107,5 & 13,5 & 14,9 & 15,2 & 15,6 & 16,0 & 17,4 & 19,1 & 20,6 & 23,0 \\
\hline 1 & 108 & 13,6 & 15,0 & 15,3 & 15,8 & 16,1 & 17,6 & 19,3 & 20,8 & 23,3 \\
\hline 1 & 108,5 & 13,7 & 15,2 & 15,5 & 15,9 & 16,3 & 17,8 & 19,5 & 21,0 & 23,5 \\
\hline 1 & 109 & 13,9 & 15,3 & 15,6 & 16,1 & 16,4 & 17,9 & 19,6 & 21,2 & 23,8 \\
\hline 1 & 109,5 & 14,0 & $\mid 15,4$ & 15,7 & 16,2 & 16,6 & 18,1 & 19,8 & 21,4 & 24,0 \\
\hline 1 & 110 & 14,1 & 15,6 & 15,9 & 16,4 & 16,7 & 18,3 & \begin{tabular}{|l|}
20,0 \\
\end{tabular} & 21,6 & 24,3 \\
\hline
\end{tabular}




\begin{tabular}{|c|c|c|c|c|c|c|c|c|c|c|}
\hline 2 & 45 & 1,9 & 2,1 & 2,1 & 2,2 & 2,2 & 2,5 & 2,7 & 2,9 & 3,3 \\
\hline 2 & 45,5 & 2,0 & 2,2 & 2,2 & 2,3 & 2,3 & 2,5 & 2,8 & 3,0 & 3,4 \\
\hline 2 & 46 & 2,0 & 2,2 & 2,3 & 2,3 & 2,4 & 2,6 & 2,9 & 3,1 & 3,5 \\
\hline 2 & 46,5 & 2,1 & 2,3 & 2,3 & 2,4 & 2,5 & 2,7 & 3,0 & 3,2 & 3,6 \\
\hline 2 & 47 & 2,1 & 2,4 & 2,4 & 2,5 & 2,6 & 2,8 & 3,1 & 3,3 & 3,8 \\
\hline 2 & 47,5 & 2,2 & 2,4 & 2,5 & 2,6 & 2,6 & 2,9 & 3,2 & 3,4 & 3,9 \\
\hline 2 & 48 & 2,3 & 2,5 & 2,6 & 2,7 & 2,7 & 3,0 & 3,3 & 3,5 & 4,0 \\
\hline 2 & 48,5 & 2,3 & 2,6 & 2,7 & 2,7 & 2,8 & 3,1 & 3,4 & 3,7 & 4,1 \\
\hline 2 & 49 & 2,4 & 2,7 & 2,7 & 2,8 & 2,9 & 3,2 & 3,5 & 3,8 & 4,2 \\
\hline 2 & 49,5 & 2,5 & 2,8 & 2,8 & 2,9 & 3,0 & 3,3 & 3,6 & 3,9 & 4,4 \\
\hline 2 & 50 & 2,6 & 2,8 & 2,9 & 3,0 & 3,1 & 3,4 & 3,7 & 4,0 & 4,5 \\
\hline 2 & 50,5 & 2,6 & 2,9 & 3,0 & 3,1 & 3,2 & 3,5 & 3,8 & 4,1 & 4,6 \\
\hline 2 & 51 & 2,7 & 3,0 & 3,1 & 3,2 & 3,2 & 3,6 & 3,9 & 4,3 & 4,8 \\
\hline 2 & 51,5 & 2,8 & 3,1 & 3,2 & 3,3 & 3,4 & 3,7 & 4,0 & 4,4 & 4,9 \\
\hline 2 & 52 & 2,9 & 3,2 & 3,3 & 3,4 & 3,5 & 3,8 & 4,2 & 4,5 & 5,1 \\
\hline 2 & 52,5 & 3,0 & 3,3 & 3,4 & 3,5 & 3,6 & 3,9 & 4,3 & 4,7 & 5,3 \\
\hline 2 & 53 & 3,1 & 3,4 & 3,5 & 3,6 & 3,7 & 4,0 & 4,4 & 4,8 & 5,4 \\
\hline 2 & 53,5 & 3,2 & 3,5 & 3,6 & 3,7 & 3,8 & 4,2 & 4,6 & 5,0 & 5,6 \\
\hline 2 & 54 & 3,3 & 3,6 & 3,7 & 3,8 & 3,9 & 4,3 & 4,7 & 5,1 & 5,8 \\
\hline 2 & 54,5 & 3,4 & 3,7 & 3,8 & 3,9 & 4,0 & 4,4 & 4,9 & 5,3 & 6,0 \\
\hline 2 & 55 & 3,5 & 3,9 & 3,9 & 4,1 & 4,1 & 4,5 & 5,0 & 5,4 & 6,1 \\
\hline 2 & 55,5 & 3,6 & 4,0 & 4,0 & 4,2 & 4,3 & 4,7 & 5,2 & 5,6 & 6,3 \\
\hline 2 & 56 & 3,7 & 4,1 & 4,2 & 4,3 & 4,4 & 4,8 & 5,3 & 5,8 & 6,5 \\
\hline 2 & 56,5 & 3,8 & 4,2 & 4,3 & 4,4 & 4,5 & 5,0 & 5,5 & 5,9 & 6,7 \\
\hline 2 & 57 & 3,9 & 4,3 & 4,4 & 4,5 & 4,6 & 5,1 & 5,6 & 6,1 & 6,9 \\
\hline 2 & 57,5 & 4,0 & 4,4 & 4,5 & 4,7 & 4,8 & 5,2 & 5,7 & 6,2 & 7,0 \\
\hline 2 & 58 & 4,1 & 4,5 & 4,6 & 4,8 & 4,9 & 5,4 & 5,9 & 6,4 & 7,2 \\
\hline 2 & 58,5 & 4,2 & 4,6 & 4,7 & 4,9 & 5,0 & 5,5 & 6,0 & 6,5 & 7,4 \\
\hline 2 & 59 & 4,3 & 4,8 & 4,9 & 5,0 & 5,1 & 5,6 & 6,2 & 6,7 & 7,6 \\
\hline 2 & 59,5 & 4,4 & 4,9 & 5,0 & 5,1 & 5,2 & 5,7 & 6,3 & 6,9 & 7,7 \\
\hline 2 & 60 & 4,5 & 5,0 & 5,1 & 5,2 & 5,4 & 5,9 & 6,5 & 7,0 & 7,9 \\
\hline 2 & 60,5 & 4,6 & 5,1 & 5,2 & 5,4 & 5,5 & 6,0 & 6,6 & 7,2 & 8,1 \\
\hline 2 & 61 & 4,7 & 5,2 & 5,3 & 5,5 & 5,6 & 6,1 & 6,7 & 7,3 & 8,3 \\
\hline 2 & 61,5 & 4,8 & 5,3 & 5,4 & 5,6 & 5,7 & 6,3 & 6,9 & 7,5 & 8,4 \\
\hline 2 & 62 & 4,9 & 5,4 & 5,5 & 5,7 & 5,8 & 6,4 & 7,0 & 7,6 & 8,6 \\
\hline 2 & 62,5 & 5,0 & 5,5 & 5,6 & 5,8 & 5,9 & 6,5 & 7,2 & 7,8 & 8,8 \\
\hline 2 & 63 & 5,1 & 5,6 & 5,7 & 5,9 & 6,0 & 6,6 & 7,3 & 7,9 & 8,9 \\
\hline 2 & 63,5 & 5,2 & 5,7 & 5,8 & 6,0 & 6,1 & 6,7 & 7,4 & 8,0 & 9,1 \\
\hline 2 & 64 & 5,2 & 5,8 & 5,9 & 6,1 & 6,2 & 6,9 & 7,5 & 8,2 & 9,2 \\
\hline 2 & 64,5 & 5,3 & 5,9 & 6,0 & 6,2 & 6,3 & 7,0 & 7,7 & 8,3 & 9,4 \\
\hline 2 & 65 & 5,4 & 6,0 & 6,1 & 6,3 & 6,5 & 7,1 & 7,8 & 8,5 & 9,5 \\
\hline 2 & 65,5 & 5,5 & 6,1 & 6,2 & 6,4 & 6,6 & 7,2 & 7,9 & 8,6 & 9,7 \\
\hline 2 & 66 & 5,6 & 6,2 & 6,3 & 6,5 & 6,7 & 7,3 & 8,0 & 8,7 & 9,8 \\
\hline 2 & 66,5 & 5,7 & 6,3 & 6,4 & 6,6 & 6,8 & 7,4 & 8,2 & 8,9 & 10,0 \\
\hline 2 & 67 & 5,8 & 6,4 & 6,5 & 6,7 & 6,9 & 7,5 & 8,3 & 9,0 & 10,1 \\
\hline
\end{tabular}




\begin{tabular}{|c|c|c|c|c|c|c|c|c|c|c|}
\hline 2 & 67,5 & 5,8 & 6,5 & 6,6 & 6,8 & \begin{tabular}{l|}
7,0 \\
\end{tabular} & 7,6 & 8,4 & 9,1 & 10,3 \\
\hline 2 & 68 & 5,9 & 6,6 & 6,7 & 6,9 & 7,1 & 7,7 & 8,5 & 9,2 & 10,4 \\
\hline$\overline{2}$ & 68,5 & $\overline{6,0}$ & 6,7 & 6,8 & 7,0 & \begin{tabular}{|l|}
7,2 \\
\end{tabular} & 7,9 & 8,6 & 9,4 & 10,6 \\
\hline 2 & 69 & 6,1 & 6,7 & 6,9 & 7,1 & \begin{tabular}{ll|}
7,3 \\
\end{tabular} & 8,0 & 8,8 & 9,5 & 10,7 \\
\hline 2 & 69,5 & 6,2 & 6,8 & 7,0 & 7,2 & \begin{tabular}{|l|}
7,3 \\
\end{tabular} & 8,1 & 8,9 & 9,6 & 10,8 \\
\hline 2 & 70 & 6,3 & 6,9 & 7,1 & 7,3 & \begin{tabular}{|l|}
7,4 \\
\end{tabular} & 8,2 & 9,0 & 9,7 & 11,0 \\
\hline$\overline{2}$ & 70,5 & 6,3 & 7,0 & 7,1 & 7,4 & \begin{tabular}{|c|}
7,5 \\
\end{tabular} & 8,3 & 9,1 & \begin{tabular}{|c|}
9,9 \\
\end{tabular} & 11,1 \\
\hline 2 & 71 & 6,4 & 7,1 & 7,2 & 7,5 & \begin{tabular}{|l|}
7,6 \\
\end{tabular} & 8,4 & 9,2 & 10,0 & 11,2 \\
\hline$\overline{2}$ & 71,5 & 6,5 & 7,2 & 7,3 & 7,6 & 7,7 & 8,5 & 9,3 & 10,1 & $\overline{11,4}$ \\
\hline$\overline{2}$ & 72 & 6,6 & 7,3 & 7,4 & 7,6 & 7,8 & 8,6 & 9,4 & 10,2 & 11,5 \\
\hline 2 & 72,5 & 6,6 & 7,4 & 7,5 & 7,7 & 7,9 & 8,7 & 9,5 & 10,3 & 11,6 \\
\hline 2 & $\overline{73}$ & 6,7 & 7,4 & 7,6 & 7,8 & 8,0 & 8,8 & 9,6 & 10,4 & 11,8 \\
\hline 2 & 73,5 & 6,8 & 7,5 & 7,7 & 7,9 & 8,1 & 8,9 & 9,7 & 10,6 & 11,9 \\
\hline 2 & 74 & 6,9 & 7,6 & 7,8 & 8,0 & 8,2 & 9,0 & 9,9 & 10,7 & 12,0 \\
\hline 2 & 74,5 & 6,9 & 7,7 & 7,8 & 8,1 & 8,3 & 9,1 & 10,0 & 10,8 & 12,2 \\
\hline 2 & 75 & 7,0 & 7,8 & 7,9 & 8,2 & 8,3 & 9,1 & 10,1 & 10,9 & 12,3 \\
\hline$\overline{2}$ & 75,5 & 7,1 & 7,8 & 8,0 & 8,3 & 8,4 & 9,2 & 10,2 & 11,0 & 12,4 \\
\hline 2 & 76 & 7,2 & 7,9 & 8,1 & 8,3 & 8,5 & 9,3 & 10,3 & 11,1 & 12,5 \\
\hline 2 & 76,5 & 7,2 & 8,0 & 8,2 & 8,4 & 8,6 & 9,4 & 10,4 & 11,2 & 12,6 \\
\hline 2 & 77 & 7,3 & 8,1 & 8,2 & 8,5 & 8,7 & 9,5 & 10,5 & 11,3 & 12,8 \\
\hline 2 & 77,5 & 7,4 & 8,2 & 8,3 & 8,6 & \begin{tabular}{|c|}
8,8 \\
\end{tabular} & 9,6 & 10,6 & 11,4 & 12,9 \\
\hline 2 & 78 & 7,5 & 8,2 & 8,4 & 8,7 & 8,9 & 9,7 & 10,7 & 11,5 & 13,0 \\
\hline 2 & 78,5 & 7,5 & 8,3 & 8,5 & 8,8 & 8,9 & 9,8 & 10,8 & 11,7 & 13,1 \\
\hline 2 & 79 & 7,6 & 8,4 & 8,6 & 8,8 & 9,0 & 9,9 & 10,9 & 11,8 & 13,3 \\
\hline 2 & 79,5 & 7,7 & 8,5 & 8,7 & 8,9 & 9,1 & 10,0 & 11,0 & 11,9 & 13,4 \\
\hline 2 & 80 & 7,8 & 8,6 & 8,7 & 9,0 & 9,2 & 10,1 & 11,1 & 12,0 & 13,5 \\
\hline 2 & 80,5 & 7,8 & 8,7 & 8,8 & 9,1 & 9,3 & 10,2 & 11,2 & 12,1 & 13,6 \\
\hline$\overline{2}$ & 81 & 7,9 & 8,8 & 8,9 & 9,2 & 9,4 & 10,3 & 11,3 & 12,2 & 13,8 \\
\hline 2 & 81,5 & 8,0 & 8,8 & 9,0 & 9,3 & 9,5 & 10,4 & 11,4 & 12,4 & 13,9 \\
\hline 2 & 82 & 8,1 & 8,9 & 9,1 & 9,4 & 9,6 & 10,5 & 11,6 & 12,5 & 14,1 \\
\hline 2 & 82,5 & 8,2 & 9,0 & 9,2 & 9,5 & 9,7 & 10,6 & 11,7 & 12,6 & 14,2 \\
\hline 2 & 83 & 8,3 & 9,1 & 9,3 & 9,6 & 9,8 & 10,7 & 11,8 & 12,8 & 14,4 \\
\hline 2 & 83,5 & $\begin{array}{l}8,4 \\
\end{array}$ & 9,2 & 9,4 & 9,7 & 9,9 & 10,9 & 11,9 & 12,9 & 14,5 \\
\hline 2 & 84 & 8,5 & 9,3 & 9,5 & 9,8 & 10,0 & 11,0 & 12,1 & 13,1 & 14,7 \\
\hline 2 & 84,5 & 8,5 & 9,4 & 9,6 & 9,9 & 10,1 & 11,1 & 12,2 & 13,2 & 14,8 \\
\hline$\overline{2}$ & 85 & 8,6 & 9,5 & 9,7 & 10,0 & 10,2 & 11,2 & 12,3 & 13,3 & 15,0 \\
\hline$\overline{2}$ & 85,5 & 8,7 & 9,6 & 9,8 & 10,1 & 10,4 & 11,3 & 12,5 & 13,5 & 15,2 \\
\hline 2 & 86 & 8,8 & 9,8 & 9,9 & 10,3 & 10,5 & 11,5 & 12,6 & 13,6 & 15,3 \\
\hline 2 & 86,5 & 8,9 & 9,9 & 10,1 & 10,4 & 10,6 & 11,6 & 12,7 & 13,8 & 15,5 \\
\hline 2 & 87 & 9,0 & 10,0 & 10,2 & 10,5 & 10,7 & 11,7 & 12,9 & 13,9 & 15,7 \\
\hline$\overline{2}$ & 87,5 & 9,1 & 10,1 & 10,3 & 10,6 & 10,8 & 11,8 & 13,0 & 14,1 & 15,8 \\
\hline$\overline{2}$ & 88 & $\overline{9,2}$ & 10,2 & 10,4 & \begin{tabular}{|c|}
10,7 \\
\end{tabular} & 10,9 & 12,0 & 13,2 & 14,2 & 16,0 \\
\hline 2 & 88,5 & 9,3 & 10,3 & 10,5 & 10,8 & 11,0 & 12,1 & 13,3 & 14,4 & 16,2 \\
\hline 2 & 89 & 9,4 & 10,4 & 10,6 & 10,9 & 11,2 & 12,2 & 13,4 & 14,5 & 16,3 \\
\hline 2 & 89,5 & 9,5 & 10,5 & 10,7 & 11,0 & 11,3 & 12,3 & 13,6 & 14,7 & 16,5 \\
\hline
\end{tabular}




\begin{tabular}{|c|c|c|c|c|c|c|c|c|c|c|}
\hline 2 & 90 & 9,6 & 10,6 & 10,8 & 11,2 & 11,4 & 12,5 & 13,7 & 14,8 & 16,7 \\
\hline 2 & 90,5 & 9,7 & 10,7 & 10,9 & 11,3 & 11,5 & 12,6 & 13,8 & 15,0 & 16,9 \\
\hline 2 & 91 & 9,8 & 10,8 & 11,0 & 11,4 & 11,6 & 12,7 & 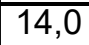 & \begin{tabular}{|c|}
15,1 \\
\end{tabular} & 17,0 \\
\hline 2 & 91,5 & 9,9 & 10,9 & 11,1 & 11,5 & 11,7 & 12,8 & 14,1 & 15,3 & 17,2 \\
\hline 2 & 92 & 10,0 & 11,0 & 11,2 & 11,6 & 11,8 & 13,0 & 14,2 & \begin{tabular}{|c|}
15,4 \\
\end{tabular} & 17,4 \\
\hline 2 & 92,5 & 10,1 & 11,1 & 11,3 & \begin{tabular}{|l|}
11,7 \\
\end{tabular} & 12,0 & 13,1 & \begin{tabular}{|l|}
14,4 \\
\end{tabular} & \begin{tabular}{|c|}
15,6 \\
\end{tabular} & 17,5 \\
\hline 2 & 93 & 10,2 & 11,2 & 11,5 & 11,8 & 12,1 & 13,2 & 14,5 & \begin{tabular}{|l|}
15,7 \\
\end{tabular} & 17,7 \\
\hline 2 & 93,5 & 10,3 & 11,3 & 11,6 & 11,9 & 12,2 & 13,3 & \begin{tabular}{|l|}
14,7 \\
\end{tabular} & 15,9 & 17,9 \\
\hline 2 & 94 & 10,4 & 11,4 & 11,7 & 12,0 & 12,3 & 13,5 & \begin{tabular}{|l|}
14,8 \\
\end{tabular} & \begin{tabular}{|c|}
16,0 \\
\end{tabular} & 18,0 \\
\hline 2 & 94,5 & 10,4 & 11,5 & 11,8 & 12,1 & 12,4 & 13,6 & \begin{tabular}{|l|}
14,9 \\
\end{tabular} & \begin{tabular}{|l|}
16,2 \\
\end{tabular} & 18,2 \\
\hline 2 & 95 & 10,5 & 11,6 & 11,9 & 12,3 & 12,5 & 13,7 & 15,1 & 16,3 & 18,4 \\
\hline 2 & 95,5 & 10,6 & 11,8 & 12,0 & 12,4 & 12,6 & 13,8 & 15,2 & \begin{tabular}{|c|}
16,5 \\
\end{tabular} & 18,6 \\
\hline 2 & 96 & 10,7 & 11,9 & 12,1 & 12,5 & 12,7 & 14,0 & 15,4 & \begin{tabular}{|l|}
16,6 \\
\end{tabular} & 18,7 \\
\hline 2 & 96,5 & 10,8 & 12,0 & 12,2 & 12,6 & 12,9 & 14,1 & 15,5 & \begin{tabular}{|c|}
16,8 \\
\end{tabular} & 18,9 \\
\hline 2 & 97 & 10,9 & 12,1 & 12,3 & 12,7 & 13,0 & 14,2 & 15,6 & 16,9 & 19,1 \\
\hline 2 & 97,5 & 11,0 & 12,2 & $\mid 12,4$ & 12,8 & 13,1 & 14,4 & \begin{tabular}{|l|}
15,8 \\
\end{tabular} & \begin{tabular}{|c|}
17,1 \\
\end{tabular} & 19,3 \\
\hline 2 & 98 & 11,1 & 12,3 & 12,5 & 12,9 & 13,2 & 14,5 & 15,9 & $\mid 17,3$ & 19,5 \\
\hline 2 & 98,5 & 11,2 & 12,4 & $\mid 12,7$ & 13,1 & 13,3 & 14,6 & \begin{tabular}{|l|}
16,1 \\
\end{tabular} & \begin{tabular}{|c|}
17,4 \\
\end{tabular} & 19,6 \\
\hline 2 & 99 & 11,3 & 12,5 & 12,8 & 13,2 & 13,5 & 14,8 & \begin{tabular}{|l|}
16,2 \\
\end{tabular} & \begin{tabular}{|l|}
17,6 \\
\end{tabular} & 19,8 \\
\hline 2 & 99,5 & 11,4 & 12,6 & 12,9 & 13,3 & 13,6 & 14,9 & \begin{tabular}{|l|}
16,4 \\
\end{tabular} & \begin{tabular}{|l|}
17,8 \\
\end{tabular} & 20,0 \\
\hline 2 & 100 & 11,5 & 12,7 & 13,0 & 13,4 & 13,7 & 15,0 & 16,5 & 17,9 & 20,2 \\
\hline 2 & 100,5 & 11,6 & 12,9 & 13,1 & 13,5 & 13,8 & 15,2 & \begin{tabular}{|l|}
16,7 \\
\end{tabular} & \begin{tabular}{|l|}
18,1 \\
\end{tabular} & 20,4 \\
\hline 2 & 101 & 11,7 & 13,0 & 13,2 & 13,7 & 14,0 & 15,3 & 16,9 & \begin{tabular}{|l|}
18,3 \\
\end{tabular} & 20,6 \\
\hline 2 & 101,5 & 11,8 & 13,1 & 13,4 & 13,8 & 14,1 & 15,5 & 17,0 & \begin{tabular}{|c|}
18,5 \\
\end{tabular} & 20,8 \\
\hline 2 & 102 & 11,9 & 13,2 & 13,5 & 13,9 & 14,2 & 15,6 & 17,2 & \begin{tabular}{|l|}
18,6 \\
\end{tabular} & 21,0 \\
\hline 2 & 102,5 & 12,0 & 13,3 & 13,6 & 14,0 & 14,4 & 15,8 & \begin{tabular}{|l|}
17,4 \\
\end{tabular} & \begin{tabular}{|l|}
18,8 \\
\end{tabular} & 21,2 \\
\hline 2 & 103 & 12,2 & 13,5 & 13,7 & 14,2 & 14,5 & 15,9 & \begin{tabular}{|l|}
17,5 \\
\end{tabular} & \begin{tabular}{|l|l|}
19,0 \\
\end{tabular} & 21,5 \\
\hline 2 & 103,5 & 12,3 & 13,6 & 13,9 & 14,3 & 14,6 & 16,1 & \begin{tabular}{|l|l}
17,7 \\
\end{tabular} & 19,2 & 21,7 \\
\hline 2 & 104 & 12,4 & 13,7 & 14,0 & 14,5 & 14,8 & 16,2 & 17,9 & 19,4 & 21,9 \\
\hline 2 & 104,5 & 12,5 & 13,9 & 14,1 & 14,6 & 14,9 & 16,4 & 18,1 & $\mid$\begin{tabular}{|l|}
19,6 \\
\end{tabular} & 22,1 \\
\hline 2 & 105 & 12,6 & 14,0 & 14,3 & 14,7 & 15,1 & 16,5 & 18,2 & 19,8 & 22,4 \\
\hline 2 & 105,5 & 12,7 & 14,1 & 14,4 & 14,9 & 15,2 & 16,7 & \begin{tabular}{|l|}
18,4 \\
\end{tabular} & $\mid 20,0$ & 22,6 \\
\hline 2 & 106 & 12,9 & 14,3 & 14,6 & 15,0 & 15,4 & 16,9 & 18,6 & 20,2 & 22,9 \\
\hline 2 & 106,5 & 13,0 & 14,4 & 14,7 & 15,2 & 15,5 & 17,1 & \begin{tabular}{|l|}
18,8 \\
\end{tabular} & 20,4 & 23,1 \\
\hline 2 & 107 & 13,1 & 14,5 & 14,8 & 15,3 & 15,7 & 17,2 & \begin{tabular}{|l|}
19,0 \\
\end{tabular} & 20,6 & 23,3 \\
\hline 2 & 107,5 & 13,2 & 14,7 & 15,0 & 15,5 & 15,8 & 17,4 & 19,2 & 20,9 & 23,6 \\
\hline 2 & 108 & 13,4 & 14,8 & 15,1 & 15,6 & 16,0 & 17,6 & \begin{tabular}{|l|}
19,4 \\
\end{tabular} & 21,1 & 23,9 \\
\hline 2 & 108,5 & 13,5 & 15,0 & 15,3 & 15,8 & 16,2 & 17,8 & \begin{tabular}{|l|}
19,6 \\
\end{tabular} & 21,3 & 24,1 \\
\hline 2 & 109 & 13,6 & 15,1 & 15,5 & 16,0 & 16,3 & 18,0 & \begin{tabular}{|l|}
19,8 \\
\end{tabular} & 21,5 & 24,4 \\
\hline 2 & 109,5 & 13,8 & 15,3 & 15,6 & 16,1 & 16,5 & 18,1 & 20,0 & 21,8 & 24,7 \\
\hline 2 & 110 & 13,9 & 15,4 & 15,8 & 16,3 & 16,7 & 18,3 & 20,2 & 22,0 & 24,9 \\
\hline
\end{tabular}


3 - Peso (kg) para estatura (cm) segundo curvas da OMS (2006) (1: sexo masculino; 2: sexo feminino)

\begin{tabular}{|c|c|c|c|c|c|c|c|c|c|c|}
\hline & & \multicolumn{9}{|c|}{ PERCENTIL } \\
\hline sexo & estatura & $P 0,1$ & P 3 & P5 & P10 & P 15 & P 50 & P 85 & P 97 & P 99,9 \\
\hline 1 & 65 & 5,8 & 6,4 & 6,5 & 6,7 & 6,8 & 7,4 & 8,1 & 8,7 & 9,7 \\
\hline 1 & 65,5 & 5,9 & 6,5 & 6,6 & 6,8 & 6,9 & 7,6 & 8,2 & 8,9 & 9,9 \\
\hline 1 & 66 & 6,0 & 6,6 & 6,7 & 6,9 & 7,1 & 7,7 & 8,4 & 9,0 & 10,0 \\
\hline 1 & 66,5 & 6,1 & 6,7 & 6,8 & 7,0 & 7,2 & 7,8 & 8,5 & 9,1 & 10,2 \\
\hline 1 & 67 & 6,2 & 6,8 & 6,9 & 7,1 & 7,3 & 7,9 & 8,6 & 9,3 & 10,3 \\
\hline 1 & 67,5 & 6,3 & 6,9 & 7,0 & 7,2 & 7,4 & 8,0 & 8,7 & 9,4 & 10,5 \\
\hline 1 & 68 & 6,4 & 7,0 & 7,1 & 7,3 & 7,5 & 8,1 & 8,9 & 9,5 & 10,6 \\
\hline 1 & 68,5 & 5 & 7,1 & 7,2 & 7,4 & 7,6 & 8,2 & 9,0 & 9,7 & 10,8 \\
\hline 1 & 69 & 5 & 7,2 & 7,3 & 7,5 & 7,7 & 8,4 & 9,1 & 9,8 & 10,9 \\
\hline 1 & $\overline{9,5}$ &, 6 & 7,3 & 7,4 & 7,6 & 7,8 & 8,5 & 9,2 & 9,9 & 11,1 \\
\hline 1 & 0 & 6,7 & 7,4 & 7,5 & 7,7 & $\overline{7,9}$ & 8,6 & 9,4 & 10,1 & 11,2 \\
\hline 1 & 70,5 & 6,8 & 7,5 & 7,6 & 7,8 & $\overline{8,0}$ & 8,7 & 9,5 & 10,2 & $\overline{11,4}$ \\
\hline 1 & $\overline{71}$ & 6,9 & 7,6 & 7,7 & 7,9 & 8,1 & 8,8 & 9,6 & 10,3 & 11,5 \\
\hline 1 & 71,5 & 7,0 & 7,7 & 7,8 & 8,0 & 8,2 & 8,9 & 9,7 & 10,5 & 11,6 \\
\hline 1 & 72 & 7,1 & 7,8 & 7,9 & 8,1 & 8,3 & 9,0 & 9,8 & 10,6 & 11,8 \\
\hline 1 & 72,5 & 7,1 & 7,8 & 8,0 & 8,2 & 8,4 & $\overline{9,1}$ & 10,0 & 10,7 & 11,9 \\
\hline 1 & $\overline{73}$ & $\overline{7,2}$ & 7,9 & 8,1 & 8,3 & 8,5 & 9,2 & 10,1 & 10,8 & 12,1 \\
\hline 1 & 73,5 & $\overline{7,3}$ & 8,0 & 8,2 & 8,4 & 8,6 & $\overline{9,3}$ & 10,2 & 11,0 & $\overline{12,2}$ \\
\hline 1 & 74 & 7,4 & 8,1 & 8,3 & 8,5 & 8,7 & 9,4 & 10,3 & 11,1 & 12,4 \\
\hline 1 & 74,5 & 7,5 & 8,2 & 8,4 & 8,6 & 8,8 & 9,5 & 10,4 & 11,2 & 12,5 \\
\hline 1 & 75 & 7,5 & 8,3 & 8,4 & 8,7 & 8,9 & 9,6 & 10,5 & 11,3 & 12,6 \\
\hline 1 & 5,5 & 7,6 & 8,4 & 8,5 & 8,8 & 9,0 & 9,7 & 10,6 & 11,4 & 12,8 \\
\hline 1 & 76 & 7,7 & 8,5 & 8,6 & 8,9 & 9,0 & 9,8 & 10,7 & 11,6 & 12,9 \\
\hline 1 & 6,5 & $\overline{7,8}$ & 8,5 & 8,7 & 8,9 & 9,1 & 9,9 & 10,8 & 11,7 & 13,0 \\
\hline 1 & 77 & 7,8 & 8,6 & 8,8 & $\overline{9,0}$ & 9,2 & \begin{tabular}{|l|}
10,0 \\
\end{tabular} & 10,9 & 11,8 & 13,1 \\
\hline 1 & 77,5 & 7,9 & 8,7 & 8,9 & 9,1 & 9,3 & \begin{tabular}{|l|l}
10,1 \\
\end{tabular} & 11,0 & 11,9 & 13,2 \\
\hline 1 & $\overline{78}$ & 8,0 & 8,8 & 8,9 & 9,2 & 9,4 & \begin{tabular}{|l|l}
10,2 \\
\end{tabular} & 11,1 & 12,0 & 13,4 \\
\hline 1 & 78,5 & 8,1 & 8,8 & 9,0 & 9,3 & 9,5 & 10,3 & 11,2 & 12,1 & 13,5 \\
\hline 1 & 79 & 8,1 & 8,9 & 9,1 & 9,4 & 9,5 & 10,4 & 11,3 & 12,2 & 13,6 \\
\hline 1 & 79,5 & $\overline{8,2}$ & 9,0 & 9,2 & $\overline{9,4}$ & 9,6 & 10,5 & 11,4 & 12,3 & 13,7 \\
\hline 1 & 80 & 8,3 & 9,1 & 9,3 & 9,5 & 9,7 & \begin{tabular}{|l|}
10,6 \\
\end{tabular} & 11,5 & 12,4 & 13,8 \\
\hline 1 & 80,5 & 8,4 & 9,2 & 9,3 & 9,6 & 9,8 & \begin{tabular}{|l|}
10,7 \\
\end{tabular} & 11,6 & 12,5 & 14,0 \\
\hline 1 & 81 & 8,4 & 9,3 & 9,4 & 9,7 & 9,9 & 10,8 & 11,8 & 12,6 & 14,1 \\
\hline 1 & 81,5 & 8,5 & 9,3 & 9,5 & 9,8 & 10,0 & 10,9 & 11,9 & 12,8 & 14,2 \\
\hline 1 & 82 & 8,6 & 9,4 & 9,6 & 9,9 & 10,1 & 11,0 & 12,0 & 12,9 & 14,3 \\
\hline 1 & 82,5 & 8,7 & 9,5 & 9,7 & 10,0 & 10,2 & 11,1 & 12,1 & 13,0 & 14,5 \\
\hline$\overline{1}$ & 83 & 8,8 & 9,6 & 9,8 & 10,1 & 10,3 & 11,2 & 12,2 & 13,1 & 14,6 \\
\hline$\overline{1}$ & 83,5 & $\overline{8,9}$ & 9,7 & 9,9 & 10,2 & 10,4 & 11,3 & 12,3 & 13,3 & 14,8 \\
\hline 1 & 8 & 9,0 & 9,8 & 10,0 & 10,3 & 10,5 & 11,4 & 12,5 & 13,4 & 14,9 \\
\hline 1 & 84,5 & 9,1 & 9,9 & 10,1 & 10,4 & 10,6 & 11,5 & 12,6 & 13,5 & 15,0 \\
\hline 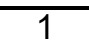 & 85 & 9,2 & 10,1 & 10,2 & 10,5 & 10,7 & 11,7 & 12,7 & 13,7 & 15,2 \\
\hline
\end{tabular}




\begin{tabular}{|c|c|c|c|c|c|c|c|c|c|c|}
\hline 1 & 85,5 & 9,3 & 10,2 & 10,3 & 10,6 & 10,9 & 11,8 & 12,8 & 13,8 & 15,3 \\
\hline 1 & 86 & $\overline{9,4}$ & 10,3 & 10,5 & 10,8 & 11,0 & 11,9 & 13,0 & 13,9 & 15,5 \\
\hline 1 & 86,5 & 9,5 & 10,4 & 10,6 & 10,9 & 11,1 & 12,0 & 13,1 & 14,1 & 15,7 \\
\hline 1 & 87 & 9,6 & 10,5 & 10,7 & 11,0 & 11,2 & 12,2 & 13,2 & 14,2 & 15,8 \\
\hline 1 & 87,5 & 9,7 & 10,6 & 10,8 & 11,1 & 11,3 & 12,3 & 13,4 & 14,4 & 16,0 \\
\hline 1 & 88 & 9,8 & 10,7 & 10,9 & 11,2 & 11,4 & 12,4 & 13,5 & 14,5 & 16,1 \\
\hline 1 & 88,5 & 9,9 & 10,8 & 11,0 & 11,3 & 11,5 & 12,5 & 13,6 & 14,6 & 16,3 \\
\hline 1 & 89 & 10,0 & 10,9 & 11,1 & 11,4 & 11,7 & 12,6 & 13,8 & 14,8 & 16,4 \\
\hline 1 & 89,5 & 10,1 & 11,0 & 11,2 & 11,5 & 11,8 & 12,8 & 13,9 & 14,9 & 16,6 \\
\hline 1 & 90 & 10,2 & 11,1 & 11,3 & 11,6 & 11,9 & 12,9 & 14,0 & 15,1 & 16,7 \\
\hline 1 & 90,5 & 10,3 & 11,2 & 11,4 & 11,8 & 12,0 & 13,0 & 14,1 & 15,2 & 16,9 \\
\hline 1 & 91 & 10,3 & 11,3 & 11,5 & 11,9 & 12,1 & 13,1 & 14,3 & 15,3 & 17,0 \\
\hline 1 & 91,5 & 10,4 & 11,4 & 11,6 & 12,0 & 12,2 & 13,2 & 14,4 & 15,5 & 17,2 \\
\hline 1 & $\overline{92}$ & 10,5 & 11,5 & 11,7 & 12,1 & 12,3 & 13,4 & 14,5 & 15,6 & 17,3 \\
\hline 1 & 92,5 & 10,6 & 11,6 & 11,8 & 12,2 & 12,4 & 13,5 & 14,7 & 15,7 & 17,5 \\
\hline 1 & $\overline{93}$ & 10,7 & 11,7 & 11,9 & 12,3 & 12,5 & 13,6 & 14,8 & 15,9 & 17,6 \\
\hline 1 & 93,5 & 10,8 & 11,8 & 12,0 & 12,4 & 12,6 & 13,7 & 14,9 & 16,0 & 17,8 \\
\hline 1 & 94 & 10,9 & 11,9 & 12,1 & 12,5 & 12,7 & 13,8 & 15,0 & 16,1 & 17,9 \\
\hline 1 & 94,5 & 11,0 & 12,0 & 12,2 & 12,6 & 12,8 & 13,9 & 15,2 & 16,3 & 18,1 \\
\hline 1 & 95 & 11,1 & 12,1 & 12,4 & 12,7 & 12,9 & 14,1 & 15,3 & 16,4 & 18,2 \\
\hline 1 & 95,5 & 11,2 & 12,2 & 12,5 & 12,8 & 13,1 & 14,2 & 15,4 & 16,6 & 18,4 \\
\hline 1 & 96 & 11,3 & 12,3 & 12,6 & 12,9 & 13,2 & 14,3 & 15,6 & 16,7 & 18,6 \\
\hline 1 & 96,5 & 11,4 & 12,4 & 12,7 & 13,0 & 13,3 & 14,4 & 15,7 & 16,9 & 18,7 \\
\hline 1 & 97 & 11,4 & 12,5 & 12,8 & 13,1 & 13,4 & 14,6 & 15,9 & 17,0 & 18,9 \\
\hline 1 & 97,5 & 11,5 & 12,7 & 12,9 & 13,3 & 13,5 & 14,7 & 16,0 & 17,2 & 19,1 \\
\hline 1 & $\overline{98}$ & 11,6 & 12,8 & 13,0 & 13,4 & 13,6 & 14,8 & 16,1 & 17,3 & 19,3 \\
\hline 1 & 98,5 & 11,7 & 12,9 & 13,1 & 13,5 & 13,8 & 14,9 & 16,3 & 17,5 & 19,5 \\
\hline 1 & $\overline{99}$ & 11,8 & 13,0 & 13,2 & 13,6 & 13,9 & 15,1 & 16,4 & 17,7 & 19,7 \\
\hline 7 & 99,5 & 11,9 & 13,1 & 13,3 & 13,7 & 14,0 & 15,2 & 16,6 & 17,8 & 19,8 \\
\hline 1 & 100 & 12,0 & 13,2 & 13,5 & 13,8 & 14,1 & 15,4 & 16,7 & 18,0 & 20,0 \\
\hline 1 & 100,5 & 12,1 & 13,3 & 13,6 & 14,0 & 14,2 & 15,5 & 16,9 & 18,2 & 20,2 \\
\hline 1 & 101 & 12,2 & 13,4 & 13,7 & 14,1 & 14,4 & 15,6 & 17,1 & 18,4 & 20,4 \\
\hline 1 & 101,5 & 12,3 & 13,6 & 13,8 & 14,2 & 14,5 & 15,8 & 17,2 & 18,5 & 20,7 \\
\hline 1 & 102 & 12,5 & 13,7 & 13,9 & 14,3 & 14,6 & 15,9 & 17,4 & 18,7 & 20,9 \\
\hline 1 & 102,5 & 12,6 & 13,8 & 14,1 & 14,5 & 14,8 & 16,1 & 17,6 & 18,9 & 21,1 \\
\hline 1 & 103 & 12,7 & 13,9 & 14,2 & 14,6 & 14,9 & 16,2 & 17,7 & 19,1 & 21,3 \\
\hline 1 & 103,5 & 12,8 & 14,0 & 14,3 & 14,7 & 15,0 & 16,4 & 17,9 & 19,3 & 21,5 \\
\hline 1 & 104 & 12,9 & 14,2 & 14,4 & 14,9 & 15,2 & 16,5 & 18,1 & 19,5 & 21,7 \\
\hline 1 & 104,5 & 13,0 & 14,3 & 14,6 & 15,0 & 15,3 & 16,7 & 18,2 & 19,7 & 22,0 \\
\hline 1 & 105 & 13,1 & 14,4 & 14,7 & 15,1 & 15,4 & 16,8 & 18,4 & 19,9 & 22,2 \\
\hline 1 & 105,5 & 13,2 & 14,5 & 14,8 & 15,3 & 15,6 & 17,0 & 18,6 & 20,1 & 22,4 \\
\hline 1 & 106 & 13,3 & 14,7 & 15,0 & 15,4 & 15,7 & 17,2 & 18,8 & 20,3 & 22,6 \\
\hline 1 & 106,5 & 13,4 & 14,8 & 15,1 & 15,6 & 15,9 & 17,3 & 19,0 & 20,5 & 22,9 \\
\hline 1 & 107 & 13,6 & 14,9 & 15,2 & 15,7 & 16,0 & 17,5 & 19,1 & 20,7 & 23,1 \\
\hline 1 & 107,5 & 13,7 & 15,1 & 15,4 & 15,8 & 16,2 & 17,7 & 19,3 & 20,9 & 23,4 \\
\hline
\end{tabular}




\begin{tabular}{|c|c|c|c|c|c|c|c|c|c|c|}
\hline 1 & 108 & 13,8 & 15,2 & 15,5 & 16,0 & 16,3 & 17,8 & 19,5 & 21,1 & 23,6 \\
\hline 1 & 108,5 & 13,9 & 15,3 & 15,6 & 16,1 & 16,5 & 18,0 & \begin{tabular}{|l|}
19,7 \\
\end{tabular} & 21,3 & 23,9 \\
\hline 1 & 109 & 14,0 & 15,5 & 15,8 & 16,3 & 16,6 & 18,2 & \begin{tabular}{|l|}
19,9 \\
\end{tabular} & 21,5 & 24,1 \\
\hline 1 & 109,5 & 14,2 & 15,6 & 15,9 & 16,4 & 16,8 & 18,3 & 20,1 & 21,7 & 24,4 \\
\hline 1 & 110 & 14,3 & 15,8 & 16,1 & 16,6 & 16,9 & 18,5 & 20,3 & 22,0 & 24,6 \\
\hline 1 & 110,5 & 14,4 & 15,9 & 16,2 & 16,7 & 17,1 & 18,7 & \begin{tabular}{|l|}
20,5 \\
\end{tabular} & 22,2 & 24,9 \\
\hline 1 & 111 & 14,5 & 16,1 & 16,4 & 16,9 & 17,2 & 18,9 & \begin{tabular}{|l|}
20,7 \\
\end{tabular} & 22,4 & 25,2 \\
\hline 1 & 111,5 & 14,7 & 16,2 & 16,5 & 17,0 & 17,4 & 19,1 & 20,9 & 22,6 & 25,4 \\
\hline 1 & 112 & 14,8 & 16,3 & 16,7 & 17,2 & 17,6 & 19,2 & 21,1 & 22,9 & 25,7 \\
\hline 1 & 112,5 & 14,9 & 16,5 & 16,8 & 17,4 & 17,7 & 19,4 & \begin{tabular}{|l|}
21,4 \\
\end{tabular} & 23,1 & 26,0 \\
\hline 1 & 113 & 15,1 & 16,6 & 17,0 & 17,5 & 17,9 & 19,6 & 21,6 & 23,4 & 26,3 \\
\hline 1 & 113,5 & 15,2 & 16,8 & 17,1 & 17,7 & 18,1 & 19,8 & 21,8 & 23,6 & 26,6 \\
\hline 1 & 114 & 15,3 & 7,0 & 17,3 & 17,8 & 18,2 & 20,0 & 22,0 & 23,8 & 26,8 \\
\hline 1 & 114,5 & 15,4 & 17,1 & 17,5 & 18,0 & 18,4 & 20,2 & 22,2 & 24,1 & 27,1 \\
\hline 1 & 115 & 15,6 & 17,3 & 17,6 & 18,2 & 18,6 & 20,4 & 22,4 & 24,3 & 27,4 \\
\hline 1 & 115,5 & 15,7 & 17,4 & 17,8 & 18,3 & 18,7 & 20,6 & 22,7 & 24,6 & 27,7 \\
\hline 1 & 116 & 15,9 & 17,6 & 17,9 & 18,5 & 18,9 & 20,8 & 22,9 & 24,8 & 28,0 \\
\hline 1 & 116,5 & 16,0 & 17,7 & 18,1 & 18,7 & 19,1 & 21,0 & 23,1 & 25,1 & 28,3 \\
\hline 1 & 117 & 16,1 & 17,9 & 18,3 & 18,8 & 19,3 & 21,2 & 23,3 & 25,3 & 28,6 \\
\hline 1 & 117,5 & 16,3 & 18,0 & 18,4 & 19,0 & 19,4 & 21,4 & 23,6 & 25,6 & 28,9 \\
\hline 1 & 118 & 16,4 & 18,2 & 18,6 & 19,2 & 19,6 & 21,6 & 23,8 & 25,8 & 29,2 \\
\hline 1 & 118,5 & 16,5 & 18,4 & 18,7 & 19,4 & 19,8 & 21,8 & 24,0 & 26,1 & 29,5 \\
\hline 1 & 119 & 16,7 & 18,5 & 18,9 & 19,5 & 20,0 & 22,0 & 24,2 & 26,3 & 29,8 \\
\hline 1 & 119,5 & 16,8 & 18,7 & 19,1 & 19,7 & 20,1 & 22,2 & 24,5 & 26,6 & 30,1 \\
\hline 1 & 120 & 16,9 & 18,8 & 19,2 & 19,9 & 20,3 & 22,4 & \begin{tabular}{|l|}
24,7 \\
\end{tabular} & 26,8 & 30,4 \\
\hline 2 & 65 & 5,5 & 6,1 & 6,3 & 6,5 & 6,6 & 7,2 & 8,0 & 8,6 & 9,8 \\
\hline 2 & 5,5 & 5,6 & 6,2 & 6,4 & 6,6 & 6,7 & 7,4 & 8,1 & 8,8 & 9,9 \\
\hline 2 & 66 & 5,7 & 6,3 & 6,5 & 6,7 & 6,8 & 7,5 & 8,2 & 8,9 & 10,1 \\
\hline 2 & 66,5 & 5,8 & 6,4 & 6,5 & 6,8 & 6,9 & 7,6 & 8,3 & 9,0 & 10,2 \\
\hline 2 & 67 & 5,9 & 6,5 & 6,6 & 6,9 & 7,0 & 7,7 & 8,5 & 9,2 & 10,3 \\
\hline 2 & 67,5 & 6,0 & 6,6 & 6,7 & \begin{tabular}{|l|}
6,9 \\
\end{tabular} & 7,1 & 7,8 & 8,6 & 9,3 & 10,5 \\
\hline 2 & 68 & 6,0 & 6,7 & 6,8 & 7,0 & 7,2 & 7,9 & 8,7 & 9,4 & 10,6 \\
\hline 2 & 68,5 & 6,1 & 6,8 & 6,9 & 7,1 & 7,3 & 8,0 & 8,8 & 9,5 & 10,8 \\
\hline 2 & 69 & 6,2 & 6,9 & 7,0 & 7,2 & 7,4 & 8,1 & 8,9 & 9,7 & 10,9 \\
\hline 2 & 69,5 & 6,3 & 7,0 & 7,1 & 7,3 & 7,5 & 8,2 & 9,0 & 9,8 & 11,0 \\
\hline 2 & 70 & 6,4 & 7,0 & 7,2 & 7,4 & 7,6 & 8,3 & 9,1 & 9,9 & 11,2 \\
\hline 2 & 70,5 & 6,4 & 7,1 & 7,3 & 7,5 & 7,7 & 8,4 & 9,3 & 10,0 & 11,3 \\
\hline 2 & 71 & 6,5 & 7,2 & 7,4 & 7,6 & 7,8 & 8,5 & 9,4 & 10,1 & 11,4 \\
\hline 2 & 71,5 & 6,6 & 7,3 & 7,4 & 7,7 & 7,9 & 8,6 & 9,5 & 10,3 & 11,6 \\
\hline 2 & 72 & 6,7 & 7,4 & 7,5 & 7,8 & 7,9 & 8,7 & 9,6 & 10,4 & 11,7 \\
\hline 2 & 72,5 & 6,8 & 7,5 & 7,6 & 7,9 & 8,0 & 8,8 & 9,7 & 10,5 & 11,8 \\
\hline$<$ & 73 & 6,8 & 7,6 & 7,7 & 8,0 & 8,1 & \begin{tabular}{|l|}
8,9 \\
\end{tabular} & 9,8 & 10,6 & 12,0 \\
\hline- & 73,5 & 6,9 & 7,6 & 7,8 & 8,0 & 8,2 & 9,0 & 9,9 & 10,7 & 12,1 \\
\hline 2 & 74 & 7,0 & 7,7 & 7,9 & 8,1 & 8,3 & 9,1 & 10,0 & 10,8 & 12,2 \\
\hline 2 & 74,5 & 7,1 & 7,8 & 8,0 & 8,2 & 8,4 & 9,2 & 10,1 & 10,9 & 12,3 \\
\hline
\end{tabular}




\begin{tabular}{|c|c|c|c|c|c|c|c|c|c|c|}
\hline 2 & 75 & 7,1 & 7,9 & 8,0 & 8,3 & 8,5 & 9,3 & 10,2 & 11,1 & 12,4 \\
\hline 2 & 75,5 & 7,2 & 8,0 & 8,1 & 8,4 & 8,6 & 9,4 & \begin{tabular}{|l|}
10,3 \\
\end{tabular} & 11,2 & 12,6 \\
\hline 2 & 76 & 7,3 & 8,0 & 8,2 & 8,5 & 8,6 & 9,5 & \begin{tabular}{|c|}
10,4 \\
\end{tabular} & 11,3 & 12,7 \\
\hline 2 & 76,5 & 7,3 & 8,1 & 8,3 & 8,5 & 8,7 & 9,6 & 10,5 & 11,4 & 12,8 \\
\hline 2 & 77 & 7,4 & 8,2 & 8,4 & 8,6 & 8,8 & 9,6 & 10,6 & 11,5 & 12,9 \\
\hline 2 & 77,5 & 7,5 & 8,3 & 8,4 & 8,7 & 8,9 & 9,7 & \begin{tabular}{|l|}
10,7 \\
\end{tabular} & 11,6 & 13,1 \\
\hline 2 & 78 & 7,6 & 8,4 & 8,5 & 8,8 & 9,0 & 9,8 & 10,8 & 11,7 & 13,2 \\
\hline 2 & 78,5 & 7,6 & 8,4 & 8,6 & 8,9 & 9,1 & 9,9 & 10,9 & 11,8 & 13,3 \\
\hline 2 & 79 & 7,7 & 8,5 & 8,7 & $\overline{9,0}$ & 9,2 & 10,0 & 11,0 & 11,9 & 13,4 \\
\hline 2 & 79,5 & 7,8 & 8,6 & 8,8 & $\overline{9,1}$ & 9,2 & 10,1 & \begin{tabular}{|l|}
11,1 \\
\end{tabular} & 12,1 & 13,6 \\
\hline 2 & 80 & 7,9 & 8,7 & 8,9 & 9,1 & 9,3 & 10,2 & 11,2 & 12,2 & 13,7 \\
\hline 2 & 80,5 & 8,0 & 8,8 & 9,0 & 9,2 & 9,4 & 10,3 & 11,4 & 12,3 & 13,8 \\
\hline 2 & 81 & 8,0 & 8,9 & 9,1 & 9,3 & 9,5 & 10,4 & 11,5 & 12,4 & 14,0 \\
\hline 2 & 81,5 & 8,1 & 9,0 & 9,2 & 9,4 & 9,6 & 10,6 & 11,6 & 12,6 & 14,1 \\
\hline 2 & 82 & 8,2 & 9,1 & 9,3 & 9,5 & 9,7 & 10,7 & 11,7 & 12,7 & 14,3 \\
\hline 2 & 82,5 & 8,3 & 9,2 & 9,4 & 9,6 & 9,9 & 10,8 & 11,9 & 12,8 & 14,4 \\
\hline 2 & 83 & $\overline{8,4}$ & 9,3 & 9,5 & 9,8 & 10,0 & 10,9 & 12,0 & 13,0 & 14,6 \\
\hline 2 & 83,5 & 8,5 & 9,4 & 9,6 & 9,9 & 10,1 & 11,0 & 12,1 & 13,1 & 14,7 \\
\hline 2 & 84 & 8,6 & 9,5 & 9,7 & 10,0 & 10,2 & 11,1 & 12,2 & 13,3 & 14,9 \\
\hline 2 & 84,5 & 8,7 & 9,6 & 9,8 & 10,1 & 10,3 & 11,3 & 12,4 & 13,4 & 15,1 \\
\hline 2 & 85 & 8,8 & 9,7 & 9,9 & 10,2 & 10,4 & 11,4 & 12,5 & 13,5 & 15,2 \\
\hline 2 & 85,5 & 8,9 & 9,8 & 10,0 & 10,3 & 10,5 & 11,5 & 12,7 & 13,7 & 15,4 \\
\hline 2 & 86 & 9,0 & 9,9 & 10,1 & 10,4 & 10,6 & 11,6 & 12,8 & 13,8 & 15,6 \\
\hline 2 & 86,5 & 9,1 & 10,0 & 10,2 & 10,5 & 10,8 & 11,8 & 12,9 & 14,0 & 15,7 \\
\hline 2 & 87 & 9,2 & 10,1 & 10,3 & 10,6 & 10,9 & 11,9 & 13,1 & 14,1 & 15,9 \\
\hline 2 & 87,5 & 9,3 & 10,2 & 10,4 & 10,8 & 11,0 & 12,0 & \begin{tabular}{|l|}
13,2 \\
\end{tabular} & 14,3 & 16,1 \\
\hline 2 & 88 & 9,4 & 10,3 & 10,5 & 10,9 & 11,1 & 12,1 & 13,3 & 14,4 & 16,2 \\
\hline 2 & 88,5 & 9,4 & 10,4 & 10,6 & 11,0 & 11,2 & 12,3 & \begin{tabular}{|l|}
13,5 \\
\end{tabular} & 14,6 & 16,4 \\
\hline 2 & 89 & 9,5 & 10,5 & 10,8 & 11,1 & 11,3 & 12,4 & \begin{tabular}{|l|}
13,6 \\
\end{tabular} & 14,7 & 16,6 \\
\hline 2 & 89,5 & 9,6 & 10,6 & 10,9 & 11,2 & 11,4 & 12,5 & 13,8 & 14,9 & 16,7 \\
\hline 2 & 90 & 9,7 & 10,8 & 11,0 & 11,3 & 11,5 & 12,6 & 13,9 & 15,0 & 16,9 \\
\hline 2 & 90,5 & 9,8 & 10,9 & 11,1 & 11,4 & 11,7 & 12,8 & 14,0 & 15,2 & 17,1 \\
\hline 2 & 91 & 9,9 & 11,0 & 11,2 & 11,5 & 11,8 & 12,9 & 14,2 & 15,3 & 17,3 \\
\hline 2 & 91,5 & 10,0 & 11,1 & 11,3 & 11,6 & 11,9 & 13,0 & 14,3 & 15,5 & 17,4 \\
\hline 2 & 92 & 10,1 & 11,2 & 11,4 & 11,7 & 12,0 & 13,1 & 14,4 & 15,6 & 17,6 \\
\hline 2 & 92,5 & 10,2 & 11,3 & 11,5 & 11,9 & 12,1 & 13,3 & 14,6 & 15,8 & 17,8 \\
\hline 2 & 93 & 10,3 & 11,4 & 11,6 & 12,0 & 12,2 & 13,4 & 14,7 & 15,9 & 17,9 \\
\hline 2 & 93,5 & 10,4 & 11,5 & 11,7 & 12,1 & 12,3 & 13,5 & 14,9 & 16,1 & 18,1 \\
\hline 2 & $\overline{94}$ & 10,5 & 11,6 & 11,8 & 12,2 & 12,4 & 13,6 & 15,0 & 16,2 & 18,3 \\
\hline 2 & 94,5 & 10,6 & 11,7 & 11,9 & 12,3 & 12,6 & 13,8 & 15,1 & 16,4 & 18,5 \\
\hline 2 & 95 & 10,7 & 11,8 & 12,0 & 12,4 & 12,7 & 13,9 & \begin{tabular}{|l|}
15,3 \\
\end{tabular} & 16,5 & 18,6 \\
\hline 2 & 95,5 & 10,8 & 11,9 & 12,1 & 12,5 & 12,8 & 14,0 & \begin{tabular}{|l|}
15,4 \\
\end{tabular} & 16,7 & 18,8 \\
\hline 2 & 96 & 10,9 & 12,0 & 12,3 & 12,6 & 12,9 & 14,1 & 15,6 & 16,9 & 19,0 \\
\hline 2 & 96,5 & 11,0 & 12,1 & 12,4 & 12,8 & 13,0 & 14,3 & \begin{tabular}{|l|}
15,7 \\
\end{tabular} & 17,0 & 19,2 \\
\hline 2 & 97 & 11,1 & 12,2 & 12,5 & 12,9 & 13,1 & 14,4 & \begin{tabular}{|l|}
15,8 \\
\end{tabular} & 17,2 & 19,3 \\
\hline
\end{tabular}




\begin{tabular}{|c|c|c|c|c|c|c|c|c|c|c|}
\hline 2 & 97,5 & 11,2 & 12,3 & 2,6 & $\overline{3,0}$ & 13,3 & 14,5 & 16,0 & 17,3 & 19,5 \\
\hline 2 & 98 & 11,3 & 12,4 & 12,7 & 13,1 & 13,4 & 14,7 & \begin{tabular}{|l|}
16,1 \\
\end{tabular} & 17,5 & 19,7 \\
\hline 2 & 98,5 & 11,4 & 12,6 & 12,8 & 13,2 & 13,5 & 14,8 & \begin{tabular}{|l|}
16,3 \\
\end{tabular} & 17,7 & 19,9 \\
\hline 2 & 99 & 11,5 & 12,7 & 12,9 & 13,3 & 13,6 & 14,9 & \begin{tabular}{|l|}
16,4 \\
\end{tabular} & 17,8 & 20,1 \\
\hline 2 & 99,5 & 11,6 & 12,8 & 13,0 & 13,5 & 13,8 & 15,1 & 16,6 & 18,0 & 20,3 \\
\hline 2 & 100 & 11,7 & 12,9 & 13,2 & 13,6 & 13,9 & 15,2 & 16,8 & 18,2 & 20,5 \\
\hline 2 & 100,5 & 11,8 & 13,0 & 13,3 & 13,7 & 14,0 & 15,4 & 16,9 & 18,3 & 20,7 \\
\hline 2 & 101 & 11,9 & 13,1 & 13,4 & 13,8 & 14,1 & 15,5 & \begin{tabular}{|l|}
17,1 \\
\end{tabular} & 18,5 & 20,9 \\
\hline 2 & 101,5 & 12,0 & 13,3 & 13,5 & 14,0 & 14,3 & 15,7 & \begin{tabular}{|l|}
17,2 \\
\end{tabular} & 18,7 & 21,1 \\
\hline 2 & 102 & 12,1 & 13,4 & 13,7 & 14,1 & 14,4 & 15,8 & 17,4 & 18,9 & 21,3 \\
\hline 2 & 102,5 & 12,2 & 13,5 & 13,8 & 14,2 & 14,5 & 16,0 & 17,6 & 19,1 & 21,6 \\
\hline 2 & 103 & 12,3 & 13,6 & 13,9 & 14,4 & 14,7 & 16,1 & \begin{tabular}{|l|l}
17,8 \\
\end{tabular} & 19,3 & 21,8 \\
\hline 2 & 103,5 & 12,4 & 13,8 & 14,1 & 14,5 & 14,8 & 16,3 & 17,9 & 19,5 & 22,0 \\
\hline 2 & 104 & 12,6 & 13,9 & 14,2 & 14,7 & 15,0 & 16,4 & \begin{tabular}{|l|}
18,1 \\
\end{tabular} & \begin{tabular}{|c|}
19,7 \\
\end{tabular} & 22,2 \\
\hline 2 & 104,5 & 12,7 & 14,0 & 14,3 & 14,8 & 15,1 & 16,6 & \begin{tabular}{|l|}
18,3 \\
\end{tabular} & 19,9 & 22,5 \\
\hline 2 & 105 & 12,8 & 14,2 & 14,5 & 14,9 & 15,3 & 16,8 & \begin{tabular}{|l|}
18,5 \\
\end{tabular} & 20,1 & 22,7 \\
\hline 2 & 105,5 & 12,9 & 14,3 & 14,6 & 15,1 & 15,4 & 16,9 & \begin{tabular}{|l|}
18,7 \\
\end{tabular} & 20,3 & 23,0 \\
\hline 2 & 106 & 13,0 & 14,5 & 14,8 & 15,2 & 15,6 & 17,1 & 18,9 & 20,5 & 23,2 \\
\hline 2 & 106,5 & 13,2 & 14,6 & 14,9 & 15,4 & 15,7 & 17,3 & 19,1 & 20,7 & 23,5 \\
\hline 2 & 107 & 13,3 & 14,7 & 15,1 & 15,6 & 15,9 & 17,5 & 19,3 & 21,0 & 23,7 \\
\hline 2 & 107,5 & 13,4 & 14,9 & 15,2 & 15,7 & 16,1 & 17,7 & 19,5 & 21,2 & 24,0 \\
\hline 2 & 108 & 13,6 & 15,0 & 15,4 & 15,9 & 16,2 & 17,8 & \begin{tabular}{|l|}
19,7 \\
\end{tabular} & 21,4 & 24,2 \\
\hline 2 & 108,5 & 13,7 & 15,2 & 15,5 & 16,0 & 16,4 & 18,0 & \begin{tabular}{|l|}
19,9 \\
\end{tabular} & 21,6 & 24,5 \\
\hline 2 & 109 & 13,8 & 15,4 & 15,7 & 16,2 & 16,6 & 18,2 & 20,1 & 21,9 & 24,8 \\
\hline 2 & 109,5 & 14,0 & 15,5 & 15,8 & \begin{tabular}{|c|}
16,4 \\
\end{tabular} & 16,7 & 18,4 & 20,3 & 22,1 & 25,1 \\
\hline 2 & 110 & 14,1 & 15,7 & 16,0 & 16,5 & 16,9 & 18,6 & 20,6 & 22,4 & 25,3 \\
\hline 2 & 110,5 & 14,3 & 15,8 & 16,2 & 16,7 & 17,1 & 18,8 & 20,8 & 22,6 & 25,6 \\
\hline 2 & 111 & 14,4 & 16,0 & 16,3 & 16,9 & 17,3 & 19,0 & 21,0 & 22,8 & 25,9 \\
\hline 2 & 111,5 & 14,5 & 16,2 & 16,5 & 17,1 & 17,4 & 19,2 & 21,2 & 23,1 & 26,2 \\
\hline 2 & 112 & 14,7 & 16,3 & 16,7 & 17,2 & 17,6 & 19,4 & 21,5 & 23,4 & 26,5 \\
\hline 2 & 112,5 & 14,8 & 16,5 & 16,8 & 17,4 & 17,8 & 19,6 & 21,7 & 23,6 & 26,8 \\
\hline 2 & 113 & 15,0 & 16,7 & 17,0 & 17,6 & 18,0 & 19,8 & 21,9 & 23,9 & 27,1 \\
\hline 2 & 113,5 & 15,1 & 16,8 & 17,2 & 17,8 & 18,2 & 20,0 & 22,2 & 24,1 & 27,4 \\
\hline 2 & 114 & 15,3 & 17,0 & 17,4 & 17,9 & 18,4 & 20,2 & \begin{tabular}{|l}
22,4 \\
\end{tabular} & 24,4 & 27,7 \\
\hline 2 & 114,5 & 15,4 & 17,2 & 17,5 & 18,1 & 18,5 & 20,5 & \begin{tabular}{|l|}
22,6 \\
\end{tabular} & 24,7 & 28,0 \\
\hline 2 & 115 & 15,6 & 17,3 & \begin{tabular}{|l|l|}
17,7 \\
\end{tabular} & 18,3 & 18,7 & 20,7 & 22,9 & 24,9 & 28,3 \\
\hline 2 & 115,5 & 15,7 & 17,5 & 17,9 & 18,5 & 18,9 & 20,9 & 23,1 & 25,2 & 28,7 \\
\hline 2 & 116 & 15,9 & 17,7 & 18,1 & 18,7 & 19,1 & 21,1 & 23,4 & 25,5 & 29,0 \\
\hline 2 & 116,5 & 16,0 & 17,9 & 18,3 & 18,9 & 19,3 & 21,3 & 23,6 & 25,7 & 29,3 \\
\hline 2 & 117 & 16,2 & 18,0 & 18,4 & 19,1 & 19,5 & 21,5 & 23,8 & 26,0 & 29,6 \\
\hline 2 & 117,5 & 16,4 & 18,2 & 18,6 & 19,2 & 19,7 & 21,7 & 24,1 & 26,3 & 29,9 \\
\hline 2 & 118 & 16,5 & 18,4 & 18,8 & 19,4 & 19,9 & 22,0 & 24,3 & 26,5 & 30,2 \\
\hline 2 & 118,5 & 16,7 & $\overline{18,6}$ & 19,0 & 19,6 & 20,1 & 22,2 & 24,6 & 26,8 & 30,6 \\
\hline 2 & 119 & 16,8 & 18,7 & 19,1 & 19,8 & 20,3 & 22,4 & 24,8 & 27,1 & 30,9 \\
\hline 2 & 119,5 & 17,0 & 18,9 & 19,3 & 20,0 & 20,5 & 22,6 & \begin{tabular}{|l|}
25,1 \\
\end{tabular} & \begin{tabular}{|l|}
27,4 \\
\end{tabular} & 31,2 \\
\hline 2 & 120 & 17,1 & 19,1 & 19,5 & 20,2 & 20,6 & 22,8 & 25,3 & 27,6 & 31,5 \\
\hline
\end{tabular}


4 - Comprimento (cm) para idade (meses) segundo curvas da OMS (2006) (1: sexo masculino; 2: sexo feminino)

\begin{tabular}{|c|c|c|c|c|c|c|c|c|c|c|}
\hline & & \multicolumn{9}{|c|}{ PERCENTIL } \\
\hline sexo & idade (meses) & $\overline{P 0,1}$ & P 3 & P5 & P10 & P 15 & P 50 & P 85 & P 97 & P 99,9 \\
\hline 1 & 0 & 44,0 & 46,3 & 46,8 & 47,5 & 47,9 & 49,9 & 51,8 & 53,4 & 55,7 \\
\hline 1 & 1 & 48,7 & 51,1 & 51,5 & 52,2 & 52,7 & 54,7 & 56,7 & 58,4 & 60,7 \\
\hline 1 & 2 & 52,2 & 54,7 & 55,1 & 55,9 & 56,4 & 58,4 & 60,5 & 62,2 & 64,6 \\
\hline 1 & 3 & 55,1 & 57,6 & 58,1 & 58,8 & 59,3 & 61,4 & 63,5 & 65,3 & 67,7 \\
\hline 1 & 4 & 57,5 & 60,0 & 60,5 & 61,2 & 61,7 & 63,9 & 66,0 & 67,8 & 70,3 \\
\hline 1 & 5 & 59,4 & 61,9 & 62,4 & 63,2 & 63,7 & 65,9 & 68,1 & 69,9 & 72,4 \\
\hline 1 & 6 & 61.0 & 63,6 & 64.1 & 64.9 & 65,4 & 67.6 & 69,8 & 71.6 & 74,2 \\
\hline 1 & 7 & 62,5 & 65,1 & 65,6 & 66,4 & 66,9 & 69,2 & 71,4 & 73,2 & 75,9 \\
\hline 1 & 8 & 63,8 & 66,5 & 67,0 & 67,8 & 68,3 & 70,6 & 72,9 & 74,7 & 77,4 \\
\hline 1 & 9 & 65,0 & 67,7 & 68,3 & 69,1 & 69,6 & 72,0 & 74,3 & 76,2 & 78,9 \\
\hline 1 & $\overline{10}$ & 66,2 & 69,0 & 69,5 & 70,4 & 70,9 & 73,3 & 75,6 & 77,6 & 80,3 \\
\hline 1 & 11 & 67,3 & 70,2 & 70,7 & 71,6 & 72,1 & 74,5 & 77,0 & 78,9 & 81,7 \\
\hline 1 & 12 & 68,4 & 71,3 & 71,8 & 72,7 & 73,3 & 75,7 & 78,2 & 80,2 & 83,1 \\
\hline 1 & 13 & 69,4 & 72,4 & 72,9 & 73,8 & 74,4 & 76,9 & 79,4 & 81,5 & 84,4 \\
\hline 1 & 14 & 70,4 & 73,4 & 74,0 & 74,9 & 75,5 & 78,0 & 80,6 & 82,7 & 85,7 \\
\hline 1 & 15 & 71,3 & 74,4 & 75,0 & 75,9 & 76,5 & 79,1 & 81,8 & 83,9 & 87,0 \\
\hline 1 & 16 & 72,2 & 75,4 & 76,0 & 76,9 & 77,5 & 80,2 & 82,9 & 85,1 & 88,2 \\
\hline 1 & 17 & 73,1 & 76,3 & 76,9 & 77,9 & 78,5 & 81,2 & 84,0 & 86,2 & 89,4 \\
\hline 1 & 18 & 73,9 & 77,2 & 77,8 & 78,8 & 79,5 & 82,3 & 85,1 & 87,3 & 90,6 \\
\hline 1 & 19 & 74,7 & 78,1 & 78,7 & 79,7 & 80,4 & 83,2 & 86,1 & 88,4 & 91,8 \\
\hline 1 & 20 & 75,5 & 78,9 & 79,6 & 80,6 & 81,3 & 84,2 & 87,1 & 89,5 & 92,9 \\
\hline 1 & 21 & 76,3 & 79,7 & 80,4 & 81,5 & 82,2 & 85,1 & 88,1 & 90,5 & 94,0 \\
\hline 1 & 22 & 77,0 & 80,5 & 81,2 & 82,3 & 83,0 & 86,0 & 89,1 & 91,6 & 95,1 \\
\hline 1 & 23 & 77,7 & 81,3 & 82,0 & 83,1 & 83,8 & 86,9 & 90,0 & 92,6 & 96,2 \\
\hline 1 & 24 & 78,4 & 82,1 & 82,8 & 83,9 & 84,6 & 87,8 & 91,0 & 93,6 & 97,3 \\
\hline 2 & 0 & 43,4 & 45,6 & 46,1 & 46,8 & 47,2 & 49,1 & 51,1 & 52,7 & 54,9 \\
\hline 2 & 1 & 47,6 & 50,0 & 50,5 & 51,2 & 51,7 & 53,7 & 55,7 & 57,4 & 59,7 \\
\hline 2 & 2 & 50,8 & 53,2 & 53,7 & 54,5 & 55,0 & 57,1 & 59,2 & 60,9 & 63,4 \\
\hline 2 & 3 & 53,3 & 55,8 & 56,3 & 57,1 & 57,6 & 59,8 & 62,0 & 63,8 & 66,3 \\
\hline 2 & 4 & 55,4 & 58,0 & 58,5 & 59,3 & 59,8 & 62,1 & 64,3 & 66,2 & 68,8 \\
\hline 2 & 5 & 57,2 & 59,9 & 60,4 & 61,2 & 61,7 & 64,0 & 66,3 & 68,2 & 70,9 \\
\hline 2 & 6 & 58,7 & 61,5 & 62,0 & 62,8 & 63,4 & 65,7 & 68,1 & 70,0 & 72,7 \\
\hline 2 & 7 & 60,1 & 62,9 & 63,5 & 64,3 & 64,9 & 67,3 & 69.7 & 71.6 & 74,4 \\
\hline 2 & 8 & 61,4 & 64,3 & 64,9 & 65,7 & 66,3 & 68,7 & 71,2 & 73,2 & 76,1 \\
\hline 2 & 9 & 62,7 & 65,6 & 66,2 & 67,0 & 67,6 & 70,1 & 72,6 & 74,7 & 77,6 \\
\hline 2 & 10 & 63,9 & 66,8 & 67,4 & 68,3 & 68,9 & 71,5 & 74,0 & 76,1 & 79,1 \\
\hline 2 & 11 & 65,0 & 68,0 & 68,6 & 69,5 & 70,2 & 72,8 & 75,4 & 77,5 & 80,6 \\
\hline 2 & 12 & 66,1 & 69,2 & 69,8 & 70,7 & 71,3 & 74,0 & 76,7 & 78,9 & 82,0 \\
\hline 2 & 13 & 67,1 & 70,3 & 70,9 & 71,8 & 72,5 & 75,2 & 77,9 & 80,2 & 83,3 \\
\hline 2 & 14 & 68,1 & 71,3 & 72,0 & 72,9 & 73,6 & 76,4 & 79,2 & 81,4 & 84,7 \\
\hline 2 & 15 & 69,0 & 72,4 & 73,0 & 74,0 & 74,7 & 77,5 & 80,3 & 82,7 & 86,0 \\
\hline 2 & 16 & 70,0 & 73,3 & 74,0 & 75,0 & 75,7 & 78,6 & 81,5 & 83,9 & 87,2 \\
\hline 2 & 17 & 70,9 & 74,3 & 75,0 & 76,0 & 76,7 & 79,7 & 82,6 & 85,0 & 88,5 \\
\hline 2 & 18 & 71,7 & 75,2 & 75,9 & 77,0 & 77,7 & 80,7 & 83,7 & 86,2 & 89,7 \\
\hline 2 & 19 & 72,6 & 76,2 & 76,9 & 77,9 & 78,7 & 81,7 & 84,8 & 87,3 & 90,9 \\
\hline 2 & 20 & 73,4 & 77,0 & 77,7 & 78,8 & 79,6 & 82,7 & 85,8 & 88,4 & 92,0 \\
\hline 2 & 21 & 74,2 & 77,9 & 78,6 & 79,7 & 80,5 & 83,7 & 86,8 & 89,4 & 93,1 \\
\hline 2 & 22 & 75,0 & 78,7 & 79,5 & 80,6 & 81,4 & 84,6 & 87,8 & 90,5 & 94,2 \\
\hline 2 & 23 & 75,7 & 79,6 & 80,3 & 81,5 & 82,2 & 85,5 & 88,8 & 91,5 & 95,3 \\
\hline 2 & 24 & 76,4 & 80,3 & 81,1 & 82,3 & 83,1 & 86,4 & 89,8 & 92,5 & 96,4 \\
\hline
\end{tabular}


5 - Estatura (cm) para idade (meses) segundo curvas da OMS (2006) (1: sexo masculino; 2: sexo feminino)

\begin{tabular}{|c|c|c|c|c|c|c|c|c|c|c|}
\hline & & \multicolumn{9}{|c|}{ PERCENTIL } \\
\hline sexo & idade (meses) & P 0,1 & P 3 & P5 & P10 & P 15 & P 50 & P 85 & P 97 & P 99,9 \\
\hline 1 & 24 & 77,7 & 81,4 & 82,1 & 83,2 & 83,9 & 87,1 & 90,3 & 92,9 & 96,6 \\
\hline 1 & 25 & 78,3 & 82,1 & 82,8 & 84,0 & 84,7 & 88,0 & 91,2 & 93,8 & 97,6 \\
\hline 1 & 26 & 79,0 & 82,8 & 83,6 & 84,7 & 85,5 & 88,8 & 92,1 & 94,8 & 98,6 \\
\hline 1 & 27 & 79,6 & 83,5 & 84,3 & 85,5 & 86,3 & 89,6 & 93,0 & 95,7 & 99,6 \\
\hline 1 & 28 & 80,2 & 84,2 & 85,0 & 86,2 & 87,0 & 90,4 & 93,8 & 96,6 & 100,6 \\
\hline 1 & 29 & 80,8 & 84,9 & 85,7 & 86,9 & 87,7 & 91,2 & 94,7 & 97,5 & 101,5 \\
\hline 1 & 30 & 81,4 & 85,5 & 86,3 & 87,6 & 88,4 & 91,9 & 95,5 & 98,3 & 102,5 \\
\hline 1 & 3 &, 0 & 86,2 & 87,0 & 88,2 & 89,1 & 92,7 & 96,2 & 99,2 & 103,4 \\
\hline 1 & 32 & 82,5 & 86,8 & 87,6 & 88,9 & 89,7 & 93,4 & 97,0 & 100,0 & 104,2 \\
\hline 1 & 3 & 83,1 & 87,4 & 88,2 & 89,5 & 90,4 & $\begin{array}{l}94,1 \\
\end{array}$ & 97,8 & 100,8 & 105,1 \\
\hline 1 & 34 & 3,6 & 88,0 & 88,8 & 90,1 & 91,0 & 94,8 & 98,5 & 101,5 & 105,9 \\
\hline 1 & 35 & 84,1 & 88,5 & 89,4 & 90,7 & 91,6 & \begin{tabular}{ll|}
95,4 \\
\end{tabular} & 99,2 & 102,3 & 106,7 \\
\hline 1 & 36 & 84,6 & 89,1 & 90,0 & 91,3 & 92,2 & $\begin{array}{ll}96,1 \\
\end{array}$ & 99,9 & 103,1 & 107,5 \\
\hline 1 & 37 & 85,1 & 89,7 & 90,6 & 91,9 & 92,8 & 96,7 & $\overline{100,6}$ & 103,8 & 108,3 \\
\hline 1 & 38 & 85,6 & 90,2 & 91,1 & 92,5 & 93,4 & 97,4 & $\overline{101,3}$ & 104,5 & 109,1 \\
\hline 1 & 39 & 86,1 & 90,8 & 91,7 & 93,1 & 94,0 & 98,0 & 102,0 & 105,2 & 109,9 \\
\hline 1 & 40 & 86,6 & 91,3 & 92,2 & 93,7 & 94,6 & \begin{tabular}{|l|}
98,6 \\
\end{tabular} & 102,7 & 105,9 & 110,6 \\
\hline 1 & 41 & 87,1 & 91,9 & 92,8 & 94,2 & 95,2 & \begin{tabular}{|l|}
99,2 \\
\end{tabular} & $\overline{103,3}$ & 106,6 & 111,4 \\
\hline 1 & 42 & 87,6 & 92,4 & 93,3 & 94,8 & 95,7 & \begin{tabular}{|l|}
99,9 \\
\end{tabular} & 104,0 & 107,3 & 112,1 \\
\hline 1 & $\overline{43}$ & 88,1 & 92,9 & 93,9 & 95,3 & 96,3 & 100,4 & 104,6 & 108,0 & 112,8 \\
\hline 1 & 44 & 88,5 & 93,4 & 94,4 & 95,9 & $\begin{array}{l}96,8 \\
\end{array}$ & 101,0 & 105,2 & 108,6 & 113,5 \\
\hline 1 & $\overline{45}$ & 89,0 & 93,9 & 94,9 & 96,4 & 97,4 & 101,6 & 105,8 & 109,3 & 114,2 \\
\hline 1 & 46 & 89,5 & 94,4 & 95,4 & 96,9 & 97,9 & 102,2 & 106,5 & 109,9 & 114,9 \\
\hline 1 & 47 & 89,9 & 94,9 & 95,9 & 97,4 & 98,5 & 102,8 & $\overline{107,1}$ & 110,6 & 115,6 \\
\hline 1 & 48 & 90,4 & 95,4 & 96,4 & 98 & 99,0 & 103,3 & 107,7 & 111,2 & 116,3 \\
\hline 1 & 49 & 90,8 & 95,9 & 96,9 & 98,5 & 99,5 & 103,9 & 108,3 & 111,8 & 117,0 \\
\hline 1 & 50 & 91,3 & 96,4 & 97,4 & 99,0 & 100,0 & 104,4 & 108,9 & 112,5 & 117,6 \\
\hline 1 & 51 & 91,7 & 96,9 & 97,9 & 99,5 & 100,5 & 105,0 & 109,5 & 113,1 & 118,3 \\
\hline 1 & 52 & 92,1 & $\overline{97,4}$ & 98,4 & $\overline{100,0}$ & $\overline{101,1}$ & 105,6 & $\overline{110,1}$ & 113,7 & 119,0 \\
\hline 1 & 53 & 92,6 & 97,9 & \begin{tabular}{|l|l|}
98,9 \\
\end{tabular} & 100,5 & 101,6 & 106,1 & 110,7 & 114,3 & 119,6 \\
\hline 1 & 54 & 93,0 & 98,4 & 99,4 & 101,0 & 102,1 & 106,7 & 111,2 & 115,0 & 120,3 \\
\hline 1 & 55 & 93,5 & 98,8 & 99,9 & 101,5 & 102,6 & 107,2 & 111,8 & 115,6 & 121,0 \\
\hline 1 & 56 & 93,9 & 99,3 & 100,4 & 102,0 & 103,1 & 107,8 & 112,4 & 116,2 & 121,6 \\
\hline 1 & 57 & 94,3 & 99,8 & 100,9 & 102,5 & 103,6 & 108,3 & $\overline{113,0}$ & 116,8 & 122,3 \\
\hline 1 & $5 \varepsilon$ & 94,8 & 100,3 & 101,4 & 103,0 & 104,1 & 108,9 & 113,6 & 117,4 & 123,0 \\
\hline 1 & 59 & 95,2 & 100,8 & 101,9 & 103,5 & 104,7 & 109,4 & $\overline{114,2}$ & 118,1 & 123,6 \\
\hline 1 & 60 & 95,6 & 101,2 & 102,3 & 104,0 & 105,2 & 110,0 & 114,8 & 118,7 & 124,3 \\
\hline 7 & 24 & 75,7 & 79,6 & 80,4 & 81,6 & 82,4 & 85,7 & 89,1 & 91,8 & 95,7 \\
\hline$?$ & 25 & 76,5 & 80,4 & 81,2 & 82,4 & 83,2 & \begin{tabular}{|l|}
86,6 \\
\end{tabular} & 90,0 & \begin{tabular}{|l|}
92,8 \\
\end{tabular} & 96,7 \\
\hline 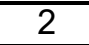 & 26 & 77,2 & 81,2 & 82,0 & 83,2 & 84,0 & 87,4 & 90,9 & 93,7 & 97,7 \\
\hline 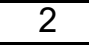 & 27 & 77,8 & 81,9 & 82,7 & 83,9 & 84,8 & 88,3 & 91,8 & 94,6 & 98,7 \\
\hline
\end{tabular}




\begin{tabular}{|c|c|c|c|c|c|c|c|c|c|c|}
\hline 2 & 28 & 78,5 & 82,6 & 83,5 & 84,7 & 85,5 & 89,1 & 92,7 & 95,6 & 99,7 \\
\hline 2 & 29 & 79,1 & 83,4 & 84,2 & 85,4 & 86,3 & 89,9 & 93,5 & 96,4 & 100,7 \\
\hline 2 & 30 & 79,8 & 84,0 & 84,9 & 86,2 & 87,0 & 90,7 & 94,3 & 97,3 & 101,6 \\
\hline 2 & 31 & 80,4 & 84,7 & 85,6 & 86,9 & 87,7 & 91,4 & 95,2 & 98,2 & 102,5 \\
\hline 2 & 32 & 81,0 & 85,4 & 86,2 & 87,5 & 88,4 & 92,2 & 95,9 & 99,0 & 103,4 \\
\hline 2 & 33 & 81,6 & 86,0 & 86,9 & 88,2 & 89,1 & 92,9 & 96,7 & 99,8 & 104,3 \\
\hline 2 & 34 & 82,2 & 86,7 & 87,5 & 88,9 & 89,8 & 93,6 & 97,5 & 100,6 & 105,1 \\
\hline 2 & 35 & 82,7 & 87,3 & 88,2 & 89,5 & 90,5 & 94,4 & 98,3 & 101,4 & 106,0 \\
\hline 2 & 36 & 83,3 & 87,9 & 88,8 & 90,2 & 91,1 & 95,1 & 99,0 & 102,2 & 106,8 \\
\hline 2 & 37 & 83,8 & 88,5 & 89,4 & 90,8 & 91,7 & 95,7 & 99,7 & 103,0 & 107,6 \\
\hline 2 & 38 & 84,4 & 89,1 & 90,0 & 91,4 & 92,4 & 96,4 & 100,5 & 103,7 & 108,5 \\
\hline 2 & 39 & 84,9 & 89,7 & 90,6 & 92,0 & 93,0 & 97,1 & 101,2 & 104,5 & 109,3 \\
\hline 2 & 40 & 85,4 & 90,3 & 91,2 & 92,6 & 93,6 & 97,7 & 101,9 & 105,2 & 110,1 \\
\hline 2 & 41 & 86,0 & 90,8 & 91,8 & 93,2 & 94,2 & 98,4 & 102,6 & 106,0 & 110,8 \\
\hline 2 & 42 & 86,5 & 91,4 & 92,4 & 93,8 & 94,8 & 99,0 & 103,3 & 106,7 & 111,6 \\
\hline 2 & 43 & 87,0 & 92,0 & 92,9 & 94,4 & 95,4 & 99,7 & 103,9 & 107,4 & 112,4 \\
\hline 2 & 44 & 87,5 & 92,5 & 93,5 & 95,0 & 96,0 & 100,3 & 104,6 & 108,1 & 113,1 \\
\hline 2 & 45 & 88,0 & 93,0 & 94,0 & 95,6 & 96,6 & 100,9 & 105,3 & 108,8 & 113,9 \\
\hline 2 & 46 & 88,5 & 93,6 & 94,6 & 96,1 & 97,2 & 101,5 & 105,9 & 109,5 & 114,6 \\
\hline 2 & 47 & 88,9 & 94,1 & 95,1 & 96,7 & 97,7 & 102,1 & 106,6 & 110,2 & 115,3 \\
\hline 2 & 48 & 89,4 & 94,6 & 95,6 & 97,2 & 98,3 & 102,7 & 107,2 & 110,8 & 116,0 \\
\hline 2 & 49 & 89,9 & 95,1 & 96,2 & 97,8 & 98,8 & 103,3 & 107,8 & 111,5 & 116,7 \\
\hline 2 & 50 & 90,4 & 95,7 & 96,7 & 98,3 & 99,4 & 103,9 & 108,4 & 112,1 & 117,5 \\
\hline 2 & 51 & 90,8 & 96,2 & 97,2 & 98,8 & 99,9 & 104,5 & 109,1 & 112,8 & 118,1 \\
\hline 2 & 52 & 91,3 & 96,7 & 97,7 & 99,3 & 100,4 & 105,0 & 109,7 & 113,4 & 118,8 \\
\hline 2 & 53 & 91,7 & 97,2 & 98,2 & 99,9 & 101,0 & 105,6 & 110,3 & 114,1 & 119,5 \\
\hline 2 & 54 & 92,2 & 97,6 & 98,7 & 100,4 & 101,5 & 106,2 & 110,9 & 114,7 & 120,2 \\
\hline 2 & 55 & 92,6 & 98,1 & 99,2 & 100,9 & 102,0 & 106,7 & 111,5 & 115,3 & 120,9 \\
\hline 2 & 56 & 93,0 & 98,6 & 99,7 & 101,4 & 102,5 & 107,3 & 112,1 & 116,0 & 121,5 \\
\hline 2 & 57 & 93,5 & 99,1 & 100,2 & 101,9 & 103,0 & 107,8 & 112,6 & 116,6 & 122,2 \\
\hline 2 & 58 & 93,9 & 99,6 & 100,7 & 102,4 & 103,5 & 108,4 & 113,2 & 117,2 & 122,8 \\
\hline 2 & 59 & 94,3 & 100,0 & 101,1 & 102,8 & 104,0 & 108,9 & 113,8 & 117,8 & 123,5 \\
\hline 2 & 60 & 94,7 & 100,5 & 101,6 & 103,3 & 104,5 & 109,4 & 114,4 & 118,4 & 124,1 \\
\hline
\end{tabular}


7 - IMC $\left(\mathrm{kg} / \mathrm{m}^{2}\right)$ para idade (meses) segundo curvas da OMS (2006) para

crianças de 2 a 5 anos (1: sexo

masculino; 2: sexo feminino)

\begin{tabular}{|c|c|c|c|c|c|c|c|c|c|c|}
\hline & & \multicolumn{9}{|c|}{ PERCENTIL } \\
\hline sexo & idade (meses) & $P 0,1$ & P3 & P5 & \begin{tabular}{|l|} 
P10 \\
\end{tabular} & P 15 & P 50 & P 85 & P 97 & P 99,9 \\
\hline 1 & 24 & 12,8 & 13,9 & 14,2 & 14,5 & 14,8 & 16,0 & 17,4 & 18,7 & 20,8 \\
\hline 1 & 25 & 12,8 & 13,9 & 14,1 & 14,5 & 14,8 & 16,0 & 17,4 & 18,6 & 20,7 \\
\hline 1 & 26 & 12,7 & 13,8 & 14,1 & 14,5 & 14,7 & 15,9 & 17,3 & 18,6 & 20,6 \\
\hline 1 & 27 & 12,7 & 13,8 & 14,0 & 14,4 & 14,7 & 15,9 & 17,3 & 18,5 & 20,6 \\
\hline 1 & 28 & 12,6 & 13,8 & 14,0 & \begin{tabular}{|l|}
14,4 \\
\end{tabular} & 14,7 & 15,9 & 17,2 & 18,5 & 20,5 \\
\hline 1 & 29 & 12,6 & 13,7 & 14,0 & 14,4 & 14,6 & 15,8 & 17,2 & 18,4 & 20,5 \\
\hline 1 & 30 & 12,5 & 13,7 & 13,9 & 14,3 & 14,6 & 15,8 & 17,2 & 18,4 & 20,4 \\
\hline 1 & 31 & 12,5 & 13,7 & 13,9 & 14,3 & 14,5 & 15,8 & 17,1 & 18,4 & 20,3 \\
\hline 1 & 32 & 12,5 & 13,6 & 13,9 & 14,2 & 14,5 & 15,7 & 17,1 & 18,3 & 20,3 \\
\hline 1 & 33 & 12,4 & 13,6 & 13,8 & 14,2 & 14,5 & 15,7 & 17,0 & 18,3 & 20,2 \\
\hline 1 & 34 & 12,4 & 13,5 & 13,8 & 14,2 & 14,4 & 15,7 & 17,0 & 18,2 & 20,2 \\
\hline 1 & 35 & 12,4 & 13,5 & 13,8 & 14,1 & 14,4 & 15,6 & 17,0 & 18,2 & 20,2 \\
\hline 1 & 36 & 12,3 & 13,5 & 13,7 & 14,1 & 14,4 & 15,6 & 17,0 & 18,2 & 20,1 \\
\hline 1 & 37 & 12,3 & 13,5 & 13,7 & 14,1 & 14,4 & 15,6 & 16,9 & 18,1 & 20,1 \\
\hline 1 & 38 & 12,3 & 13,4 & 13,7 & 14,1 & 14,3 & 15,5 & 16,9 & 18,1 & 20,1 \\
\hline 1 & 39 & 12,2 & 13,4 & 13,6 & 14,0 & 14,3 & 15,5 & 16,9 & 18,1 & 20,0 \\
\hline 1 & 40 & 12,2 & 13,4 & 13,6 & 14,0 & 14,3 & 15,5 & 16,8 & 18,1 & 20,0 \\
\hline 1 & 41 & 12,2 & 13,3 & 13,6 & 14,0 & 14,2 & 15,5 & 16,8 & 18,0 & 20,0 \\
\hline 1 & 42 & 12,1 & 13,3 & 13,6 & 13,9 & 14,2 & 15,4 & 16,8 & 18,0 & 20,0 \\
\hline 1 & 43 & 12,1 & 13,3 & 13,5 & \begin{tabular}{|l|}
13,9 \\
\end{tabular} & 14,2 & 15,4 & 16,8 & 18,0 & 20,0 \\
\hline 1 & 44 & 12,1 & 13,3 & 13,5 & 13,9 & 14,2 & 15,4 & 16,8 & 18,0 & 20,0 \\
\hline 1 & 45 & 12,1 & 13,2 & 13,5 & 13,9 & \begin{tabular}{|l|}
14,2 \\
\end{tabular} & 15,4 & 16,8 & 18,0 & 20,0 \\
\hline 1 & 46 & 12,1 & 13,2 & 13,5 & 13,9 & \begin{tabular}{|l|}
14,1 \\
\end{tabular} & 15,4 & 16,7 & 18,0 & 20,0 \\
\hline 1 & 47 & 12,0 & 13,2 & 13,5 & 13,8 & 14,1 & 15,3 & 16,7 & 18,0 & 20,0 \\
\hline 1 & 48 & 12,0 & 13,2 & 13,4 & 13,8 & 14,1 & 15,3 & 16,7 & 18,0 & 20,0 \\
\hline 1 & 49 & 12,0 & 13,2 & 13,4 & 13,8 & \begin{tabular}{|l|}
14,1 \\
\end{tabular} & 15,3 & 16,7 & \begin{tabular}{|l|}
18,0 \\
\end{tabular} & 20,0 \\
\hline 1 & 50 & 12,0 & 13,2 & 13,4 & 13,8 & \begin{tabular}{|l|}
14,1 \\
\end{tabular} & 15,3 & 16,7 & 18,0 & 20,1 \\
\hline 1 & 51 & 12,0 & 13,1 & 13,4 & 13,8 & 14,0 & 15,3 & 16,7 & 18,0 & 20,1 \\
\hline 1 & 52 & 12,0 & 13,1 & 13,4 & 13,8 & 14,0 & 15,3 & 16,7 & 18,0 & 20,1 \\
\hline 1 & 53 & 11,9 & 13,1 & 13,3 & 13,7 & 14,0 & 15,3 & 16,7 & 18,0 & 20,1 \\
\hline 1 & 54 & 11,9 & 13,1 & 13,3 & 13,7 & 14,0 & 15,3 & 16,7 & 18,0 & 20,2 \\
\hline 1 & 55 & 11,9 & 13,1 & 13,3 & \begin{tabular}{|l|}
13,7 \\
\end{tabular} & 14,0 & 15,2 & 16,7 & 18,0 & 20,2 \\
\hline 1 & $\overline{56}$ & 11,9 & $\overline{13,1}$ & 13,3 & \begin{tabular}{|l|}
13,7 \\
\end{tabular} & 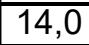 & 15,2 & 16,7 & 18,0 & 20,3 \\
\hline 1 & 57 & 11,9 & 13,0 & 13,3 & 13,7 & 14,0 & 15,2 & 16,7 & 18,0 & 20,3 \\
\hline 1 & 58 & 11,9 & 13,0 & 13,3 & 13,7 & 13,9 & 15,2 & 16,7 & 18,0 & 20,3 \\
\hline 1 & 59 & 11,9 & 13,0 & 13,3 & 13,7 & 13,9 & 15,2 & 16,7 & 18,1 & 20,4 \\
\hline 1 & 60 & 11,9 & 13,0 & 13,3 & 13,6 & 13,9 & 15,2 & 16,7 & \begin{tabular}{|l|}
18,1 \\
\end{tabular} & 20,5 \\
\hline 2 & 24 & 12,3 & 13,5 & 13,7 & $\mid 14,1$ & \begin{tabular}{|l|}
14,4 \\
\end{tabular} & 15,7 & 17,2 & \begin{tabular}{|l|}
18,5 \\
\end{tabular} & 20,8 \\
\hline 2 & 25 & 12,3 & 13,4 & 13,7 & \begin{tabular}{|l|}
14,1 \\
\end{tabular} & \begin{tabular}{|l|}
14,4 \\
\end{tabular} & 15,7 & 17,1 & 18,5 & 20,8 \\
\hline$\overline{2}$ & 26 & 12,3 & 13,4 & 13,7 & \begin{tabular}{|l|}
14,1 \\
\end{tabular} & 14,4 & 15,6 & 17,1 & 18,5 & 20,7 \\
\hline 2 & 27 & 12,2 & 13,4 & 13,7 & 14,0 & 14,3 & 15,6 & 17,1 & 18,4 & 20,7 \\
\hline
\end{tabular}




\begin{tabular}{|l|l|l|l|l|l|l|l|l|l|l|}
\hline 2 & 28 & 12,2 & 13,4 & 13,6 & 14,0 & 14,3 & 15,6 & 17,0 & 18,4 & 20,7 \\
\hline 2 & 29 & 12,2 & 13,4 & 13,6 & 14,0 & 14,3 & 15,6 & 17,0 & 18,4 & 20,6 \\
\hline 2 & 30 & 12,2 & 13,3 & 13,6 & 14,0 & 14,3 & 15,5 & 17,0 & 18,3 & 20,6 \\
\hline 2 & 31 & 12,2 & 13,3 & 13,6 & 14,0 & 14,2 & 15,5 & 17,0 & 18,3 & 20,6 \\
\hline 2 & 32 & 12,1 & 13,3 & 13,5 & 13,9 & 14,2 & 15,5 & 16,9 & 18,3 & 20,5 \\
\hline 2 & 33 & 12,1 & 13,3 & 13,5 & 13,9 & 14,2 & 15,5 & 16,9 & 18,3 & 20,5 \\
\hline 2 & 34 & 12,1 & 13,2 & 13,5 & 13,9 & 14,2 & 15,4 & 16,9 & 18,2 & 20,5 \\
\hline 2 & 35 & 12,1 & 13,2 & 13,5 & 13,9 & 14,1 & 15,4 & 16,9 & 18,2 & 20,5 \\
\hline 2 & 36 & 12,0 & 13,2 & 13,5 & 13,8 & 14,1 & 15,4 & 16,9 & 18,2 & 20,5 \\
\hline 2 & 37 & 12,0 & 13,2 & 13,4 & 13,8 & 14,1 & 15,4 & 16,8 & 18,2 & 20,5 \\
\hline 2 & 38 & 12,0 & 13,2 & 13,4 & 13,8 & 14,1 & 15,4 & 16,8 & 18,2 & 20,5 \\
\hline 2 & 39 & 12,0 & 13,1 & 13,4 & 13,8 & 14,1 & 15,3 & 16,8 & 18,2 & 20,5 \\
\hline 2 & 40 & 11,9 & 13,1 & 13,4 & 13,8 & 14,0 & 15,3 & 16,8 & 18,2 & 20,5 \\
\hline 2 & 41 & 11,9 & 13,1 & 13,3 & 13,7 & 14,0 & 15,3 & 16,8 & 18,2 & 20,6 \\
\hline 2 & 42 & 11,9 & 13,1 & 13,3 & 13,7 & 14,0 & 15,3 & 16,8 & 18,2 & 20,6 \\
\hline 2 & 43 & 11,9 & 13,0 & 13,3 & 13,7 & 14,0 & 15,3 & 16,8 & 18,2 & 20,6 \\
\hline 2 & 44 & 11,8 & 13,0 & 13,3 & 13,7 & 14,0 & 15,3 & 16,8 & 18,2 & 20,6 \\
\hline 2 & 45 & 11,8 & 13,0 & 13,3 & 13,7 & 14,0 & 15,3 & 16,8 & 18,3 & 20,7 \\
\hline 2 & 46 & 11,8 & 13,0 & 13,2 & 13,7 & 13,9 & 15,3 & 16,8 & 18,3 & 20,7 \\
\hline 2 & 47 & 11,8 & 13,0 & 13,2 & 13,6 & 13,9 & 15,3 & 16,8 & 18,3 & 20,7 \\
\hline 2 & 48 & 11,7 & 12,9 & 13,2 & 13,6 & 13,9 & 15,3 & 16,8 & 18,3 & 20,8 \\
\hline 2 & 49 & 11,7 & 12,9 & 13,2 & 13,6 & 13,9 & 15,3 & 16,8 & 18,3 & 20,8 \\
\hline 2 & 50 & 11,7 & 12,9 & 13,2 & 13,6 & 13,9 & 15,3 & 16,8 & 18,3 & 20,9 \\
\hline 2 & 51 & 11,7 & 12,9 & 13,2 & 13,6 & 13,9 & 15,3 & 16,8 & 18,4 & 20,9 \\
\hline 2 & 52 & 11,7 & 12,9 & 13,1 & 13,6 & 13,9 & 15,2 & 16,9 & 18,4 & 21,0 \\
\hline 2 & 53 & 11,6 & 12,9 & 13,1 & 13,6 & 13,9 & 15,3 & 16,9 & 18,4 & 21,0 \\
\hline 2 & 54 & 11,6 & 12,9 & 13,1 & 13,6 & 13,9 & 15,3 & 16,9 & 18,4 & 21,0 \\
\hline 2 & 55 & 11,6 & 12,9 & 13,1 & 13,5 & 13,9 & 15,3 & 16,9 & 18,4 & 21,1 \\
\hline 2 & 56 & 11,6 & 12,8 & 13,1 & 13,5 & 13,8 & 15,3 & 16,9 & 18,5 & 21,1 \\
\hline 2 & 57 & 11,6 & 12,8 & 13,1 & 13,5 & 13,8 & 15,3 & 16,9 & 18,5 & 21,2 \\
\hline 2 & 58 & 11,6 & 12,8 & 13,1 & 13,5 & 13,8 & 15,3 & 16,9 & 18,5 & 21,2 \\
\hline 2 & 59 & 11,6 & 12,8 & 13,1 & 13,5 & 13,8 & 15,3 & 16,9 & 18,5 & 21,3 \\
\hline 2 & 60 & 11,6 & 12,8 & 13,1 & 13,5 & 13,8 & 15,3 & 17,0 & 18,6 & 21,3 \\
\hline
\end{tabular}


Anexo 3: Certificado de Capacitação para uso do instrumento de Avaliação Neuropsicomotora Bayley

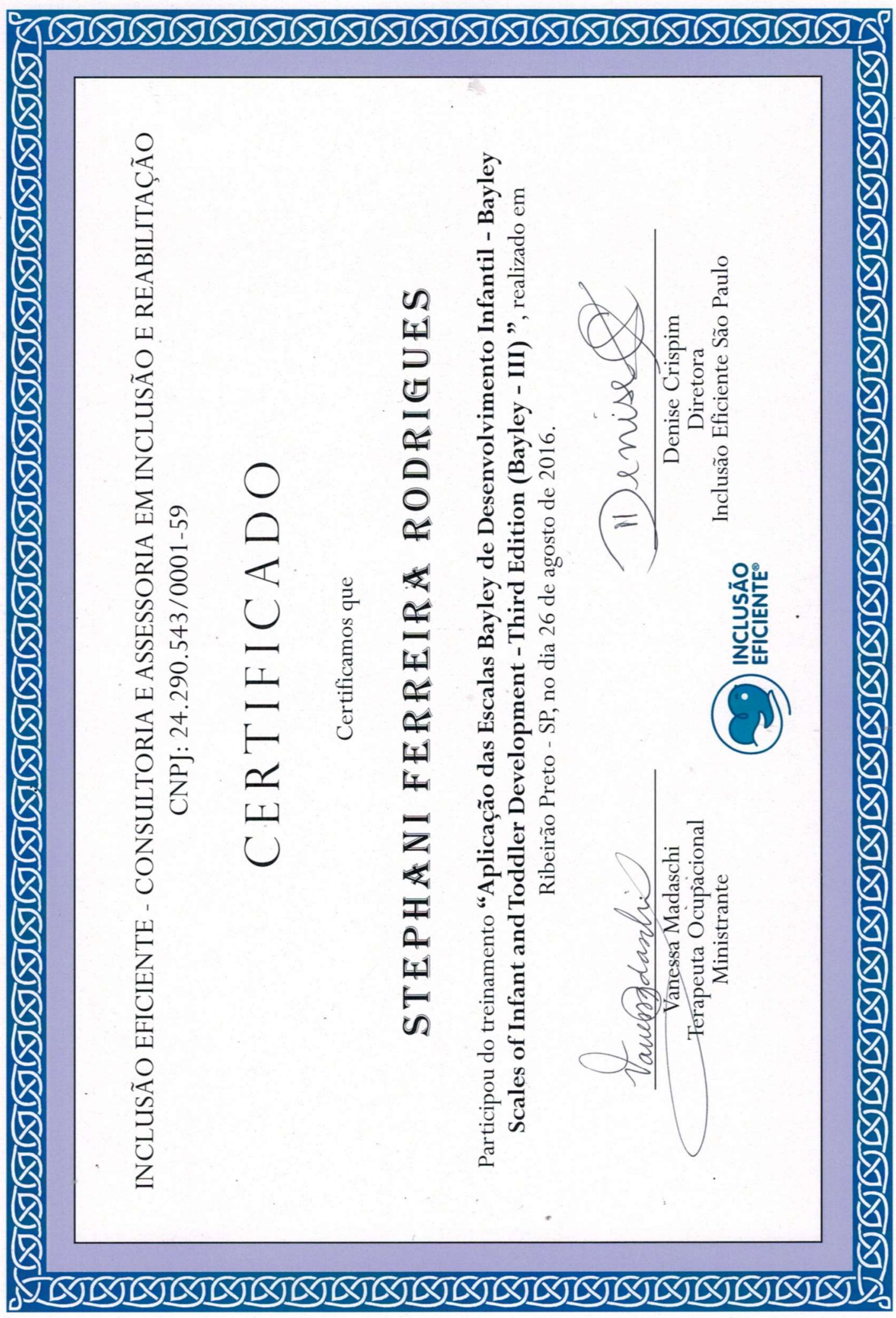


Anexo 4: Avaliação de Desenvolvimento Neuromotor Infantil

\section{Formulário de Registro Screening}

Nome da criança:

MNon:M

Bayley

Sexo:( ) M ( ) F

Identificação:

Nome do examinador:

Escola:

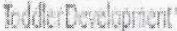

IHID

Razão para avaliação

Escores dos Subtestes

\begin{tabular}{|l|l|l|l|l|}
\hline \multirow{2}{*}{ Subtestes } & $\begin{array}{c}\text { Escore } \\
\text { Bruto }\end{array}$ & \multicolumn{3}{|c|}{ Categorias } \\
\cline { 2 - 5 } & & Risco & Emergente & Competente \\
\hline Cognitivo & & & & \\
\hline & & & \\
\hline $\begin{array}{l}\text { Comunicação } \\
\text { Receptiva }\end{array}$ & & & & \\
\hline $\begin{array}{l}\text { Comunicação } \\
\text { Expressiva }\end{array}$ & & & & \\
\hline Motor Fino & & & & \\
\hline Motor Grosso & & & & \\
\hline
\end{tabular}

Observações:
Cálculo de Idade

\begin{tabular}{|c|c|c|c|}
\hline 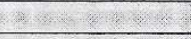 & Anos & Meses & Dias \\
\hline \multicolumn{4}{|l|}{ Data Teste } \\
\hline \multicolumn{4}{|l|}{$\begin{array}{r}\text { Data } \\
\text { Nascimento }\end{array}$} \\
\hline \multicolumn{4}{|l|}{ Idade } \\
\hline \multirow{2}{*}{$\begin{array}{r}\text { Idade em } \\
\text { meses e dias }\end{array}$} & Anos $\times 12$ & & \\
\hline & + meses & & \\
\hline $\begin{array}{r}\text { Ajuste para } \\
\text { prematuridade }\end{array}$ & $\begin{array}{c}\text { Ajuste } \\
\text { até } \\
24 \mathrm{~m} \\
\end{array}$ & & \\
\hline $\begin{array}{r}\text { Idade } \\
\text { Ajustada } \\
\end{array}$ & 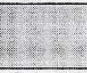 & & s. \\
\hline $\begin{array}{r}\text { Ponto de } \\
\text { Partida }\end{array}$ & \multicolumn{2}{|c|}{$\begin{array}{l}\text { Calcule ponto de } \\
\text { partida de acordo } \\
\text { com tabela abaixo }\end{array}$} & \\
\hline \multicolumn{2}{|c|}{ Idade * } & \multicolumn{2}{|c|}{$\begin{array}{c}\text { Ponto de } \\
\text { Partida }\end{array}$} \\
\hline \multicolumn{2}{|l|}{ 1- 6 meses } & \multicolumn{2}{|c|}{ A } \\
\hline \multicolumn{2}{|l|}{$7-12$ meses } & \multicolumn{2}{|c|}{$B$} \\
\hline \multicolumn{2}{|l|}{$13-24$ meses } & \\
\hline \multicolumn{2}{|l|}{ 25-42 meses } & \multicolumn{2}{|l|}{$\mathrm{D}$} \\
\hline
\end{tabular}




\section{Subteste Cognitivo}

Regra de Aplicação: A criança deve obter o escore 1 no primeiro item do ponto de partida de alguma idade para seguir em frente. Se a criança obtiver o escore 0 no primeiro item, deve-se voltar ao ponto de partida da idade anterior e administra os itens desta idade.

Regra de Parada: Parar a administração quando a criança obtiver escore 0 em quatro itens consecutivos.

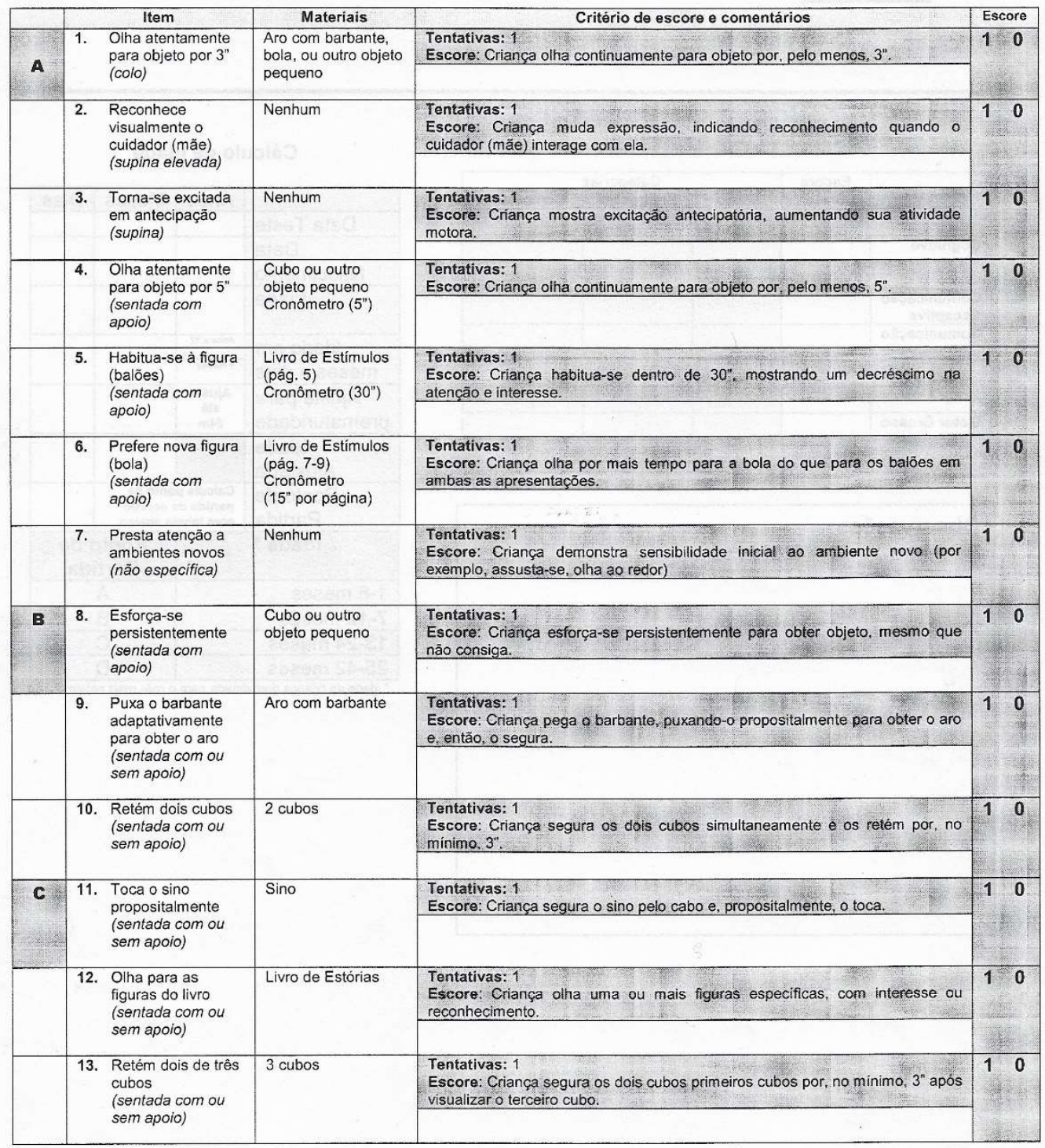




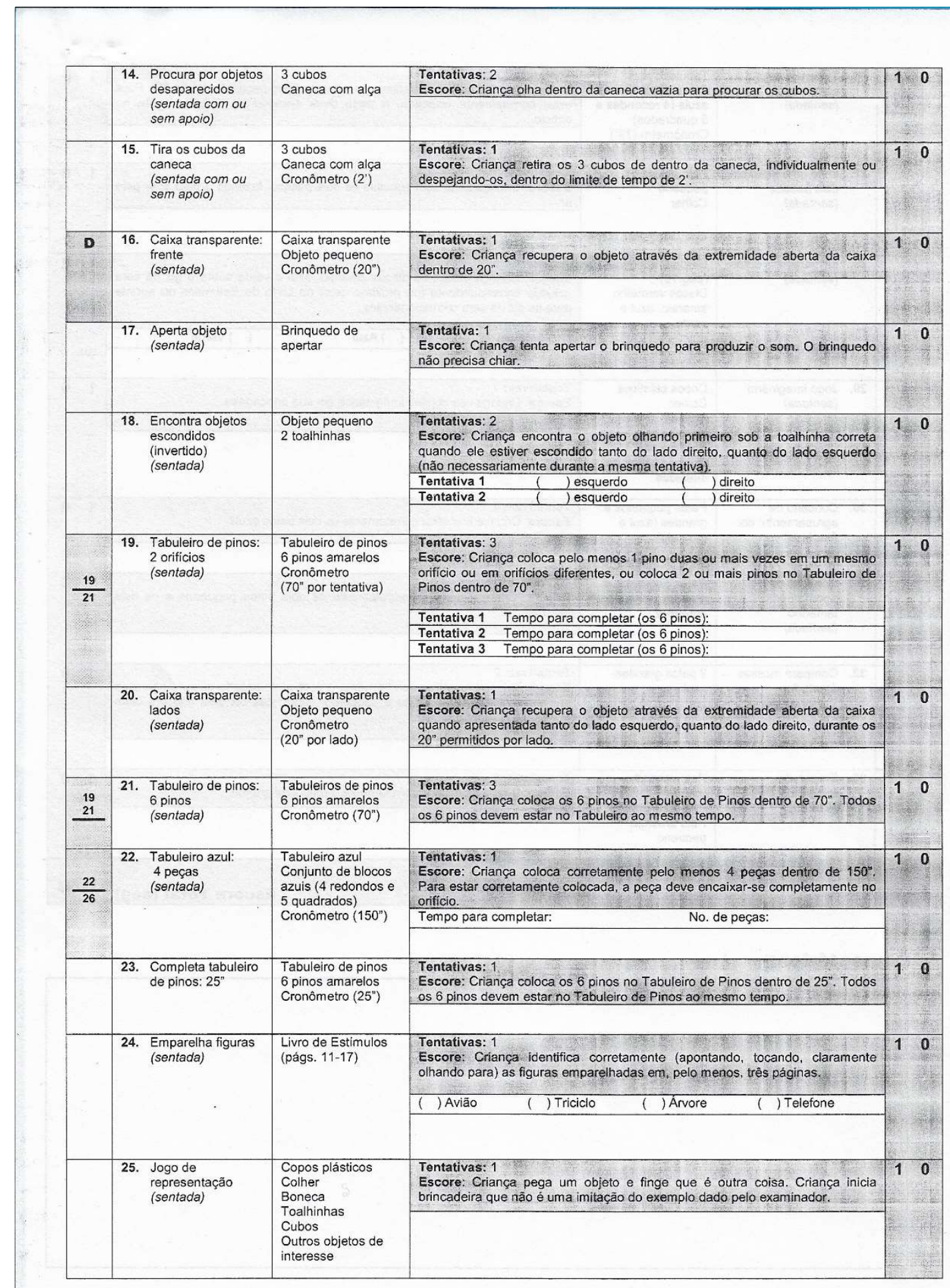




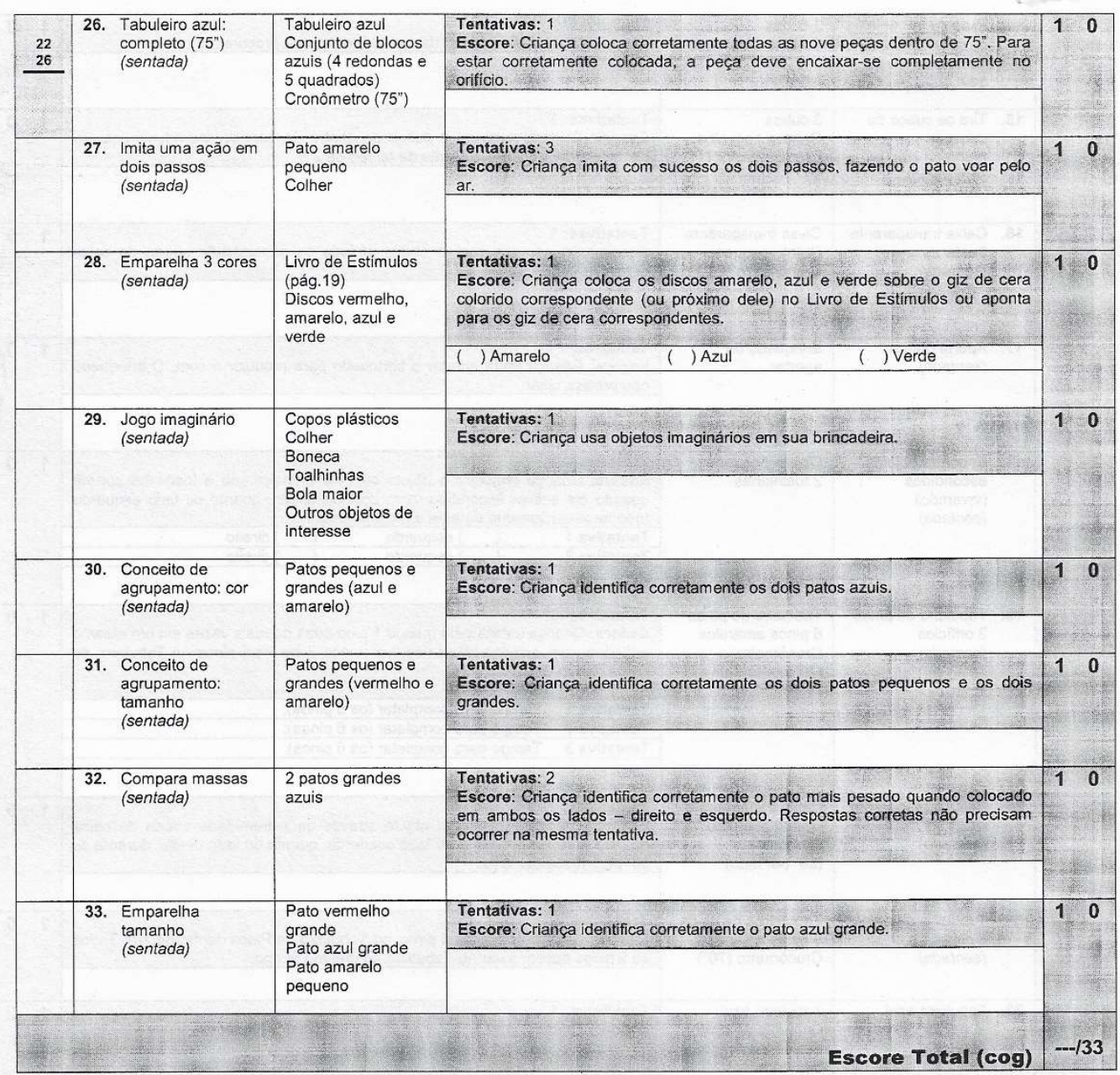

\section{Comentários:}




\section{Subteste Motor Grosso}

Regra de Aplicação: A criança deve obter o escore 1 no primeiro item do ponto de partida de alguma idade para seguir em frente. Se a criança obtiver o escore 0 no primeiro item, deve-se voltar ao ponto de partida da idade anterior e administra os itens desta idade.

Regra de Parada: Parar a administração quando a criança obtiver escore 0 em quatro itens consecutivos.

\begin{tabular}{|c|c|c|c|c|c|}
\hline & & Item & Materiais & Critério de escore e comentários & Escore \\
\hline \multirow{3}{*}{$\begin{array}{l}\text { A } \\
1 \\
2 \\
5\end{array}$} & \multirow{3}{*}{\multicolumn{2}{|c|}{$\begin{array}{l}\text { S.érie controle de } \\
\text { cabeça enquanto } \\
\text { vertical: eleva a } \\
\text { cabeça } \\
\text { (apoiada no ombro) }\end{array}$}} & \multirow[t]{3}{*}{ Cronômetro } & $\begin{array}{l}\text { Escore: Criança intermitentemente levanta a cabeça do seu ombro sem } \\
\text { suporte. }\end{array}$ & \multirow[t]{3}{*}{10} \\
\hline & & & & Tempo em que mantém cabeça erguida: & \\
\hline & & & & & \\
\hline \multirow{5}{*}{$\frac{1}{2}$} & \multirow[t]{2}{*}{2.} & \multirow{2}{*}{$\begin{array}{l}\text { Série controle de } \\
\text { cabeça enquanto } \\
\text { vertical: } 3^{n} \\
\text { (apoiada no ombro) }\end{array}$} & \multirow[t]{2}{*}{ Cronômetro } & $\begin{array}{l}\text { Escore: Criança intermitentemente levanta a cabeça do seu ombro sem } \\
\text { suporte. }\end{array}$ & \multirow[t]{2}{*}{10} \\
\hline & & & & Tempo em que mantém cabeça erguida: & \\
\hline & 3. & $\begin{array}{l}\text { Vira a cabeça para } \\
\text { o lado } \\
\text { (prona) }\end{array}$ & Objeto de interesse & $\begin{array}{l}\text { Escore: Criança vira a cabeça de um lado para o outro, levantando a } \\
\text { cabeça da superficie de apoio o suficiente para liberar o nariz. A criança } \\
\text { deve ser capaz de virar a cabeça para os dois lados. }\end{array}$ & 10 \\
\hline & \multirow[t]{2}{*}{4.} & \multirow{2}{*}{$\begin{array}{l}\text { Faz movimentos de } \\
\text { engatinhar } \\
\text { (prona) }\end{array}$} & \multirow[t]{2}{*}{ Nenhum } & Escore: Criança faz movimentos alternados de engatinhar com as pernas. & \multirow{2}{*}{10} \\
\hline & & & & & \\
\hline \multirow{4}{*}{$\begin{array}{l}1 \\
2 \\
5 \\
\end{array}$} & \multirow[t]{2}{*}{5.} & \multirow{2}{*}{$\begin{array}{l}\text { Série controle de } \\
\text { cabeça enquanto } \\
\text { vertical: } 15^{\prime \prime} \\
\text { (apoiada no ombro) }\end{array}$} & \multirow[t]{2}{*}{ Cronômetro $\left(15^{n}\right)$} & $\begin{array}{l}\text { Escore: Criança mantém cabeça ereta e constante por, pelo menos, } 15^{\prime \prime} \\
\text { sem suporte. }\end{array}$ & \multirow[t]{2}{*}{10} \\
\hline & & & & & \\
\hline & \multirow[t]{2}{*}{6.} & \multirow{2}{*}{$\begin{array}{l}\text { Eleva tronco } \\
\text { enquanto na } \\
\text { posição prona: } \\
\text { cotovelos e } \\
\text { antebraços }\end{array}$} & \multirow[t]{2}{*}{ Objeto de interesse } & $\begin{array}{l}\text { Escore: Criança eleva a cabeça e a parte superior do tronco (tórax), } \\
\text { empurrando-se para cima com os cotovelos ou antebraços. }\end{array}$ & \multirow[t]{2}{*}{10} \\
\hline & & & & & \\
\hline \multirow[t]{2}{*}{$\frac{7}{8}$} & \multirow[t]{2}{*}{7.} & \multirow{2}{*}{$\begin{array}{l}\text { Série senta com } \\
\text { suporte: } \\
\text { brevemente } \\
\text { (sentada) }\end{array}$} & \multirow[t]{2}{*}{ Cronômetro } & $\begin{array}{l}\text { Escore: Criança tensiona os músculos em um esforço para manter-se na } \\
\text { posição sentada. }\end{array}$ & \multirow[t]{2}{*}{10} \\
\hline & & & & Tempo sentada: & \\
\hline \multirow{4}{*}{$\begin{array}{l}B \\
7 \\
8\end{array}$} & \multirow[t]{2}{*}{8.} & \multirow{2}{*}{$\begin{array}{l}\text { Série senta com } \\
\text { suporte: } 30^{\prime \prime} \\
\text { (sentada) }\end{array}$} & Cronômetro $\left(30^{\prime \prime}\right)$ & Escore: Criança senta com leve apoio por, pelo menos, 30". & 10 \\
\hline & & & & & \\
\hline & & Rola da posição de & Sino ou chocalho & Escore: Criança rola de costas para ambos os lados: direito e esquerdo. & 10 \\
\hline & & (supina) & & & \\
\hline & & $\begin{array}{l}\text { Rola da posição de } \\
\text { costas para a de }\end{array}$ & Sino ou chocalho & $\begin{array}{l}\text { Escore: Criança rola da posição de costas para a posição de bruços, } \\
\text { rolando para qualquer lado. }\end{array}$ & 10 \\
\hline & & (supina) & & & \\
\hline & & $\begin{array}{l}\text { Senta sem apoio e } \\
\text { segura objeto } \\
\text { (sentada) }\end{array}$ & $\begin{array}{l}\text { Objeto de interesse } \\
\text { Cronômetro }\left(60^{\circ}\right)\end{array}$ & $\begin{array}{l}\text { Escore: Criança senta sozinha por, pelo menos, } 60 \text { "enquanto manipula um } \\
\text { objeto. }\end{array}$ & 10 \\
\hline & 12. & Rasteja sobre o & Objeto de interesse & $\begin{array}{l}\text { Escore: Criança usa os braços para mover-se para a frente sobre o } \\
\text { estômago por aproximadamente } 90 \mathrm{~cm} \text { ou mais. }\end{array}$ & 10 \\
\hline $\begin{array}{l}\text { C } \\
13\end{array}$ & 13. & $\begin{array}{l}\text { Série andar: com } \\
\text { apoio }\end{array}$ & Nenhum & $\begin{array}{l}\text { Escore: Criança anda de maneira coordenada, alternando movimento de } \\
\text { passos. }\end{array}$ & 10 \\
\hline 16 & & (empe) & & & \\
\hline
\end{tabular}




\begin{tabular}{|c|c|c|c|c|c|}
\hline & & $\begin{array}{l}\text { Senta-se com } \\
\text { controle }\end{array}$ & Nenhum & $\begin{array}{l}\text { Escore: Criança propositalmente abaixa-se da posição em pé para a } \\
\text { posição sentada, de maneira controlada. }\end{array}$ & \\
\hline & 15. & Fica em pé sozinha & Nenhum & Escore: Criança fica em pé sozinha por, pelo menos, $3^{\prime \prime}$ & 1 \\
\hline & & (em pé) & & & \\
\hline $\begin{array}{c}\text { D } \\
13\end{array}$ & 16. & $\begin{array}{l}\text { Série andar: } \\
\text { sozinha com }\end{array}$ & Nenhum & $\begin{array}{l}\text { Escore: Criança dá pelo menos } 5 \text { passos de maneira independente, } \\
\text { mostrando coordenação e equilibrio. }\end{array}$ & 10 \\
\hline 16 & & $\begin{array}{l}\text { coordenação } \\
\text { (em pé) }\end{array}$ & $=$ & 60 & \\
\hline & 17. & $\begin{array}{l}\text { Agacha sem apoio } \\
\text { (em pé) }\end{array}$ & Objeto de interesse & $\begin{array}{l}\text { Escore: Criança move-se da posição em pé para a posição agachada e } \\
\text { depois para em pé, mantendo o equilibrio sem necessidade de apoio. }\end{array}$ & 10 \\
\hline & 18. & $\begin{array}{l}\text { Desde escada com } \\
\text { ambos os pés em } \\
\text { cada degrau, com }\end{array}$ & Escadas & $\begin{array}{l}\text { Escore: Criança desce escada pelo menos três degraus, usando a parede } \\
\text { ou o corrimão como apoio. Criança coloca ambos os pés em cada degrau } \\
\text { antes de descer para o próximo. }\end{array}$ & 10 \\
\hline & & $\begin{array}{l}\text { apoio } \\
(e m p e ́)\end{array}$ & & & \\
\hline 19 & 19. & $\begin{array}{l}\text { Série equilibra-se } \\
\text { sobre o pé }\end{array}$ & Cronômetro & $\begin{array}{l}\text { Escore: Criança equilibra-se sobre o pé esquerdo, enquanto vocé segura } \\
\text { uma de suas mãos. }\end{array}$ & 10 \\
\hline$\overline{26}$ & & $\begin{array}{l}\text { esquerdo: com } \\
\text { apoio } \\
\text { (em pé) }\end{array}$ & & & (a) \\
\hline & 20. & $\begin{array}{l}\text { Salta do degrau } \\
\text { mais baixo }\end{array}$ & Escadas & Escore: Criança pula para o chão. & 10 \\
\hline & & (empé) & & & 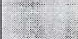 \\
\hline & 21. & $\begin{array}{l}\text { Chuta a bola } \\
\text { (em pé) }\end{array}$ & Bola maior & $\begin{array}{l}\text { Tentativas: } 3 \\
\text { Escore: Criança mantém o equilíbrio enquanto chuta a bola para frente por, } \\
\text { pelo menos, } 30 \mathrm{~cm} \text {. }\end{array}$ & 10 \\
\hline & 22. & $\begin{array}{l}\text { Anda para a frente } \\
\text { na linha }\end{array}$ & Caminho reforçado & $\begin{array}{l}\text { Escore: Criança anda com pelo menos um pé (direito ou esquerdo) sobre a } \\
\text { linha por pelo menos } 5 \text { pés. }\end{array}$ & 10 \\
\hline & & (em pé) & & & 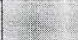 \\
\hline 23 & 23. & Série sobe & Escadas & $\begin{array}{l}\text { Escore: Criança sobe escada pelo menos três degraus sem apoio. Criança } \\
\text { coloca ambos os pés em cada degrau antes de subir para o próximo. }\end{array}$ & 10 \\
\hline 28 & & $\begin{array}{l}\text { degrau, sozinha } \\
\text { (em pé) }\end{array}$ & & & \\
\hline & 24. & $\begin{array}{l}\text { Salta para a frente } \\
10 \mathrm{~cm}\end{array}$ & Caminho reforçado & $\begin{array}{l}\text { Tentativa: } 3 \\
\text { Escore: Criança salta pelo menos } 10 \mathrm{~cm} \text { em alguma tentativa. }\end{array}$ & 10 \\
\hline & & & & & \\
\hline 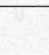 & 25. & $\begin{array}{l}\text { Equilibra-se sobre } \\
\text { o pé direito por } 2^{\prime \prime}\end{array}$ & Cronômetro & Escore: Criança equilibra-se sozinha sobre o pé direito por, pelo menos, 2 & 10 \\
\hline & & $\begin{array}{l}\text { sozinha } \\
\text { (em pé) }\end{array}$ & & & \\
\hline 19 & 26. & $\begin{array}{l}\text { Série equilibra-se } \\
\text { sobre o pé }\end{array}$ & Cronômetro & $\begin{array}{l}\text { Escore: Criança equilibra-se sozinha sobre o pé esquerdo por, pelo menos, } \\
2 \text {. }\end{array}$ & 10 \\
\hline & & $\begin{array}{l}\text { sozinha } \\
\text { (em pé) }\end{array}$ & & & 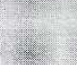 \\
\hline & 27. & Anda para trás & Caminho reforçado & Escore: Criança anda para trás próximo à linha por, pelo menos, 5 passos. & 10 \\
\hline & & $\begin{array}{l}\text { caminho } \\
\text { (em pé) }\end{array}$ & & & \\
\hline 23 & 28. & $\begin{array}{l}\text { Série sobe } \\
\text { escadas: }\end{array}$ & Escadas & $\begin{array}{l}\text { Escore: Criança sobe escadas sem usar a parede ou o corrimão como } \\
\text { apoio, e alternando os pés em cada degrau. }\end{array}$ & 10 \\
\hline & & $\begin{array}{l}\text { alternando os pés, } \\
\text { sozinha } \\
\text { (em pé) }\end{array}$ & & & \\
\hline & & & & Escore Total (CR) & 28 \\
\hline
\end{tabular}




\section{Subteste Motor Fino}

Regra de Aplicação: A criança deve obter o escore 1 no primeiro item do ponto de partida de alguma idade para seguir em frente. Se a criança obtiver o escore 0 no primeiro item, deve-se voltar ao ponto de partida da idade anterior e administra os itens desta idade.

Regra de Parada: Parar a administração quando a criança obtiver escore 0 em quatro itens consecutivos.

\begin{tabular}{|c|c|c|c|c|}
\hline & Item & Materiais & Critério de escore e comentários & Escore \\
\hline \multirow[t]{2}{*}{ A } & \multirow{2}{*}{$\begin{array}{l}\text { 1. Olhos seguem } \\
\text { pessoa se } \\
\text { movendo } \\
\text { (supina elevada) }\end{array}$} & \multirow[t]{2}{*}{ Nenhum } & $\begin{array}{l}\text { Tentativas: } 1 \\
\text { Escore: Criança segue com os olhos pessoa se movendo através da linha } \\
\text { média, da esquerda para a direita. }\end{array}$ & \multirow[t]{2}{*}{10} \\
\hline & & & & \\
\hline & \multirow{2}{*}{$\begin{array}{l}\text { Olhos } \\
\text { acompanham aro } \\
\text { (horizontal) } \\
\text { (supina) }\end{array}$} & \multirow[t]{2}{*}{ Aro com barbante } & $\begin{array}{l}\text { Tentativas: } 3 \\
\text { Escore: Criança acompanha o aro durante uma excursão completa. }\end{array}$ & \multirow[t]{2}{*}{10} \\
\hline & & & & \\
\hline & \multirow{2}{*}{$\begin{array}{l}\text { 3. Tenta levar mão à } \\
\text { boca } \\
\text { (nâo especificada) }\end{array}$} & \multirow[t]{2}{*}{ Nenhum } & $\begin{array}{l}\text { Tentativas: } 1 \\
\text { Escore: Criança propositalmente tenta colocar sua mão na boca. }\end{array}$ & \multirow[t]{2}{*}{10} \\
\hline & & & & \\
\hline & $\begin{array}{l}\text { 4. Segura o aro } \\
\text { (supina) }\end{array}$ & Aro com barbante & $\begin{array}{l}\text { Tentativas: } 1 \\
\text { Escore: Criança segura o aro por, no mínimo, 2". }\end{array}$ & 10 \\
\hline & \multirow{2}{*}{$\begin{array}{l}\text { 5. Olhos } \\
\text { acompanham aro } \\
\text { (circular) } \\
\text { (supina) }\end{array}$} & \multirow[t]{2}{*}{ Aro com barbante } & $\begin{array}{l}\text { Tentativas: } 3 \\
\text { Escore: Criança segue com os olhos aro durante uma excursão completa } \\
\text { (metades superior e inferior do círculo). }\end{array}$ & \multirow[t]{2}{*}{10} \\
\hline & & & & \\
\hline B & $\begin{array}{l}\text { 6. Agarra o aro } \\
\text { suspenso } \\
\text { (supina) }\end{array}$ & Aro com barbante & $\begin{array}{l}\text { Tentativas: } 2 \\
\text { Escore: Criança usa pelo menos uma mão para agarrar } 0 \text { aro por, no } \\
\text { minimo, } 2 \text {. }\end{array}$ & 10 \\
\hline \multirow{2}{*}{$\frac{7}{9}$} & \multirow{2}{*}{$\begin{array}{l}\text { 7. Série cubo: } \\
\text { esforça-se para } \\
\text { obter o cubo } \\
\text { (sentada) }\end{array}$} & \multirow[t]{2}{*}{ Cubo } & $\begin{array}{l}\text { Tentativas: } 2 \\
\text { Escore: Criança estende uma ou ambas as mãos para frente para obter o } \\
\text { cubo. A criança não precisa agarraro cubo. }\end{array}$ & \multirow[t]{2}{*}{10} \\
\hline & & & & \\
\hline \multirow{2}{*}{$\frac{8}{11}$} & \multirow{2}{*}{$\begin{array}{l}\text { 8. Série bolinha de } \\
\text { açúcar: agarra com } \\
\text { mão inteira } \\
\text { (sentada) }\end{array}$} & \multirow[t]{2}{*}{ Bolinha de açúcar } & $\begin{array}{l}\text { Tentativas: } 1 \\
\text { Escore: Criança usa a mão inteira para agarrar a bolinha. }\end{array}$ & \multirow[t]{2}{*}{10} \\
\hline & & & & \\
\hline \multirow[t]{2}{*}{$\begin{array}{l}7 \\
9 \\
\end{array}$} & \multirow{2}{*}{$\begin{array}{l}\text { 9. Série cubo: agarra } \\
\text { com ponta dos } \\
\text { dedos e polegar } \\
\text { (sentada) }\end{array}$} & \multirow[t]{2}{*}{ Cubo } & $\begin{array}{l}\text { Tentativas: } 2 \\
\text { Escore: Criança usa a ponta dos dedos e o polegar para agarrar o cubo. }\end{array}$ & \multirow[t]{2}{*}{10} \\
\hline & & & & \\
\hline \multirow[t]{2}{*}{ C } & \multirow[t]{2}{*}{ 10. L } & Caneca com alça & $\begin{array}{l}\text { Tentativas: } 1 \\
\text { Escore: Criança levanta a caneca pela alça usando uma mão. }\end{array}$ & 10 \\
\hline & & & & \\
\hline $\begin{array}{c}8 \\
11\end{array}$ & $\begin{array}{l}\text { 11. Série bolinha de } \\
\text { açúcar: agarra com } \\
\text { ponta dos dedos e }\end{array}$ & Bolinha de açúcar & $\begin{array}{l}\text { Tentativas: } 1 \\
\text { Escore: Criança usa a ponta dos dedos e do polegar para agarrar a bolinha } \\
\text { de açucar. }\end{array}$ & 10 \\
\hline & (sentada) & & & \\
\hline$\frac{12}{18}$ & $\begin{array}{l}\text { 12. Série preensão: } \\
\text { palmar } \\
\text { (sentada) }\end{array}$ & $\begin{array}{l}\text { Giz de cera } \\
\text { Papel sulfite }\end{array}$ & $\begin{array}{l}\text { Tentativas: } 1 \\
\text { Escore: Criança pega o giz de cera usando uma preensão palmar enquanto } \\
\text { rabisca o papel. }\end{array}$ & \\
\hline & $\begin{array}{l}\text { 13. Dedo indicador } \\
\text { estendido } \\
\text { (sentada) }\end{array}$ & $\begin{array}{l}\text { Tabuleiro de pinos } \\
\text { (sem os pinos) }\end{array}$ & $\begin{array}{l}\text { Tentativas: } 1 \\
\text { Escore: Criança estende o dedo indicador enquanto mantém os outros } \\
\text { dedos curvados }\end{array}$ & 10 \\
\hline
\end{tabular}




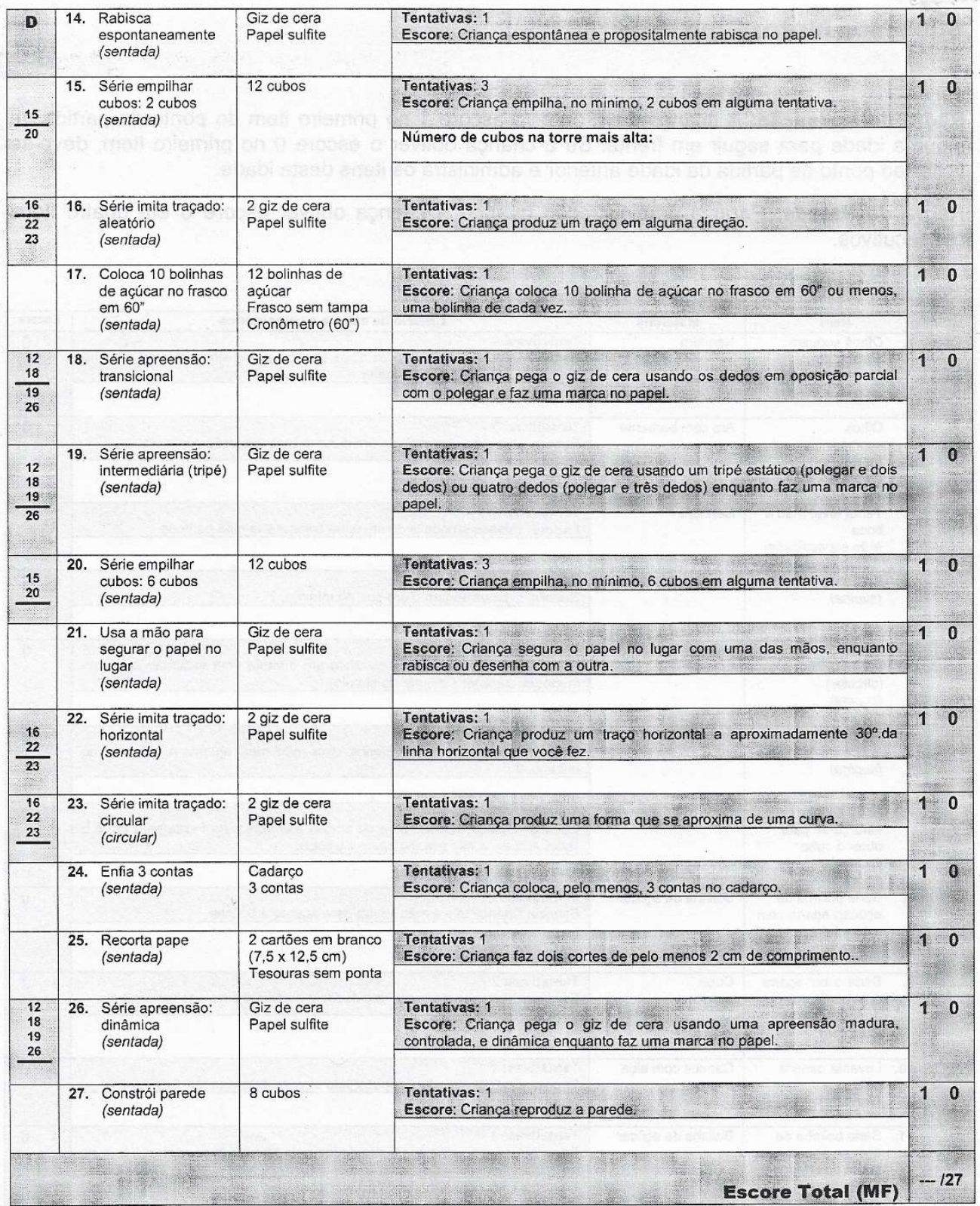




\section{Subteste Comunicação Expressiva}

Regra de Aplicação: A criança deve obter o escore 1 no primeiro item do ponto de partida de alguma idade para seguir em frente. Se a criança obtiver o escore 0 no primeiro item, deve-se voltar ao ponto de partida da idade anterior e administra os itens desta idade.

Regra de Parada: Parar a administração quando a criança obtiver escore 0 em quatro itens consecutivos.

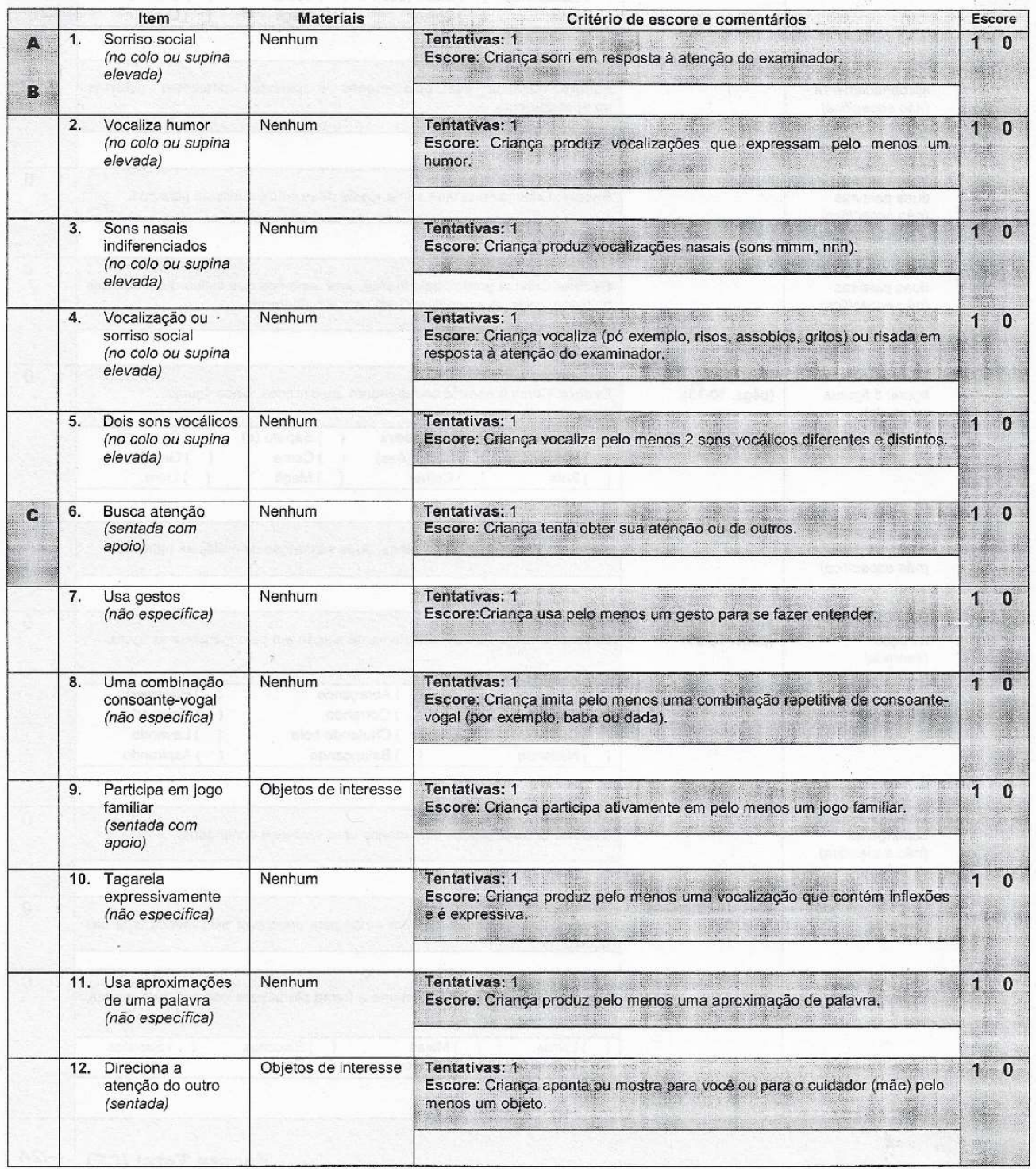




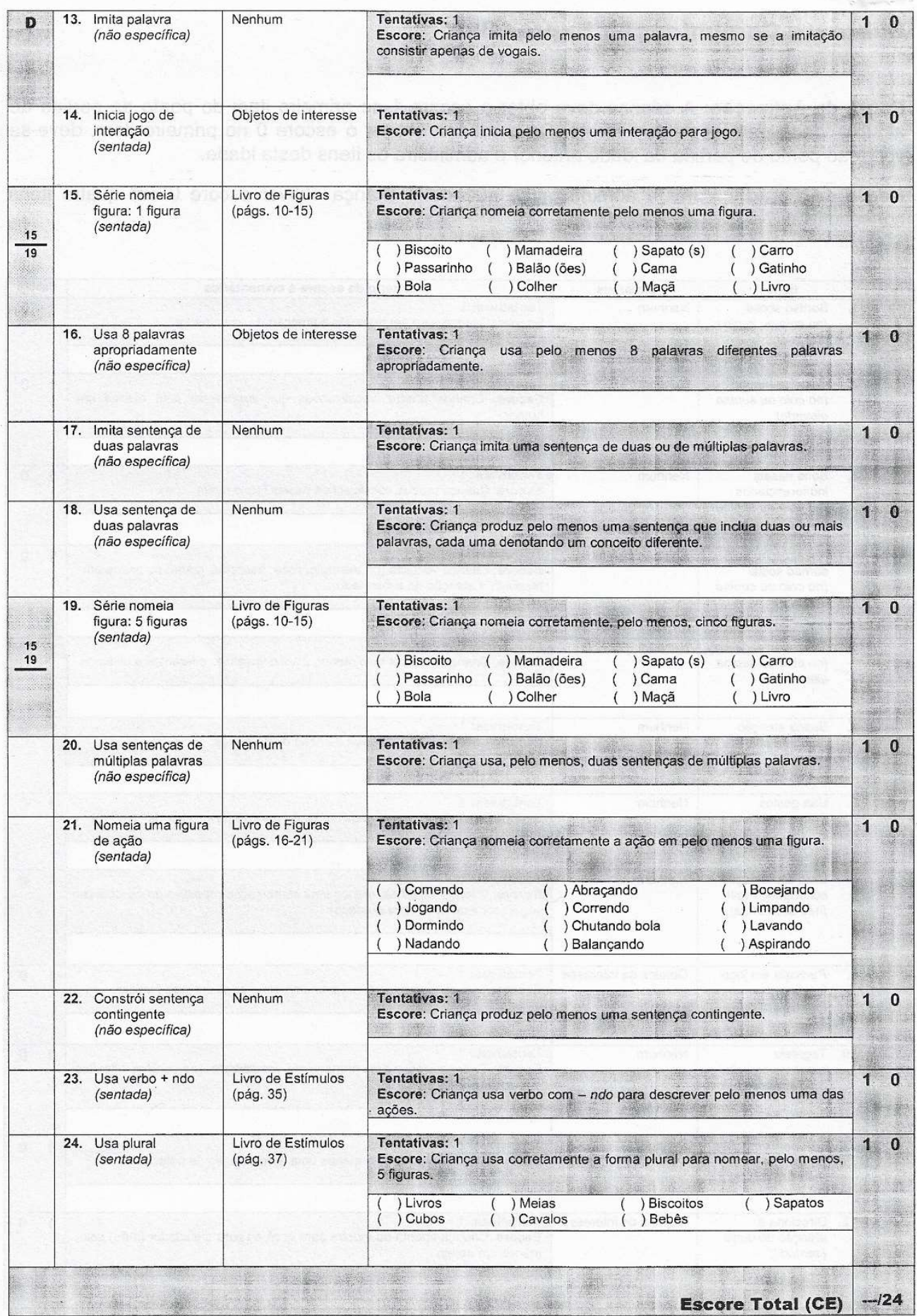




\section{Subteste Comunicação Receptiva}

Regra de Aplicação: A criança deve obter o escore 1 no primeiro item do ponto de partida de alguma idade para seguir em frente. Se a criança obtiver o escore 0 no primeiro item, deve-se voltar ao ponto de partida da idade anterior e administra os itens desta idade.

Regra de Parada: Parar a administração quando a criança obtiver escore 0 em quatro itens consecutivos.

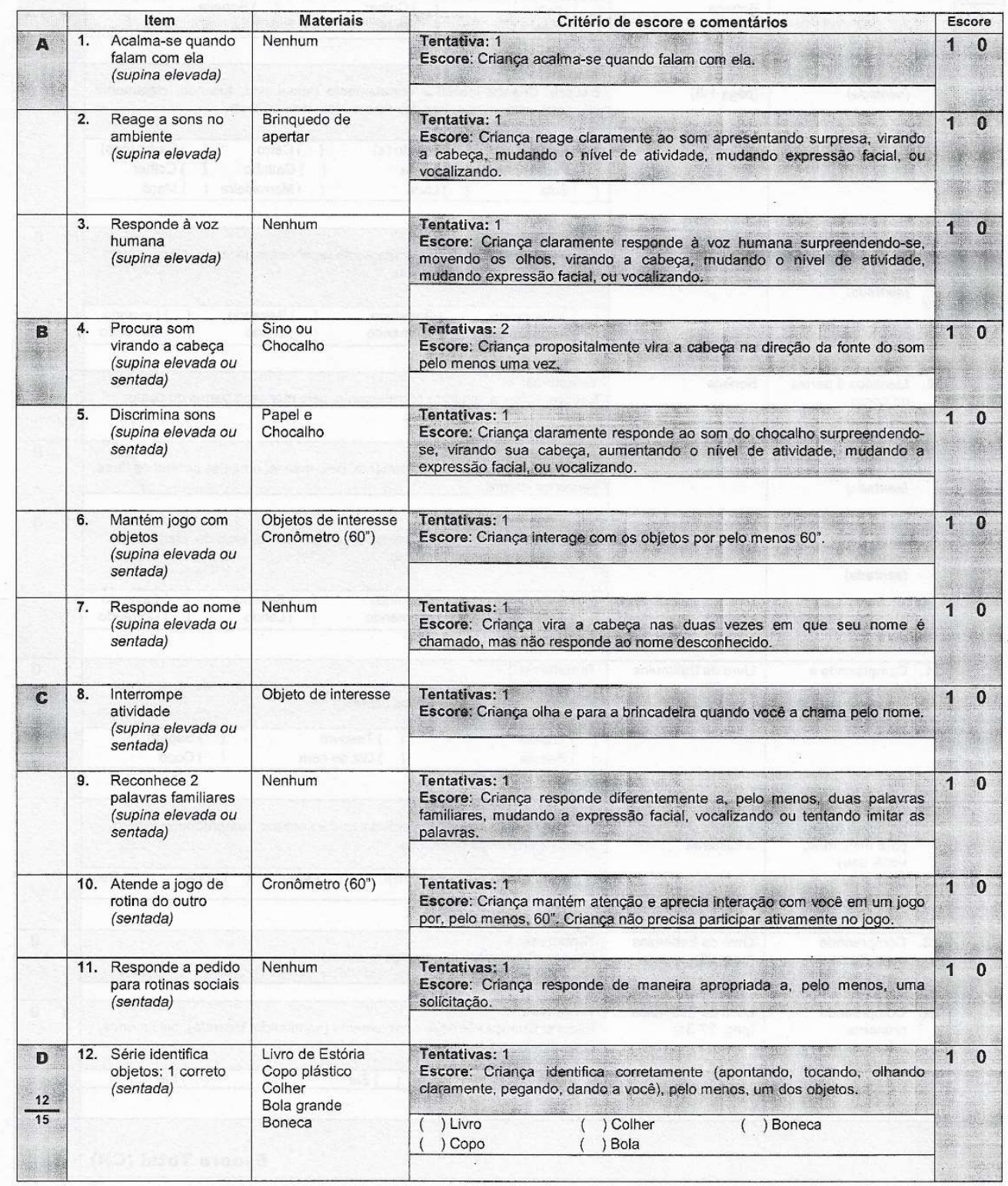




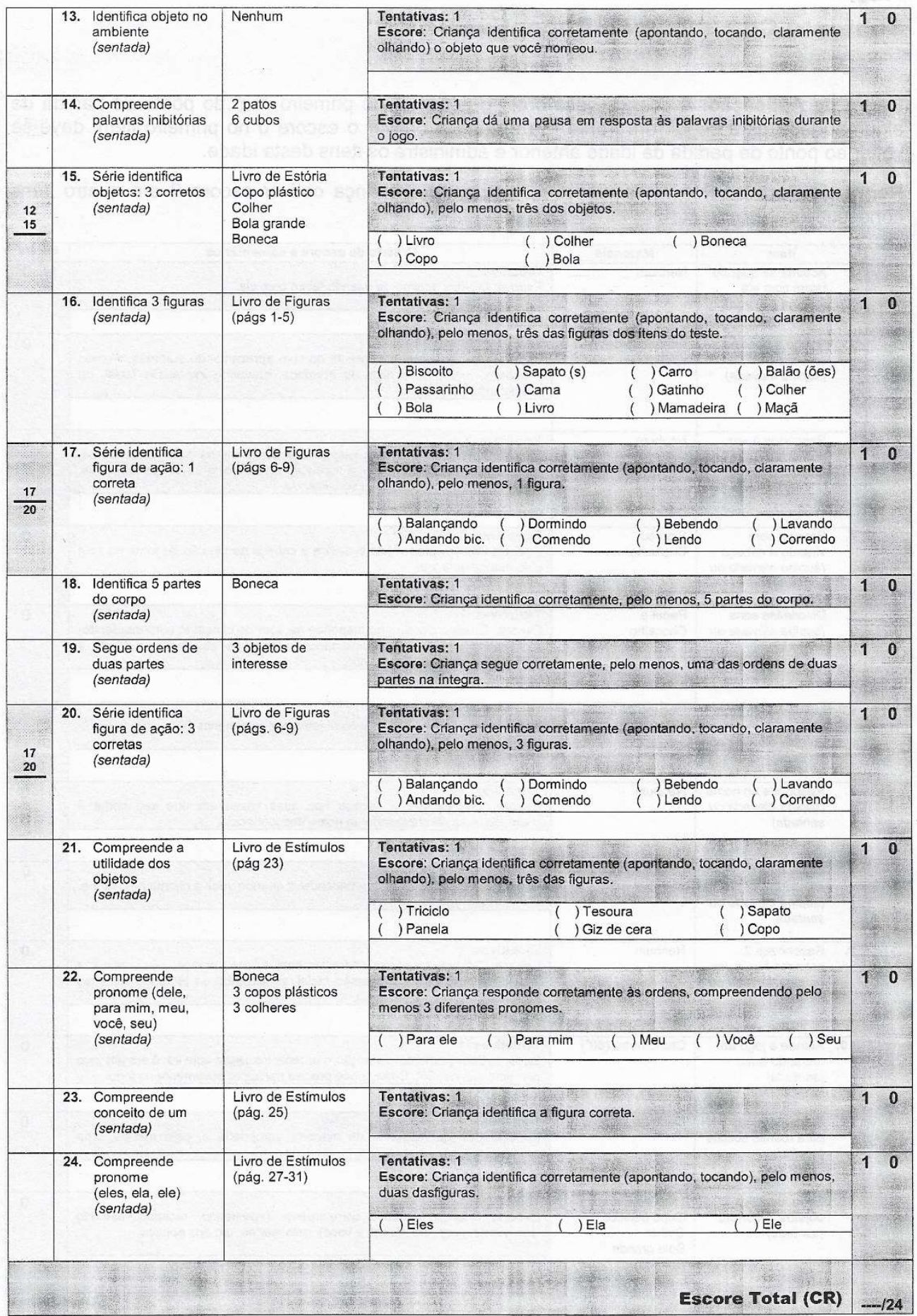

